\title{
"Winning Hearts and Minds"? An Exploration of New Zealand Peacekeeping, Masculinities, and Identity in the Solomon Islands
}

\author{
Kiri Stevens
}

2013

A thesis submitted to Victoria University of Wellington in partial fulfilment of requirements for the degree of Master of Development Studies

School of Geography, Environment and Earth Sciences 


\section{Abstract}

Close attention to the practices of masculinity, and individual negotiations of identity are often rendered invisible when exploring the implications of having soldiers engaged as peacekeepers in communities emerging from conflict. Using a feminist post-structural framework and qualitative interviews, I investigate whether involvement in peacekeeping is producing new gender and identity experiences for some New Zealand soldiers. Specifically, I explore the perceptions of two New Zealand Army Reserve Force soldiers who participated in the Regional Assistance Mission to the Solomon Islands. Additionally, I engage with the reflections of seven Solomon Islanders to understand the impacts that these new understandings of gender and identity might have for conflict resolution and gender equality in local communities.

My research finds that the practices that soldiers value and consider most useful to be a successful soldier are changing as a result of their involvement in peacekeeping. New ideas about masculinity in the armed forces are being engendered by the need for soldiers to express a sense of equality and respect towards local people. The changing nature of soldering is resulting in the emergence of practices that offer alternatives and/or challenge hegemonic and racialized militarized masculinities over those more traditionally valued in the armed forces. However, at the same time, some soldiers continue to place value on practices associated with hegemonic militarized masculinities, such as a belief in the continued need to carry weapons to create security.

I further suggest that Solomon Islanders interpreted participating soldiers' behaviours through broader historical-cultural narratives about different countries forces and their perceived cultural sensitivity. Therefore, soldiers' everyday resistances to racial narratives and militarized masculinities were important for creating a sense of trust and respect with local residents. However, while some Solomon Islanders welcomed the sense of security that soldiers produced, the carrying of weapons by soldiers undermined local conflict resolution practices. 
By focussing on men and masculinities, my research contributes to discussions about hegemonic and militarized masculinities in peacekeeping, and challenges ideas that see men, masculinities and other aspects of identity as static or unconnected to historical and social practices.

\section{Key words}

Masculinities, gender, nationality, peacekeeping, Solomon Islands, New Zealand soldiers'. 


\section{Acknowledgments}

Firstly and most importantly, thank you to the two participants from the New Zealand Army, for freely sharing their memories about their deployments. Similarly, thank you to the seven participants and their families in the Solomon Islands who gave their time to share stories and opinions of New Zealand soldiers and RAMSI.

In the Solomon Islands, thank you to Terence Wood for helping me in countless ways introducing me to potential participants, drawing me maps and sharing the secrets to catching buses in Honiara. Thank you to Alexa for connecting me up with several participants, and to Anastasia for accompanying me to the village. Thank you to Sandra, who among many other things was always happy to "hook a sista up" and drive me to the beach. Finally, to the people in the Solomon Islands who shared insights about New Zealanders, Australians, RAMSI and many other things in between.

In New Zealand, thank you to both my supervisors Carol Harrington and Sara Kindon for their support and guidance throughout the research process. Thank you for the financial assistance that I received from the Asia Pacific Research Award, the White Peace Poppy Scholarship and the New Zealand Aid Field Research Grant. Thank you to my friends who were supportive in many ways throughout this research process.

Thank you to Lillian, my fellow intellectual traveller and navigator of "how to write a thesis". To Marianne, who shared my interest in researching men and masculinities. To Gradon, for always 'getting' my theories about gender and reassuring me that it made sense. To Amanda, for the many lunchtime discussions that reminded me to keep doing what you are passionate about. To Emma, Raven and Cristian for always being willing to distract me in the office. A particular thank you to those who read various drafts - Gradon, Marianne, Amie, Hannah Van, Anj and my brothers Ari and Tim. To Anj for her constant support, care, encouragement and special deliveries of afternoon treats. Finally, thank you to my Mum and Dad for believing I would succeed and being proud of me. 


\section{Table of Contents}

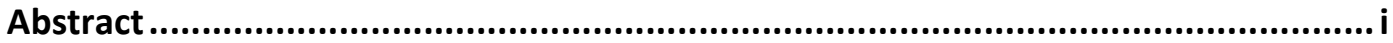

Acknowledgments ............................................................................................... ii

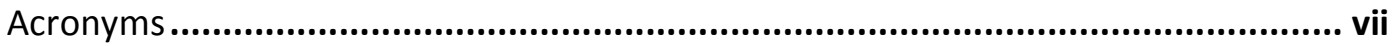

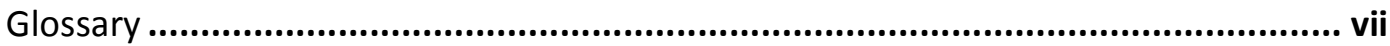

Table of Figures...............................................................................................................................vii

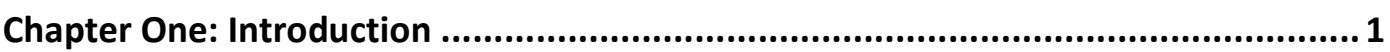

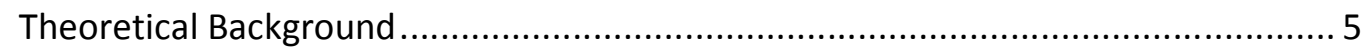

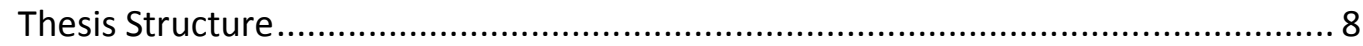

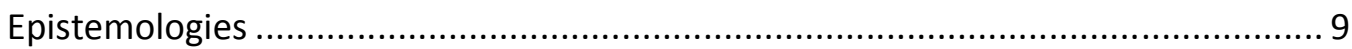

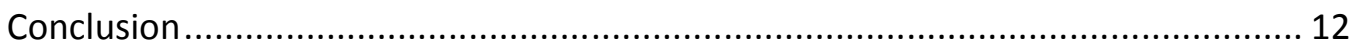

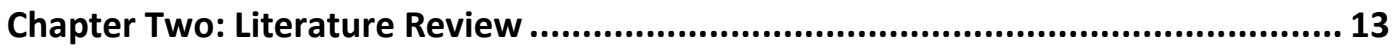

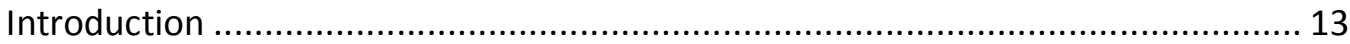

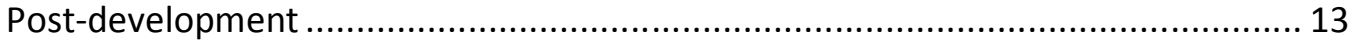

'Building' Peace and 'Keeping' the Peace ..................................................... 15

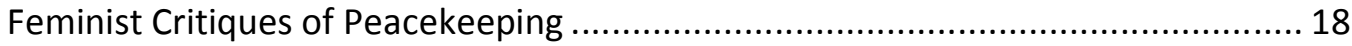

Linking Masculinity, Violence and the Military ............................................... 21

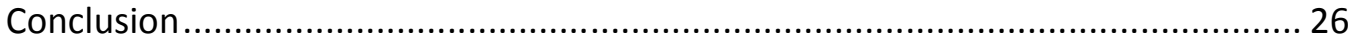

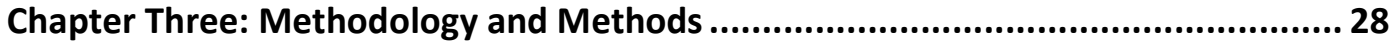

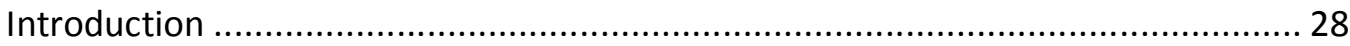

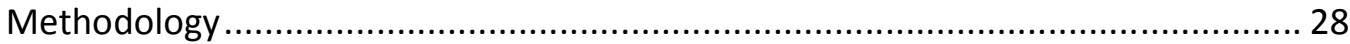

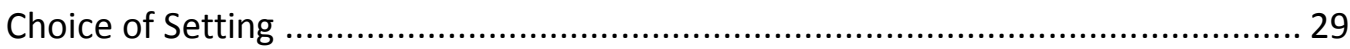

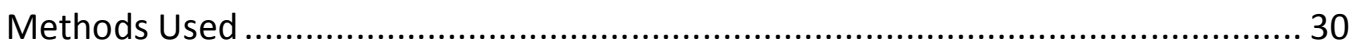

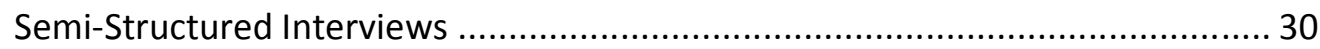

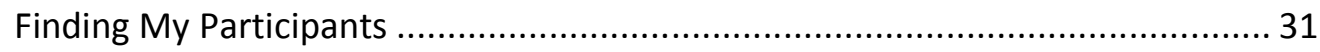

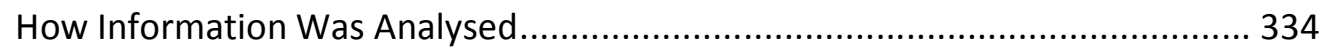

Negotiating Self-Other Relations and other Ethical Considerations....................... 35 
Thinking About Myself. 366

Other Ethical Considerations 40

Conclusion Error! Bookmark not defined.

Chapter Four: RAMSI - A Pacific Solution ...................................................... 433

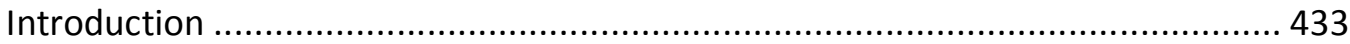

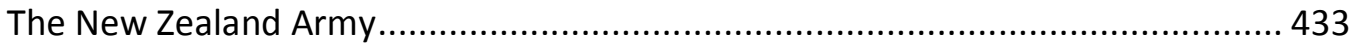

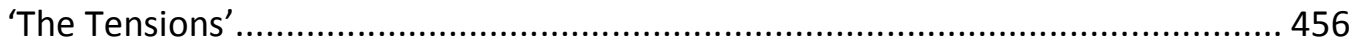

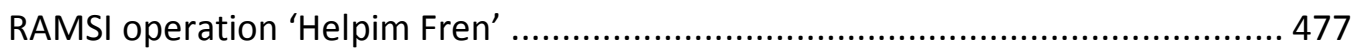

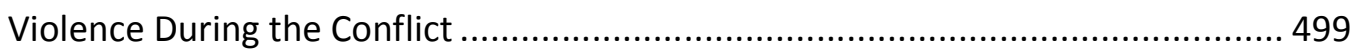

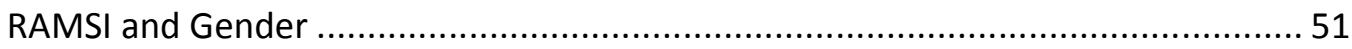

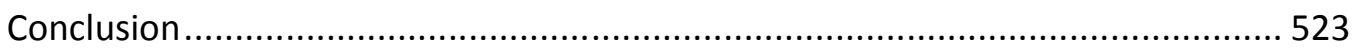

Chapter Five: "Hard-out War-y" Types and "Living and Breathing” the 'Hearts and

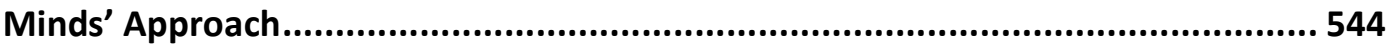

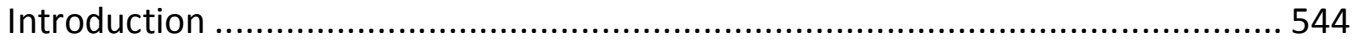

Militarized Masculinities: The "hard-out war-y" types ...................................... 555

Being "totally sold on hearts and minds": Alternatives to Militarized Masculinity. 655

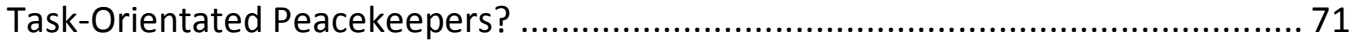

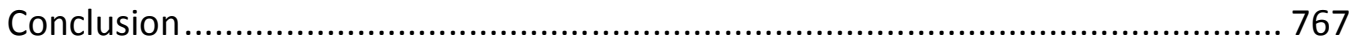

Chapter Six: Framing Peacekeeping - Intersections of Identity............................ 788

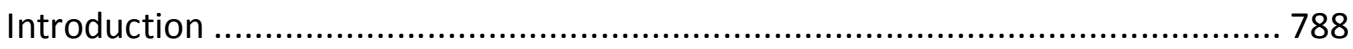

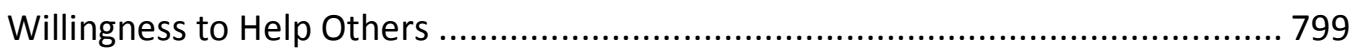

The Pacific Way: Biculturalism/Multiculturalism .............................................. 844

Individuals' Negotiations of Identity ......................................................... 911

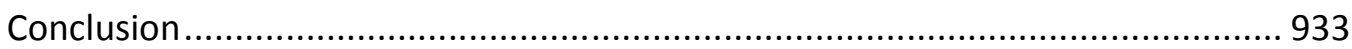

Chapter Seven: Solomon Island Peoples' Narratives about RAMSI soldiers............ 944

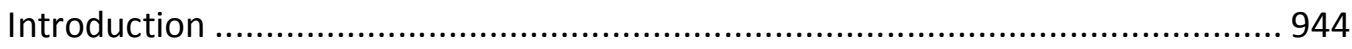

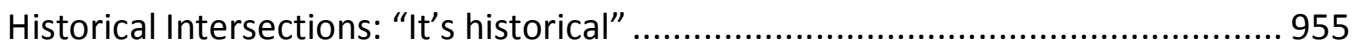


Everyday Interactions: Sitting Together and "eating from the same plate" 100

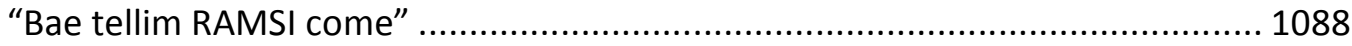

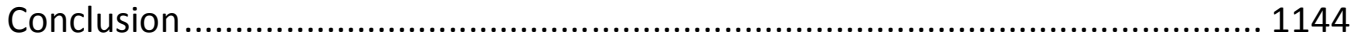

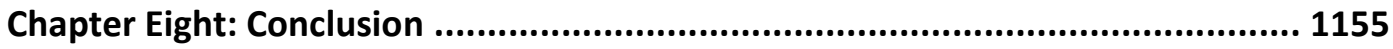

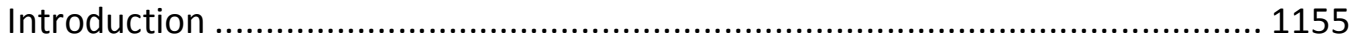

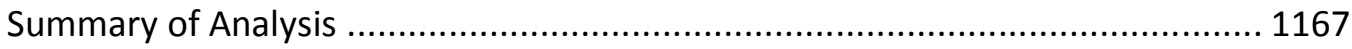

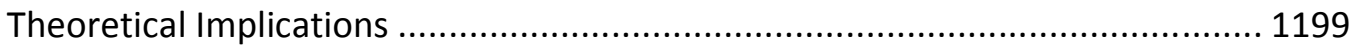

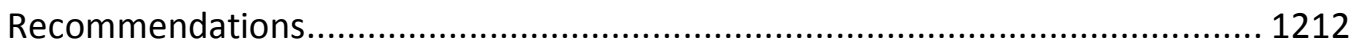

Limitations and New Areas of Research ....................................................... 1223

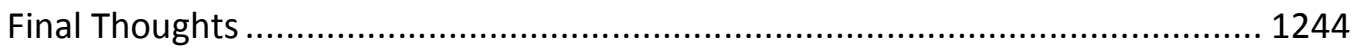

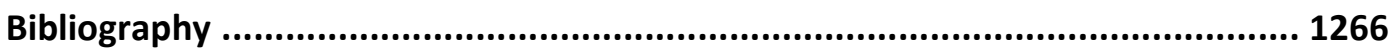

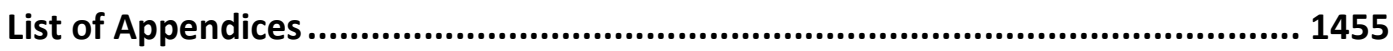

Appendix One: Map of Solomon Islands ................................................ 1466

Appendix Two: Map of Guadalcanal .................................................... 1477

Appendix Three: Victoria University of Wellington Ethics Forms...................... 1488

Appendix 3a: Information Sheet for semi-structured interviews with Solomon

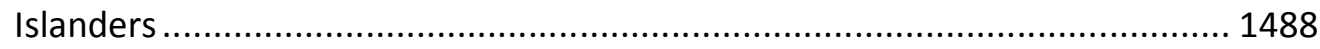

Appendix 3b: Consent form for semi-structured interviews with Solomon

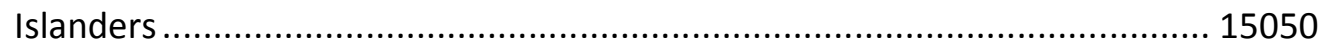

Appendix 3c: Question guide for Solomon Islanders ............................... 1511

Appendix 3d: Information Sheet for semi-structured interviews with New Zealand

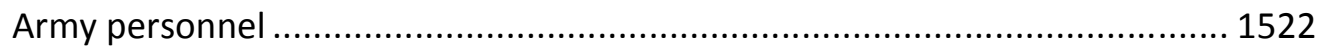

Appendix 3e: Consent form for semi-structured interviews with New Zealand

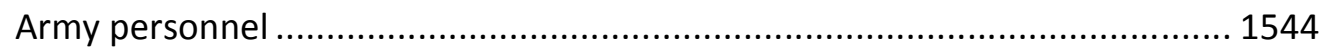

Appendix 3f: Question guide for New Zealand Army personnel .................... 1555

Appendix Four: Approved research permit for the Solomon Islands .................. 1566 


\section{Acronyms}

$\begin{array}{ll}\text { AuSAID } & \begin{array}{l}\text { Australian Agency for International Development } \\ \text { CEDAW }\end{array} \\ \text { United Nations Convention on the Elimination of All Forms of } \\ \text { Discrimination Against Women } \\ \text { Australian Department of Foreign Affairs and Trade } \\ \text { IFM } & \begin{array}{l}\text { Isatabu Freedom Movement } \\ \text { GLF } \\ \text { MEF }\end{array} \\ \text { UN } & \text { Maladalcanal Liberation Front } \\ \text { NCO } & \text { United Nations } \\ \text { NGO } & \text { Non-commissioned officer } \\ \text { NZAID } & \text { Non-governmental Organisation } \\ \text { PPF } & \text { New Zealand Agency for International Development } \\ \text { PSO } & \text { Participating Police Forces (of the RAMSI mission) } \\ \text { RAMSI } & \text { Peace Support Operation } \\ \text { RSIPF } & \text { Regional Assistance Mission to Solomon Islands }\end{array}$

\section{Glossary}

$\begin{array}{ll}\text { Aussies } & \text { Australians } \\ \text { Gardens } & \text { Food producing gardens in Solomon Islands } \\ \text { Gwale } & \text { Colloquial term for a person of Guadalcanal ethnicity } \\ \text { Haka } & \text { Traditional Maori war cry, dance or challenge } \\ \text { Hangi } & \text { Traditional Maori earth oven } \\ \text { Kastom } & \text { Pijin for custom } \\ \text { Kiwi } & \text { Colloquial name for a New Zealander } \\ \text { Kwaso } & \text { Locally brewed Solomon Islands alcohol } \\ \text { Motu } & \text { Traditional Solomon Islands oven } \\ \text { Raskals } & \text { Pijin for criminals } \\ \text { Rat pack } & \text { Army Ration Pack } \\ \text { Recon } & \text { Reconnaissance } \\ \text { SI } & \text { Solomon Islands } \\ \text { Sollies } & \text { Solomon Islands } \\ \text { The Tensions } & \text { The 1998-2002 conflict in the Solomon Islands } \\ \text { Waku } & \text { Pijin for Chinese people }\end{array}$

\section{Table of Figures}

Figure 1 Pseudonyms used for participants 


\section{Chapter One: Introduction}

The concept of 'winning hearts and minds' has long been present in military vocabulary. While it is a fluid concept, at the centre of the hearts and minds approach is the importance of gaining the trust and support of local people where military forces are deployed. Soldiers are not new to the post-conflict development space, however the way that we think about them has changed significantly over the last thirty years. With their increasing presence in this space, it is crucial to understand further the implications of this. Using the New Zealand Army's contribution to the Regional Assistance Mission to the Solomon Islands (RAMSI) mission 2003-2012, as the basis for my research, I explore the experiences and understandings of two soldiers deployed to the Solomon Islands as peacekeepers ${ }^{1}$, and seven Solomon Islanders who interacted with RAMSI forces. I investigate the implications that soldiers' masculinities, and other intersecting notions of identity, have for creating respectful and equal gender relations, and achieving long-term peace in the post-conflict ${ }^{2}$ development space.

As a result of the increasing securitisation of development (Duffield, 2001), and the particular security challenges faced in countries emerging from conflict, increasingly military forces have been utilised as peacekeepers to provide security for the creation of the 'conditions' for state reform and 'building' ${ }^{3}$. An example of this can be seen in the military components of the RAMSI mission, which was deployed 2003-2012 in response to insecurity and civil unrest in the Solomon Islands. From the beginning, RAMSI expressed a commitment to ensuring both men and women benefit from the mission. However, Greener et al. (2011) argue that while the broader RAMSI mission should be commended for attempting to put gender considerations into practice, they

\footnotetext{
${ }^{1}$ No single definition of 'Peacekeeping' exists however it is used widely in feminist literature (discussed in Chapter Three: Literature Review) to refer to the use of military personnel in conflict and post-conflict spaces. In this thesis I will attempt to use 'soldier' most often, but when expedient I will also use 'peacekeeper' recognising they are somewhat interchangeable terms. See http://www.unac.org/peacekeeping/en/un-peacekeeping/fact-sheets/from-peacekeeping-topeacebuilding/ for a further discussion of 'peacekeeping'.

${ }^{2}$ Post-conflict is a contested term in feminist scholarship, as some feminists have noted that for many the end of war often sees the beginning of an increase in gender-based violence. See Meintjes et al. The Aftermath: Women in Post-War Transformation, 2001 for further discussion.

${ }^{3}$ I use inverted commas here to highlight the contested nature of state building, held by some as a liberal neo-colonial project, and the suggestion that there is a linear path of development.
} 
could be doing better. Thus, in order for the New Zealand Army to not reinforce gender inequalities in future peacekeeping missions, they must be committed to accounting for and valuing gender equality in both their policies and their practice. This means not only paying attention to gender identities in relation to women, but in terms of men and social-cultural understandings of masculinities and femininities (Carpenter, 2002).

Peacekeeping is used in this thesis to refer to the military components of the wider multilateral approaches to create sustainable peace in societies emerging from conflict known as peace-building or Peace Support Operations ${ }^{4}$. When engaging in peacebuilding, fully integrating a gender perspective requires the assessment of femininity and masculinity and incorporation of both men and women in practice. However, discussions of gender issues in the Solomon Islands thus far have been restricted to a focus on women (Charlesworth, 2008; Greener et al., 2011). Both men and women are affected by conflict and encouraged to adopt dominant or hegemonic expressions of gendered behaviours in order to gain respect and status in different contexts. Thus, in addition to considering women and femininities in relation to post-conflict Solomon Islands, it is also important to pay attention to men and masculinities when considering the gendered implications of peacekeeping.

In different social contexts there are different expectations of how men are able to demonstrate masculinity. Masculinity can be defined as "behaviour, languages and practices, existing in specific cultural and organizational locations, which are commonly associated with males and thus culturally defined as not feminine" (Whitehead \& Barrett, 2001, pp. 15-16). Masculinities are fluid and relational constructions, defined in binary opposition to femininity, with connections to dichotomies such as active/passive, rationality/ emotion, war/peace, competitive/caring and order/disorder, whereby the first 'masculine' term in each pair is generally valued above the second 'feminine' term (Hooper, 2001, pp. 31-2). Within this, some masculinities are privileged over others in order to secure power and

\footnotetext{
${ }^{4}$ The New Zealand government commonly refer to peacekeeping and peace-building as Peace Support Operations (PSOs) to reflect the wider rubric of peace enforcement operations and non-UN led deployments. I will use however use 'peacekeeping ' as it is more widely used in the literature I refer to.
} 
respect over others. They are mediated by other intersecting aspects of identity, and social-historical narratives. If men fail to conform to the hegemonic form within a social structure, they may be discriminated against and may not gain status or respect.

It is important to note this, as within the armed forces, hegemonic constructions of masculinity have traditionally been aligned with the strength and capacity for violence (Carrigan, Connell, \& Lee, 1985; Duncanson, 2007, 2009; Enloe, 1983; Goldstein, 2003; Woodward, 2003). Thus traditionally, enacting masculinities that align more closely with violence have been privileged. This privileging of violence has become problematic with the increasing use of military forces for peacekeeping duties where it is necessary for soldiers to place value on non-violent conflict resolution practices, such as creating relationships of trust and equality with local people. However, because gendered understandings are fluid constructs, I question whether the increasing use of soldiers as peacekeepers and the need for non-violent conflict resolution practices is potentially interrupting these militarized notions of masculinity.

Furthermore, feminist academics have more recently suggested that peacekeeping represents a new form of colonialism, where peacekeepers are framed as white, western saviours of the inherently disordered and violent 'third world'(Orford, 1999; Razack, 2004; Whitworth, 2004a). Yet, the New Zealand Army prides itself on its bicultural and multicultural identity and inclusion of tikanga Maori ${ }^{5}$ in its culture and practices, which potentially complicates this criticism. It is therefore important to question whether other aspects of soldiers' identities, which intersect with masculinities, are engendering new understandings of peacekeeping practices beneficial for non-violent conflict resolution. When analysing the challenges soldiers make to the way that they understand peacekeeping in post-conflict development spaces, what other aspects of their identity are important to consider?

In light of these considerations above, the central aim of this research is to question whether this shift to peacekeeping roles is engendering new identity experiences for

\footnotetext{
${ }^{5}$ In this thesis I have chosen to italicise only Solomon Islands pidgin language words (Pijin). Not italicising te reo Maori is to highlight the prevalence of Maori words and culture in New Zealand society, thus the irrelevance of positioning it as different.
} 
soldiers. Additionally, I ask what the implications are of these different understandings of peacekeeper identity, for gender relations and for conflict resolution in a country emerging from conflict.

To address this central aim, I answer the following questions:

1) What forms of masculinity are evident from the understandings of two New Zealand soldiers and what forms of masculinity are valued in their narratives? In what ways do they challenge the hegemony of militarized masculinities?

2) In what way do other intersections of identity frame peacekeeping in the soldiers' understandings?

3) What understandings of peacekeepers are evident in Solomon Islanders' reflections on engagements with New Zealand soldiers during RAMSI?

Higate and Henry (2009, p. 23) ask "what does it feel like to enter the space of a peacekeeping mission?" noting that each mission has its own feel to it, dependant on the historical and political context of the country, the number of troops deployed and the number of ex-pat contractors. Importantly, they note that in considering the implications of soldiers in the development space, attention to the everyday and experiences and interactions of soldiers are essential. What feelings are produced for New Zealand soldiers on their arrival into Honiara? Do they experience excitement, surprise, disorientation, relief? And for local residents, what does the arrival of foreign security forces elicit - disinterest, curiosity, fear? Considering the particularities of the New Zealand Army's contribution to peacekeeping is a valuable contribution to an emerging discussion on masculinities and peacekeeping.

Therefore, overall, I would like this research to contribute to discussions about hegemonic militarized masculinities, and wider understandings of the place of men and masculinities in a feminist and gendered approach to peace. In order for this to occur, this thesis recognises further research needs to be done exploring the nuances of masculinity and identity present in the military and the role that emerging forms of positive masculinities and other identities can have for peace-making. 


\section{Theoretical Background}

Conflict is now a central concern in development discourses. Mark Duffield (2001) has argued that increasingly there has been a merging of development and security so that the modalities of underdevelopment are seen as dangerous. Mainstream development discourses have shifted from approaching poverty as a development aid issue, to one where people in developing nations become inherently understood as dangerous to developed nations because of their poverty, regardless of whether developing nations are actually experiencing conflict (Abrahamsen, 2004). Since the Cold War, peacekeeping operations have increasingly been mandated by the UN to engage in activities outside of that considered traditional military work (Bellamy, 2010). Thus increasingly, soldiers have entered development spaces in which they had not previously engaged. In doing so, simultaneously soldiers have begun to engender new understandings of 'development' and we have been forced to consider the implications of soldiers' presence in the development space.

The gendered practices and gendering processes of the military have been an avenue of research for feminists studying questions of security and military involvement in peace-building (Haaland, 2012). Feminist analyses of the gendered nature of armed forces in peacekeeping situations have typically emphasised that the presence of peacekeeping forces does not improve the security of women and 'vulnerable others'. 6 Whitworth and others (Cockburn \& Zarkov, 2002; P. Higate, 2004; Kronsell \& Svedberg, 2012) have highlighted the increase in prostitution, trafficking, sexual harassment and violence in peace-building environments, arguing that the particular form of militarized masculinity valued and produced in militaries makes soldiers unsuitable for peacekeeping operations and not conducive to creating lasting peace. Whitworth (2004a) for example, argues that while involvement in peacekeeping solves a 'crisis of legitimacy' for defence forces in a post-cold war era, at the same time it spurs a crisis of masculinity, resulting from the restriction on fighting necessary on peacekeeping missions. She states "militarized peacekeeping results in greater

\footnotetext{
${ }^{6}$ I would like to recognise here that it is not only 'women, the old and children' who are vulnerable in conflict. Charli Capenter (Carpenter, 2001) has criticised the gendered construction of the 'civilian' that fails to recognise the targeting of civilian men and boys in armed conflicts. Furthermore, I would like to recognise the vulnerabilities of those considered 'the perpetrators' in conflict, recognising the variety of reasons people become involved in conflict.
} 
insecurity for far too many people, women and men, who through the exclusionary practices of militarism and armed intervention become targets of sexual abuse and racist violence" (Whitworth, 2004a, p. 186).

In using a gendered analysis to examine peacekeeping, feminist scholars have most often focused on the experiences of women, both in the military and in post-conflict communities. This has meant feminist solutions to the negative impacts of peacekeeping forces are commonly located with women. Policy development has relied on the 'empowerment of women'7 (Carpenter, 2002) and advocated for the increased inclusion of women as a solution to insecurities that arise post-conflict more policewomen, more female soldiers and more local women in peace-building and reconciliation processes (Charlesworth, 2008). Seeing the inclusion of women as conducive to creating increased gender sensitivity is echoed in the UN Security Council Declaration 1325 on women, peace and security, which "recognized the under-valued and under-utilized contributions women make to conflict prevention, peacekeeping, conflict resolution and peace-building" (Women's International League for Peace and Freedom, n.d.). While the inclusion and valuing of women and femininities in postconflict processes is a vital and necessary step towards gender equality, some feminists have been highly critical of the 'add women and stir' approach (Aroussi, 2009; Charlesworth, 2008).

This focus on women, which relies on normative assumptions about women as peaceful, has tended to render women the 'victims' and men the 'perpetrators' of violence (Carpenter, 2002). This is a problematic construction as it fails to examine more closely how and why more violent forms of masculinity become more valued, particularly in organisations such as the military. This failure to explore the men as gendered subjects (Carpenter, 2002) has resulted in little development of gender policy that is inclusive of different forms of masculinity or the positive roles men can have in establishing gender equality post-conflict, nor does it recognise the stake that men also have in long-term peace and security that is gender sensitive. More deeply,

\footnotetext{
${ }^{7}$ See Megan Mackenzie's article 'Empowerment boom or bust? Assessing women's post-conflict empowerment initiatives' (2009), for a further discussion about the normative use of 'empowerment' in women and gender policies.
} 
the failure to examine the "discursive support that hierarchies of gender lend to military solutions" (Otto, 2006, pp. 113-114) results in the failure to examine alternative practices that lead to long-term peace solutions and means that responsibility for changing gender inequality is placed upon women.

One aspect of paying more attention to men and masculinities in the post-conflict development space is in investigating the ways that soldiers understand and enact masculine practices in relation to their position as peacekeepers. Claire Duncanson (Duncanson, 2007) has questioned whether there is an emergence of an alternative discourse of 'peacekeeper masculinity' that challenges the traditional 'warrior masculinity' present in the British military. In doing so, Duncanson examines the implications that alternative discourses of masculinities in the armed forces might have for achieving peace and security, and in terms of gender relations. Duncanson's findings are important for this research as, since the Vietnam War, New Zealand soldiers have predominantly engaged in non-combat tasks on overseas deployments. This shift in tasks has resulted in the need for soldiers to be trained to undertake peacekeeping tasks in addition to combat training. Whether the value of this approach is reflected in military culture can be explored through looking at the kinds of masculinities that are evident in the discourses of individual soldiers and through examining self-representation in Army documents such as the New Zealand 'Army News'.

Furthermore, the New Zealand Army's role in peacekeeping and peace-building is particularly interesting to examine in light of the criticisms levelled by feminist scholars against peace-building, as these criticisms do not fit obviously with the dominant image of New Zealand forces held by the majority of the New Zealand public, nor the contribution that the New Zealand Defence Force's involvement in peacekeeping internationally has had for New Zealand's image as a small, 'peace-loving nation'. This perception is particularly notable in comparison to the militaries of larger nations such as the United States or the United Kingdom, who appear to me more prone to war than peace, and whose society is far more militarized (Enloe, 1990; Haaland, 2012). 
The New Zealand Army is also an interesting case to examine because their stated commitment to ethnic equality within forces informs the perception that New Zealand soldiers are especially adept at engaging in cross-cultural relations. More broadly, this understanding of New Zealand soldiers is informed by a narrative of 'equality' being a distinctive feature of New Zealand's society. Higate and Henry (2009) emphasise the importance of taking national identity into consideration when understanding perceptions of peacekeepers. They examine how this intersects with understandings of how soldiers embodied performances are gendered, arguing that:

While it is clear that national troops identity and geopolitical imperatives articulate with one another in ways that shape how peacekeepers are seen, there remains little consideration of what this might look like on the ground in ongoing missions. How did the country of origin of peacekeepers shape the perceptions of security performance? What did national identity mean for the kinds of professionalism these peacekeepers were believed to be capable of in the post-conflict space? (Higate \& Henry, 2009, p. 120)

To do this they argue paying attention to the everyday experiences and interactions of soldiers on the ground are important. Part of doing so, I argue, is accounting for local perceptions of soldiers. Exploring the everyday interactions and experiences of local Solomon Islanders is vital for understanding the implications of soldiers' intersectional identities. Feminist literature on peacekeeping has paid attention to the negative impacts of militarized masculinities on local host communities, yet I could find little feminist literature on peacekeeping that explores local perspectives on the presence of soldiers in their community. Thus, in addition to paying attention to the individual experiences of two Reserve Force soldiers, this thesis aims to look at local Solomon Islanders' understandings of soldiers further.

\section{Thesis Structure}

Following the Introduction, Literature Review, Methodology and Context chapters (One, Two, Three and Four), which are focussed on providing the framework that informed this research, this thesis is divided into four analysis chapters. These subsequent chapters explore my research questions through the reflections of Reserve Force soldiers Steve and Henry, and local Solomon Island participants; Billy, Ronnie, 
Alex, Rich and Mary, and Rachel and James ${ }^{8}$. Chapter Five contributes to the first research question by exploring what forms of masculinities were evident in Steve and Henry's discourse. I argue that while there is evidence that both soldiers continue to value the aspects of military practices, which are associated with militarized masculinities, they also challenge these narratives by placing value on practices that are associated with non-violent conflict resolution practices. In Chapter Six I explore other intersecting aspects of identity also reflected on by Steve and Henry to understand their position as peacekeepers. In doing so, this chapter addresses my second research question by exploring constructions about the Solomon Islands as a place 'in need of help' and discourses about the cultural sensitivity of the different participating forces. In Chapter Seven I argue that in order to understand the implications of soldiers' challenges to hegemonic militarized masculinity, it is also important to explore local Solomon Islanders' reflections on RAMSI soldiers. Thus in this chapter I shift my attention to exploring the perceptions of Solomon Island participants. This chapter addresses research question three. I emphasise that local residents actively engage with the contested nature of peacekeeping, interpreting soldiers' behaviour through established social-historical narratives. Furthermore, local participants demonstrated a valuing of the approach of New Zealand soldiers based on behaviours more aligned with non-violent masculinities, more suitable to conflict resolution. Finally, I discuss the implications that different masculine practices have for the creation of long-term peace, and for relationships of gender and racial equality. I raise the question of whether the presence of armed soldiers ultimately militarizes Solomon Island understandings of how to achieve peace. In Chapter Eight, the final chapter in this thesis, I conclude by summarising the findings of the preceding chapters. I discuss the theoretical and practical implications of my research. Finally, I discuss some of the shortcomings of this thesis and suggest future directions of research that would enrich understandings of masculinities, identity and peacekeeping.

\section{Epistemologies}

In this final section I would like to discuss the way that I think about knowledge production and 'ways-of-knowing' (Evans, 2010). Epistemologies informed how I

\footnotetext{
${ }^{8}$ All names used in this thesis are pseudonyms.
} 
conceived of, conducted, interpreted and represented this thesis. Therefore they orientate this thesis in a particular way that is important to consider before proceeding further.

This thesis is positioned by a feminist post-structural approach to 'ways-of knowing.' Feminist post-structural academics are amongst anti-positivist academics that have challenged the use of an objective scientific model for research (Nielsen, 1990, p. 9). They refute the neo-positivist assertion that there is the possibility of a neutral, detached researcher. They see the latter as responsible for marginalisation of particular peoples based on concepts of 'difference'; their identities, lived experience, knowledge production, and understandings of the world around them. Rather, feminist post-structural frameworks "recognize that multiple and conflicting realities exist," (Winchester \& Rofe, 2010, p. 21) and deliberately challenge hegemonic structures by creating spaces for voices previously silenced or ignored. Rose states "In contrast to the god-trick of claiming to see the whole world while remaining distanced from it, subjugated and critical knowledges work from their situatedness to produce partial perspectives on the world. They see the world from specific locations, embodied and particular, and never innocent; siting is intimately involved in sighting" (1997, p. 308). Thus my research is premised within the understanding that "all knowledge is produced in specific circumstances and that those circumstances shape it in some way" (Rose, 1997, p. 305).

Feminist post-structural frameworks are concerned with researching ethically in a way that does not exploit research subjects or reinforce existing inequalities. To create research from this space, some, such as Doreen Mattingly and Karen Falconer-Al-Hindi (Mattingly \& Falconer-Al-Hindi, 1995) advocate making one's position in relation to your research known and your conclusions limited - not making universal claims, recognising that language can be used to both obscure and expose. We should never mask the 'other' (McDowell, 1994a, p. 244) and if an "author draws the veil over the implications of her own position" then we should be wary (McDowell, 1994b, p. 403,407). Furthermore, a feminist post-structural approach identifies language as not only reflective but constitutive of social life (Mansvelt \& Berg, 2010, p. 339). Thus in analysing participants' responses, I have paid close attention to their language. 
Furthermore, with these understandings of the research process, this thesis was undertaken with the belief that engaging in research is a transformative process where the researcher has the responsibility to critically engage and challenge normative assumptions that marginalise particular identities. To this aim, my research focuses on the gendered identity experiences of men and masculinities, an area of research that has often been full of silences (Myrttinen, 2008).

Feminists use gender as the central mechanism with which to explore identitymeaning. Implicit in their analysis is an understanding that gendered experiences are socially constructed (Letherby, 2003). Therefore, this research is aimed at exploring the social constructions of masculinities attached to peacekeeping, and how particular gendered ideas and knowledge about soldiers come to the forefront while others are marginalised. While feminist researchers tend to focus on the way that ideas about gender marginalise women, they have also studied the manner in which ideas about masculinity marginalise alternative embodiments of masculinity. However, women are still the prevalent subjects of feminist researchers' gaze, and as such some feminists continue to argue that feminist research should be "by women for women" (Webb, 1993, p. 416). Yet post-structural feminist frameworks understand gender as relational, and thus ideas about men and masculinity tell us important things about women and femininity and the socially constructed nature that marginalise particular gender performances. That I chose to ask only male soldiers to participate was a political choice, aimed at directing what I perceive as some much needed attention at examining men and masculinities.

Within the five interviews I conducted in the Solomon Islands there were widely different experiences of the tensions and the subsequent RAMSI mission. Thus I was not concerned with uncovering the 'real story'. The ad-hoc process that each interview resulted from, meant that each of the interview participant's experiences and perceptions of the tensions, and the resulting peacekeeping operation, were mediated by a myriad of factors. This included: location during the conflict, ethnicity, social status, occupation and gender. This is reflected in the different ways that interviewees interpreted and related experiences with New Zealand soldiers. Concurrently 
however, there were some similarities in experience and common themes present in the narratives they shared about their engagements with New Zealand soldiers. Likewise, the two soldiers interviewed, while sharing some similarities in experience and identity; both were Pakeha New Zealanders, both Reserve Force soldiers from the South Island, under 35 and male, and present in the Solomon Islands in the mid-late period of the deployment; their experiences were also mediated by the individualities of their identity, the security situation at the time of their deployment and their personal interpretations of events. Post-structural epistemologies assert complexity and contradiction should be embraced (England, 1994, p. 81). Thus for both the interviews conducted with Solomon Islanders and New Zealand soldiers, in exploring our discussions of this period of Solomon Island history, I recognise that I am drawing out elements or strands from their narratives to form a loosely connected structure of ideas, which I believe is a subjective and only ever partial picture full of said complexity and contradiction.

\section{Conclusion}

In this chapter I have highlighted the need for closer attention to be paid to the kinds of masculinities evident in peacekeeping, and how this impacts on gender relations and the achievement of peace in regions emerging from conflict. In doing so, I have pointed out that the merging of security and development has meant there has been an increase in military involvement in post-conflict development. In relation to this, I have discussed feminist criticisms of peacekeeping forces, which argue that the particular forms of 'militarized masculinity' valued in the armed forces means that often there has been increasing insecurities as a result of their presence. I have noted that Duncanson has questioned whether this is always the case, exploring if peacekeeping has led to more peace-orientated masculinities being valued in military forces. In seeking to understand this further, others, such as Higate and Henry (2009), have explored the intersections of nationality and gender in evaluating how peacekeepers were perceived. Finally, I have outlined my research aims and the questions I have posed to explore these aims further. In the next chapter, there will be a further discussion about the literature surrounding the inclusion of security concerns in development discourse, masculinities, and gender considerations in peacekeeping. 


\section{Chapter Two: Literature Review}

\section{Introduction}

Soldiers acting as peacekeepers in the post-conflict development space are not new; yet increasingly soldiers are working multilaterally and interacting with local people in peacekeeping missions. Because peacekeeping personnel are interacting with local civilians, gender sensitivity and cultural awareness are increasingly necessary. Yet, scant research attention has been paid to exploring the individual experiences and understandings of soldiers working in the development space - nor has the impact this can have on the success of gender and cultural sensitivity been evaluated. Furthermore, there has been little extensive feminist exploration of soldiers' gendered impacts on host communities that engage with local people's perceptions as a methodology. Therefore, this literature review argues that more critical attention needs to be given to intersectional identities of soldiers, particularly men's gendered experiences of masculinity, by paying close attention to the personal experiences of soldiers and the local people they engage with.

The expanding and blurring lines of the development space mean that exploring development issues is not confined to disciplines or particular established bodies of development literature. Nonetheless, the literature that situates my research is connected by shared concerns about the ways that development is engaged with and, specifically, how communities can encourage peace and security when emerging from conflict. I will begin by outlining some of the broad discussions about the Western assumptions that underlie development, and how these play out in critiques of peacebuilding. Secondly, I will explore some feminist gendered critiques of peacekeeping. Next, I will review the literature that links masculinity and violence. Finally, I suggest that discussions about militarized masculinity could be enriched by considering the intersections of gender and other identities. This will lead me to ask: Is a shift to peacekeeping roles engendering new identity experiences for some soldiers?

\section{Post-development}

No school of development literature has been more critical in its evaluation of development than that coming from post-development. Importantly for this thesis, 
post-development literature turns the focus back onto development workers and aid donors, questioning their motives and the unequal power inherent in the donorrecipient relationship. Using a post-structural approach, post-development thinkers have subjectively examined the concept of 'development' with the understanding that ideas about development result from particular historically produced discourses that privilege some ways of knowing over others (Crush, 1995; Escobar, 1995; Ferguson, 1994; Rahnema \& Bawtree, 1997; Sachs, 1992). They argue development interventions and ideas about the goal of development are embedded in Enlightenment discourses of progress, science and modernity; where development is positioned as a technical problem that development experts from Western nations are tasked with fixing. This is done by introducing Western technology, institutions and practices to 'underdeveloped' nations (Parpart, 2002). Escobar (1995) and Esteva (1992) argue that these ideas of 'development' are used to control and spread western capitalism around the world. Tucker (1999) argues that after three decades of development it appears that development "is part of the problem rather than the solution" where "[t]he development discourse is part of an imperial process whereby other peoples are appropriated and turned into objects" (Tucker, 1999, p. 2).

Barbara Heron (2007) draws on post-structural ideas about subjectivity, feminism, post-colonial studies and critical race theory to examine the experiences of white Canadian women who have worked in Africa. She argues that the desire for development is intimately tied to the making of the 'self' in ways that are raced, classed and gendered, and contingent on notions of goodness and of 'Othering' the subjects of western development. In doing so, she engenders new understandings about whiteness and development practice. Similarly, Moser (1993) and Mohanty (1988) use a critical gendered analysis to question the patriarchal nature of development practice and discourse. Mohanty pays particular attention to the construction of a singular 'third world woman' where the totalising assumption of oppression sees women in developing nations constructed monolithically as uneducated, poor, tradition-bound, family-orientated and victimised, in such a way that they can only be rescued with the help of 'liberal westerners'. This also simultaneously constructs men in the 'third world' as hypermasculine and aggressive perpetrators of violence. It is important to note this for this thesis, as these monolithic constructions 
of 'third world' men and women are problematic because they obscure the multitude of roles and identities outside of these constructions and make it easier to legitimise western interventions - such as peacekeeping - without reflecting on the assumptions that underlie these interventions.

To date, post-development literature has not extensively dealt with peacekeeping. However, with increasingly blurry boundaries between what is considered traditional 'development' and the entry of new development actors, such as soldiers, this thesis finds post-development literature a relevant consideration because of the way it critically engages with the constructed nature of development. Furthermore, the questions post-development literature raise about the underlying notions of development interventions can similarly be used to question peace-building.

Finally, post-development literature is important for this thesis as some academics have cautioned post-development thinkers that a focus on local rationalities as "progressive standpoints of the oppressed" sees the "representation of existing cultures in modernizing societies as the ultimate and irreducible force in development" (Nanda, 2002, p. 39). If one is not to romanticise the 'Other', paying close attention to the particularities of local contexts is necessary, and attention to the personal experience vital. Thus, paying close attention to the interactions that occur between local actors and soldiers turns the lens not only back on soldiers, but it provides a more complex picture of how development is engaged with.

\section{'Building' Peace and 'Keeping' the Peace}

There is a burgeoning body of literature discussing how to support development in communities emerging from conflict. Repeated cycles of insecurity and high levels of poverty are understood to disrupt the development process and contribute to instability and insecurity (The World Bank, 2011). This view is reflected in this statement by the UN Secretary-General in 2005:

In an increasingly interconnected world, progress in the areas of development, security and human rights must go hand in hand. There will be no development without security and no security without development. And both development and security also depend on respect for human rights and the rule of law (Schnabel \& Farr, 2012, p. 18). 
As Duffield has argued, the post-Cold War development space has seen a merging of development and security, which has resulted in the modalities of underdevelopment being regarded as dangerous. Development, he argues, has reinvented itself as a "structural form of conflict prevention" (Duffield, 2001, p. 121). Abrahamsen (2004) offers a critical perspective on this merging of development and security, by arguing that the 'securitisation' of Africa has resulted in discourses shifting from one focusing on development as a form of humanitarianism, to one where those living in poverty are understood as a threat to the security of the developed world. This shift in discourse means development aid from western countries becomes understood as much about securing our own security, as it is about providing 'improved' futures for those in developing countries. Abrahamsen argues that this is problematic as it makes development more about protecting donors' self-interest and constructs recipients as inherently dangerous because of their lack of resources. This securitization of development creates a new sense of urgency and legitimises the use of military forces and military solutions to deal with issues of poverty and underdevelopment. This area of research has been explored in relation to the Pacific region's perceived 'failing state' - the Solomon Islands (Dinnen \& Firth, 2008; Hoadley, 2005; Ponzio, 2005). For example, Ponzio argues that the post 9/11 rhetoric of the Solomon Islands as a failing state with the potential to become a "post-modern badland" and thus a potential centre for wider regional instability, increasingly became key in influencing the decision for the RAMSI mission (Ponzio, 2005, p. 93).

The securitization of development has given new legitimacy to efforts to encourage security through 'peace-building', particularly in countries emerging from conflict. Peace-building is understood as a uniform 'package' of post-conflict modalities aimed at providing security. This is done by using peacekeepers to promote stabilisation to allow the introduction of the rule of law, security sector reform, reconciliation processes and disarmament, re-starting the formal economy and the introduction of good governance principles (Beaudet, Haslam, \& Schafer, 2012). Literature on peacebuilding examines both the technical and political aspects of this enterprise. For example, much attention has been given to producing documents that centre around improving cooperation and coordination between the military and civil actors in post- 
conflict development spaces (ACMC, 2012; NMCG, n.d.). These methodologies are largely instrumental in approach and provide frameworks for operating successfully with little to no attention to the assumptions that underpin their presence.

However, the military component of peace-building, commonly referred to as peacekeeping, has also been critiqued by some within development schools of thought (Duffield, 2001; Roberts, 2010; Saikal, 1996; Shannon, 2009). They have tended to focus on the impact of the increasingly blurry boundaries between humanitarian work by NGOs and that done by the armed forces. Shannon (2009) points out that in Afghanistan, bringing peacekeepers into the humanitarian space, which has more traditionally been the domain of 'impartial' NGOs such as the Red Cross, has blurred the boundaries between different international actors and posed new challenges and dilemmas for NGOs and peacekeepers alike. Shannon argues that this blurring can compromise the neutrality of NGOs and thus limit their access to communities in need.

Furthermore, like post-development critiques of 'development', peacekeeping interventions have also been questioned for their underlying notions that frame western countries as necessary in order to create peace and stability in states that threaten, rather than protect their own peoples. Some scholars (Hameiri, 2011; Paris, 2004; Pugh et al., 2011) question the underlying assumptions of 'state-building'. They see peace-building as a pursuit of Western power and argue that its promotion is based on western notions of a linear process for 'building' that promotes particular liberal values and enables the west to control developing nations in new ways since the demise of colonialism. Purg et al. (2011) question if peacekeeping is just a form of 'riot control' for the south. Like post-development debates about western-driven development, some argue (Bellamy et al., 2010; Pugh et al., 2011; Rieff, 2003; Thomas, 2001) that peace-building missions are "intended to secure order and maintain the current economic systems, rather than being altruistic interventions aimed at resolving the conflict and its underlying causes" (Duncanson, 2007, p. 23). While existing arguments provide valuable insights into peace-building, this literature has failed to examine the gendered and gendering processes of post-conflict reconstruction (O’Reilly, 2012). 
To mitigate the inequalities in this relationship, some research on peacekeeping has emphasised the need for peace-builders to take into account local context and the need for building relationships with local people in a culturally aware way (Vuga 2010; Haddad 2010; Tomforde 2010; Harland). With regards to peacekeepers, Tomforde notes "there is no doubt that different actors in a conflict, be they conflicting parties, multinational peacekeepers or those planning the mission, carry with them certain cultural perceptions. Indispensible in adjusting to local cultures is an examination of the self and interactions of culture across different actors in the development space" (Tomforde, 2010). Connecting this to gendered understandings, placing value on developing cultural awareness can be seen as a 'feminine' undertaking and is thus not prioritised. This is because it necessitates qualities such as communication, empathy and compassion, which have not traditionally been valued as key skills in the military (Duncanson, 2008; Stiehm, 2000).

\section{Feminist Critiques of Peacekeeping}

Connecting international military violence with everyday forms of violence, no one has been more at the forefront of criticising soldiers as peacekeepers than feminist researchers (Cockburn \& Zarkov, 2002; Enloe, 1983). With their close attention to gender and women's security, Turpin et al. (1998), Cockburn et al. (2002) and Whitworth (2004a) have questioned the use of soldiers to create and maintain peace. They point out that the presence of military peacekeepers has often not improved the security of those made vulnerable through conflict. They highlight the increases of sexual exploitation, human trafficking, sexual harassment and aggression towards civilians in peacekeeping interventions. They attribute this to the kinds of violent masculinities that are valourised in the military, such as toughness, strength and aggressive heterosexuality. Thus they note that while the presence of peacekeepers may result in the cessation of warring parties, the continuance of gender inequality and gendered violence means that for many, peace is not a reality (Whitworth, 2004a).

Many of these critiques have sought to empower local women by increasing the representation of local women in peace-building and reconciliation processes and/or advocating for the increased participation of women in the armed forces on peace- 
building missions (Carreiras, 2010). With regards to women in the armed forces, it has been argued that women have a calming effect in dangerous situations, are more likely to encourage gender-balanced host societies, ensure personnel act in ways that are considered 'civilised', and give legitimacy to missions when they may not have been so. As Hutton and Hendricks (2008) have argued:

Local men and women tend to see female peacekeepers as more approachable and less threatening than male peacekeepers; female peacekeepers are needed at roadblocks, airports etc...to perform body searches on women;...female military personal serve as monitors of excessive behaviour among male soldiers; female soldiers provide positive role models for local women to join armed and security forces.

The perceived benefits of having women in peacekeeping and policing have been utilised to encourage women's increased inclusion in peace-building and peacekeeping initiatives (Hudson, 2005; Mazurana, Raven-Roberts, \& Parpart, 2005; Olsson \& Tryggestad, 2001; Rehn \& Johnson Sirleaf, 2002). Thus female soldiers and policewomen, both local and international, are seen as a feminising force for areas traditionally populated by men.

Likewise, feminists advocating for the inclusion of more local women's perspectives in post-conflict peace-building and peace negotiations, saw the adoption of UNSCR1325 on women and peace and security in 2000 as a triumph (Parpart, 2002) ${ }^{9}$. This was because it was seen by women's organisations as an important step in ensuring a gender perspective is integrated into the resolution of conflict (Barnes, 2006; Whitworth, 2004a). The resolution:

[u]rges all actors to increase the participation of women and incorporate gender perspectives in all United Nations peace and security efforts. It also calls on all parties to conflict to take special measures to protect women and girls from gender-based violence, particularly rape and other forms of sexual abuse, in situations of armed conflict ("Landmark resolution on Women, Peace and Security (Security Council resolution 1325)," n.d.).

\footnotetext{
${ }^{9}$ Two further UN documents call for increased gender sensitivity in peace-building - Mainstreaming a Gender Perspective in Multidimensional Peace Operations; and the Windhoek Declaration Namibia Plan of Action on Mainstreaming a Gender Perspective in Multidimensional Peace Support Operations.
} 
However, these arguments for the increased inclusion of women in all aspects of postconflict peace-building, rely on notions of women as innately peaceful. As argued by Enloe and $(1983,1990)$ Turpin et al. (1998), there is little evidence that increasing the number of women in the defence forces challenges gender stereotypes and oppression. Similarly, as Sahla Aroussi argues, feminist writings on UNSCR1325 have overly represented women as "mythical peace-builders and romanticised their contributions to peace" and overstated women's victimisation "at the hands of violent and bellicose masculinity" (Aroussi, 2009, p. 1). This representation has, Aroussi argues, only reinforced hierarchical gender dichotomies and therefore sustains the very gender inequalities and exclusion of women from peace and security the resolution seeks to rectify. She argues that if we disconnect femininity from peace we would dismantle a major source of militarism (Aroussi, 2009). While her focus is on challenging the discourses of women as inherently more peaceful than men, this is important for this thesis as she recognises that these dichotomies also unfairly and inaccurately construct men monolithically, who are only understood as the perpetrators and aggressors'. While men are most often the victors of this gender dichotomy, this leaves very little space for "the expression of positive masculine agency" and results in a homogenised masculinity, where men affirm their masculinity through the objectification and exclusion of women (Shepherd, 2008, p. 39).

The small amount of literature that has considered the cultural and gender sensitivity of RAMSI in the Solomon Islands has likewise focussed mainly on women (Allen, 2006; Greener et al., 2011; Greener, 2005). While not taking gender into account, Allan has suggested the RAMSI intervention needs to pay far more attention to building connections and interacting with the local community, and points out that Australian soldiers were criticised for failing to "come down to the people" (M. Allen, 2006, p. 197). Charlesworth (2008) has been critical of the failure of RAMSI to ensure that women partake in the peace process at the cessation of the conflict, pointing out that many women who had been involved in peace processes during the conflict were marginalised post-conflict because of RAMSI's culturally inaccurate assumptions about the role of women in the Solomon Islands being confined to the 'domestic sphere'. This failure to recognise women's customary roles in peace processes, because of generalised ideas about their traditional roles in the Solomon Islands, has impacted in 
gender equality as it has served to diminish their status post-conflict (Higgins, 2008). Greener et al. have used a gender analysis to argue that in addition to side-lining women in the peace processes, RAMSI have done little to reduce violence in the everyday lives of women, ${ }^{10}$ pointing to a survey done in 2008 where 31 per cent of female respondents felt their community was safe and peaceful ${ }^{11}$. They point out that "this notion that peace-building is to promote a 'just society' takes us beyond the mere cessation of public violence between armed militants to that of a deeper form of peace within society" (2011, p. 18). Both Greener et al., and Charlesworth focus on women when exploring the gendered implications of the RAMSI mission in the Solomon Islands, however both acknowledge further research into the gender impacts of RAMSI on men and masculinities is needed. This thesis seeks to address this lack of attention.

\section{Linking Masculinity, Violence and the Military}

Critical research into men's gendered experiences and the experience of masculinity has grown increasingly since the 1980s. Feminist attention to exposing and highlighting the power, position and practices of men before this had tended to class men as 'the problem', offering men little more than negative images of masculinity (Cornwall, 1997). Yet it is important to highlight the ways that men and masculinities are understood and the subsequent ways in which masculinities are enacted, as they have a relational impact on the value placed on femininities and women. Thus, increasingly feminists have paid attention to the complex gendered experiences of men. Charlotte Hooper has pointed out that neither masculinity nor femininity are monolithic unchanging categories, rather there are a plurality of masculinities and femininities available at any given time. Which attributes are considered masculine or feminine "depends on circumstances and is subject to change and struggle" (Hooper, 2001 , p. 4). Work on masculinities in gender studies has highlighted that there is a hierarchy of masculinities that is dominated by evolving hegemonic forms (R. W. Connell, 2001; Hooper, 2001). Connell's (1987) influential work introduced the concept of hegemonic masculinities. Connell (2002) argues that although there are many ways

\footnotetext{
${ }^{10}$ Approximately 64 per cent of women and girls report having experienced physical or sexual violence in the home. No statistics of the violence experienced by boys and men are available.

${ }^{11}$ Interestingly, only slightly more - 40 per cent - of men respondents responded that they felt their community was safe and peaceful.
} 
of being a man, some are more valued than others. Commonly in the cultural landscape there are ideas about what an 'ideal' man is. Men don't necessarily fit this ideal - it is more something which men are expected to aspire or conform to. If men do not conform, or appear to conform, they may be discriminated against, or find themselves at a disadvantage (Cornwall, 1997). Connell emphasises that "gender, and specifically masculinity, [is a] structure of social practice, one that is reproduced within historical situations through daily actions" (Whitehead \& Barrett, 2001, p. 27). Gender identity is fractured, shifting "often marked by internal contradictions and historical disruptions" (Whitehead \& Barrett, 2001, p. 28). With regards to conceptualising hegemonic masculinity we must be careful to recognise that "hegemonic masculinity is not fixed character type, always and everywhere the same. It is rather, the masculinity that occupies the hegemonic position in a given pattern of gender relations, a position always contestable" (R. W. Connell, 2001, p. 38). Recognising this plurality of gender identities, means moving away from analysis of masculinity to an analysis of masculinities (Hooper, 2001).

This becomes useful when examining the connections between violence, masculinity and the armed forces. Feminist, critical men's studies and postcolonial contributions studying national militaries and peacekeeping, have explored military and 'militarized masculinity' across a variety of contexts from the international to the everyday (Arkin \& Dobrovsky, 1990; Barrett, 2001; Goldstein, 2003; Higate \& Henry, 2010; Higate, 2003; D. Morgan, 2004; O'Reilly, 2012; Razack, 2004; Whitworth, 2004a, 2004b). One aspect of this has seen feminist scholars increasingly examine the gendered and gendering processes of the military with regards to ideas and practices of masculinities. Barrett argues that "the military is a prime candidate for the study of masculinity, not only because it is an institution populated with men, but also plays a primary role in shaping images of masculinity in the larger society" (Barrett, 2001, p. 77). Feminists exploring questions of security have pointed out that war, soldiering and masculinity are intimately connected (Cockburn \& Enloe, 2012; Cockburn \& Zarkov, 2002; R. Connell, 2002; Enloe, 1983, 1990; Goldstein, 2003; Sylvester, 1994). Men dominate militaries, police forces, militias and armed gangs; most often make the decisions to go to war; and are those most often given guns to play with as children (Cockburn \& Zarkov, 2002). As Enloe (1983) has noted: 
The notion of combat plays a central role in the construction of notions of manhood and justifications for the superiority of maleness in the social order. In reality, of course, to be a soldier of the state means to be subservient, obedient, and almost totally dependent. But that mundane reality is hidden behind a potent myth: to be a soldier means possibility to experience 'combat' and only in combat lies the ultimate test of a man's masculinity (Enloe, 1983, p. 12).

However, this does not mean that men are naturally more violent - killing does not come naturally to men (Goldstein, 2003, p. 253). While many men choose violent means, there are more who do not, or desire not to (R. Connell, 2002), and many women, while constructed as naturally more peaceful, are intimately involved in violence (Duncanson, 2008). Gender meanings that construct men as aggressive and tough, and women as peaceful and weak, are vital in maintaining a system that justifies military intervention and men's and women's support of it (Steans, 2006). On the whole, as Goldstein argues, men and women involved in combat find fighting horrible and unnatural. Thus the development of masculinity to be associated with toughness under fire is necessary. Indeed, the strict punishments for desertion, harsh discipline and the exultation of fighting forces would be unnecessary if the reality was not that conflict is scary and confusing (Goldstein, 2003, p. 253).

Like Steans (2006), Whitworth (2004a) has explored the unequal social structures that peacekeeping interventions are premised on from a gendered perspective. She argues that peacekeeping solves the crisis of legitimacy that western nations' defence forces faced at the end of the cold war, noting that peacekeeping is particularly important for 'small' and 'medium' power militaries such as Canada, as involvement in post-conflict security offers financial gain that allows the military to continue to operate. It further provides a purpose for nations that face little external threat. At the very least, even with the best of intentions, peace-building operations reflect particular ideas about security, governance, development and an inherent superiority of peacekeepers and actors over that of the conflict-ridden society. This occurs in a very gendered and racialised way. Peacekeepers are positioned as "white, male heroes- advanced, civilized, democratic- and feminize the rest of the world as backward, chaotic and primitive" (Duncanson, 2008, p. 24; Orford, 1999; Razack, 2004; Whitworth, 2004b). 
These criticisms of peacekeeping, much like post-development literature, argue peacekeeping interventions represent a new form of imperialism where the interventions of predominantly white, male armed forces are normalized as altruistic and expected, and perpetuate ideas about who is "advanced, democratic and good, and who is backward, primitive and in need of help" (Duncanson, 2008, p. 24).

However we must be careful to not suppose that military operations work on a basis of traditional hero archetypes unchanged by changes in the military (Carreiras, 2010, 474-5). Militarized masculinities are understood as a form of hegemonic masculinity, thus it is important to recognise that there are multiple and changing forms of militarized masculinities and consider the intersecting identities that affect soldiers' behaviours. "Images of masculine heroism have shifted throughout history" (Carreiras, 2010, 474), and different models of masculinity coexist within society, which is reflected in the military as well. An important part of understanding how hegemonic masculinities shift and adapt to retain power is considering the wider politics of identity construction. In gender hierarchy, gender intersects with other identities, such as class and sexuality. By examining other fluid forms of identities that intersect with gender we can begin to see some forms of masculine identity become subordinate. For example, some feminist scholars have investigated the ways that a range of particular hierarchical and gender identities have been reproduced and created through particular forms of nationalism and colonialism (Hooper, 2001; Pettman, 1996).

Feminist academics have highlighted that there is a hierarchy of hegemonic and subordinated masculinities which sees different divisions within the military defining themselves against one another, based on whom can align themselves more closely with the hegemonic model (Barrett, 2001; R. W. Connell, 2000; Enloe, 1990; Higate, 2003). For example, Barrett (2001) has explored the alternative masculine discourses and identities that personnel construct across different job specialities in the Navy, finding that there are a number of different strands of hegemonic masculinity that soldiers can draw on in order to secure a sense of masculine identity. This concept of hegemonic and subordinate masculinities is valuable, as it acknowledges multiple masculinities while retaining attention to the operation of power (Hooper, 2001). 
This recognition of multiple and changing militarized masculinities has been extensively explored by Duncanson (2008, 2009) who questions whether peacekeeping is engendering new forms of masculinities in the British forces. She suggests that the shift to peacekeeping since the 1990s has seen changing ideas about what is valued and considered masculine by soldiers. While traditional 'warrior' types remain valued, other alternative masculinities have begun to be positioned as more masculine than traditional militarized masculinities. In her research, Duncanson questions whether this is leading to a shift in hegemonic masculinities or whether this holds possibilities for a more revolutionary re-gendering of the military, where attributes more normally associated with femininity are positioned as valuable. She argues that when qualities such as negotiation, relationship-building and empathy are seen as useful for peacekeeping and are de-linked from violent masculinities this holds great potential for increasing gender sensitivity and equality in peacekeeping deployments, and within the armed forces.

Higate and Henry $(2009 ; 2003)$ have similarly pointed to the need for further research into soldiers' individual negotiations of identity in peacekeeping deployments, arguing that while increasingly the international community turns to peacekeepers when all else fails, the impact of their everyday security work and the responses this induces are explored by few scholars. In doing so, they note that that placing unquestioning responsibility of blame for peacekeeping shortcomings on militarized masculinities constructs peacekeepers as a one-dimensional. Instead, they focus on the embodied experiences, beliefs and feelings of local populations and soldiers. These things, they argue, are mediated through perceptions of national identity and gender which draw on local and global stereotypes about particular identities:

While it is clear that national troops' identity and geopolitical imperatives articulate with one another in ways that shape how peacekeepers are seen, there remains little consideration of what this might look like on the ground in ongoing missions. How did the country of origin of peacekeepers shape the perceptions of security performance? (Higate \& Henry, 2009, p. 120)

This thesis recognises and highlights that it is vital to pay attention to identities that intersect with masculinities, such as ideas of race and nationality, in order to further 
understand how these attributes affect the ways that peacekeepers conceptualise and engage with their work (Cockburn \& Zarkov, 2002; P. Higate, 2007; Miller \& Moskos, 1995). Duncanson and Higate and Henry's work is important as it notes that soldiers' approach to work is not entirely controlled by militarized masculinities. Instead, they recognise that soldiers engaging in peacekeeping are active in reconstructing their identities, demonstrating the agency of individual soldiers to create new masculine identities in ways that can lead to more respectful community engagement (Duncanson, 2008). Furthermore, constructing soldiers as controlled by their militarized identity removes the agency of individual soldiers to actively reframe their identities in ways that are suitable for the local context and in ways that are more useful for conflict resolution (Duncanson, 2008; P. Higate, 2007).

\section{Conclusion}

To conclude, it is clear that in peacekeeping missions, different international and community understandings of gender, race, ethnicity and nation come into play. Postdevelopment thinkers have highlighted the need to direct attention back on developed nations to uncover the assumptions that are commonly unquestioned by those involved in development. With the increasingly blurry lines in post-conflict spaces between the military and traditional development actors, it is important to direct our gaze toward investigating the implications of soldiers in this space. Within this, considering the intersectionality of gender with other identities is needed in order to address the resulting layers of performance and identity (Kirby \& Henry, 2012). In order to pay more attention to the workings of masculinities within the armed forces, this thesis looks at the case of New Zealand Forces in Solomon Islands. While recognising that there are particular context-specific implications, at the same time it offers a unique perspective into understanding the machinations of masculinities in the armed forces, and the intersections of race and gender in a masculine organisation more broadly. Ultimately, as Kirby and Henry argue, the "disjunctures, slippages and paradoxes in the performance of masculinity" (Kirby \& Henry, 2012) remind us that "masculinity (indeed, all gender) is always incomplete, but in a constant dialectic shifting in different fields, and established temporarily and evasively". With this in mind, this thesis "incompletely and temporarily" adds to the current literature by exploring whether participation in peacekeeping engenders new identity meaning for 
some soldiers. In the next chapter, I will explore the methodologies and methods I used to this end, as well as examining some of the challenges I faced in the research process. 


\section{Chapter Three: Methodology and Methods}

\section{Introduction}

For me 'entering the field' was "probably the most dramatic and shocking event" (Dumont, 1978, p. 48) that I experienced throughout the research process (Leslie \& Storey, 2003). Regardless of the preparations I made, the reading that I did and the people that I contacted, arriving in a new environment, culture and climate was marked by the gaps in what I imagined and the very real and different sense of space and time. The context of my fieldwork differed widely from the Solomon Islands to New Zealand, as did the particular contexts that different interviews occurred within these two geographic locations. While there are obvious cultural and language differences between the two contexts that affected interactions between participants and me, there were also similarities of power, societal norms and expectations in both locations. Furthermore, while there are limits to knowing how others positioned and interpreted me, the way that I positioned myself within both field locations was just as important to shaping our interactions. In this chapter, I will discuss some of the ways that I planned, carried out and interpreted my research. In doing so I will deconstruct some of the norms, expectations and structures of power that influenced the ways participants and I engaged, and the effect these had on how I came to interpret these encounters and the subsequent effect this had on the way I have presented this data. I conclude with a discussion of some of the ethical issues that I encountered and some of the limitations they place on the results.

\section{Methodology}

This thesis has used qualitative methods. Higate and Cameron note that, "military agendas tend to have skewed military sociology towards an empirical focus" (Higate \& Cameron, 2006, p. 221). Thus much of the research done into the military in the past has been quantitative in focus and ontologically positivist, using methods which were aimed at investigating "causal relationships between variables... within a value-free framework" (Denzin \& Lincoln, 2000, p. 8). Yet post-structural academics have questioned the use of objective scientific models to generate data, arguing that this foregrounds particular knowledge at the expense of other knowledges and realities (Winchester \& Rofe, 2010). 
In order to step away from this empirical bias, qualitative methods were chosen to conduct the research. Brockington and Sullivan (2003, p. 58) explain:

Qualitative research is characterised by three commitments (Bryman and Burgess, 1999). First it seeks to understand the world through interacting with, empathising with and interpreting the actions and perceptions of its actors. Qualitative methods are used to explore the meanings of people's worlds - the myriad personal impacts of impersonal social structures, and the nature and causes of individual behaviour. Second, qualitative research tends to collect data in natural settings, rather than artificial and constructed contexts (such as laboratories). Third, it tends to generate theory rather than test it. Qualitative methods work inductively, building up theory from observations, rather than deductively, testing theories by trying to refute their propositions.

Thus, in line with this explanation, this research sought to understand the experiences of soldiers in the post-conflict development space by interacting, empathising and interpreting the actions and perceptions of the actors present in this space, and the meaning that is generated from this. Therefore qualitative methods are the most useful. Furthermore, these methods are appropriate as the data was collected in settings chosen mostly by participants.

I chose not to use quantitative data as my research is based on perceptions and meaning generated through my interactions with interview subjects, thus while quantitative data is a useful form of data collection - it did not offer the subjective understandings of knowledge that frame this thesis. Similarly, large quantities of subjects or data collection such as surveys were not chosen because of the difficulties faced in getting participants and furthermore, I felt it would constrain the exploration of participant's perceptions to a depth I desired.

\section{Choice of Setting}

Development research and practice is heavily orientated to those in 'need of development' however, post-development critiques have highlighted that it is just as important to turn the gaze back onto the 'agents of development' when exploring the structural impacts of development (Crush, 1995; Escobar, 1995; Ferguson, 1994; Rahnema \& Bawtree, 1997; Sachs, 1992). This shaped my desire to look at the way that New Zealand and New Zealanders engage with development. Soldiers are not 
new in the post-conflict development space, yet thinking around their presence has changed significantly in the last twenty years (explored in Chapter Three: Literature Review). Therefore, the experiences of individual New Zealand soldiers were seen as appropriate to research.

The Solomon Islands is the context in which New Zealand soldiers 'entered' the postconflict development space, thus the Solomon Islanders provided the orientation from which to further explore the presence of soldiers in this space. While New Zealand also has soldiers in East Timor/Timor Leste and Afghanistan, practical concerns about safety in Afghanistan, and the advice given that Timorese are "researched-out", resulted in the choice of the Solomon Islands. Furthermore, the New Zealand Army had Regular Force and Reserve Force soldiers present in the Solomon Islands acting in a peacekeeping role from 2003-2012. In this time little attention has been paid to exploring the experiences of individual soldiers outside of defence force circles and occasional mentions in New Zealand newspapers. This lack of attention made RAMSI an interesting example of peacekeeping to research as a case study.

Research does not only occur in the immediate interview situation but in the experience of sights, smells, interactions with people and conversations that bookend each interview, thus I travelled to the Solomon Islands as much to conduct interviews, as to experience the environment for myself. While many feminist analyses of peacekeeping utilise military documents and interviews with personnel, I saw interviewing Solomon Islanders as important because they provide an important and unique perspective on how the soldiers' actions are perceived by local residents in post-conflict peacekeeping environments. Thus, despite criticising the impact of soldiers' masculinities on peacekeeping, only a few feminist scholars have included local perspectives when exploring gender and peacekeeping (see Pouligny 2006; Mazurana, Raven-Roberts, and Parpart 2005).

\section{Methods Used}

\section{Semi-Structured Interviews}

From 06 June till 19 June 2012 I carried out five semi-structured interviews with seven Solomon Islanders. Two months later I interviewed two Reserve Force soldiers based 
in Christchurch and Dunedin. Semi-structured interviews were chosen as a research method as they allowed participants to provide open-ended responses but also gave me room to guide the interview. This also allowed me the flexibility to explore main themes and questions in a way that flowed naturally and suited the tone and setting of each particular interview. Finally, semi-structured interviews gave the participants the ability to articulate any other information that they thought was relevant, something not possible with more structured interview techniques and questionnaires (Brockington \& Sullivan, 2003; Willis, 2006).

Two interviews were conducted with two people simultaneously in the Solomon Islands. No local translator was hired, rather I relied on someone present being able to translate and my understanding of Pijin if needed. One section of the interview transcript in Pijin was translated later by a local friend in the Solomon Islands.

\section{Finding My Participants}

All of the interviews I conducted were a result of networking, recommendations from friends and no small amount of lucky encounters. Key 'gatekeepers' - people able to pass on my details to people they felt might be interested in my research - were the primary method through which all of my interviews resulted (Overton \& Murray, 2003). All interviews were conducted with a Dictaphone and supplementary notes made during the interviews.

Before leaving for the Solomon Islands informal networks were drawn on to establish contacts for me engage with on my arrival. I used a loose snowballing method in order to find interview participants once in the Solomon Islands (Overton \& Murray, 2003; Vaioleti, 2006) This involved many face to face meetings with various contacts I had been given through my informal networks and included an Anglican bishop, several development workers, a PhD student living in Honiara, a Solomon Island university lecturer, a Solomon Islander working for Australian Aid (AusAID) and a local resident recently returned from studying in New Zealand.

As Vaioleti points out "The Pacific way is spoken rather than written, based on oratory and verbal negotiation which have deep traditional roots in Pacific cultures," (Vaioleti, 
2006, p. 25) Therefore, while I made contact via email and phone, I relied on engaging in unstructured conversation with as many people as possible to connect into existing familial, work, friend and community networks. I attempted to engage people I met day-to-day in conversations about RAMSI and the presence of soldiers in the Solomon Islands. This included taxi drivers, fellow boarders from other islands at the guest house, the guest house staff, and local and expat people I met through informal socialising. These informal discussions were important for my understanding of the context and wider issues surrounding the presence of RAMSI and soldiers in the Solomon Islands, and for ascertaining places that New Zealand soldiers had been present and thus what geographic and ethnic groups would be the most valuable to talk to (Hay, 2010; Kearns, 2010). Meeting face to face was the most important aspect of establishing familiarity and allowing people to assess me. Most meetings were conducted at one of the local kai-bars - a busy public outdoor food arcade. A couple of meetings occurred at one of the local cafes that caters to ex-pats. Numerous serendipitous outcomes resulted from these meetings and all of my interviews were a result of the goodwill of people who gave me their time.

My intention to interview New Zealand soldiers initially saw me making contact with the NZDF through a contact at Massey University. From there I was passed onto an Organisational Research Manager for the NZDF. I intended to gain permission to interview New Zealand soldiers however after many months of little obvious progress I made the decision to abandon this avenue of enquiry (my application is still in process' to this day). Fortunately a friend who is a Reserve Force soldier agreed to be interviewed and was able to secure the second interview for me.

This difficulty obtaining interviews with New Zealand soldiers imposes some limitations on the breadth of the conclusions that can be drawn about negotiations of identity by soldiers in this thesis. While ultimately the focus of my research was on the everyday individual negotiations of identity by Steve and Henry, my conclusions would have been much enriched with interviews with New Zealand soldiers that reflected the diversity of the forces. No soldier would experience and interpret their role and deployment to the Solomon Islands the same and differences such as rank, age, education, employment background, gender and ethnic identity could highlight some 
important variations in understandings of peacekeeping. In particular the perceptions of Maori and Pacific Island soldiers would have been a particularly valuable contribution. Further research into exploring these differences would be invaluable but for the purposes of this thesis I have attempted to acknowledge these limitations by focussing on what the individual experiences of two soldiers' highlights and how these experiences intersect with, or differ from current literature on peacekeeper masculinities ${ }^{12}$.

Figure 1. details some information that I consider pertinent to share about each participant attached to the pseudonyms I use in this thesis.

Figure1. Pseudonyms used for participants.

\begin{tabular}{|c|c|c|}
\hline Pseudonym & Participant Information & Date and Location of Interview \\
\hline Steve & $\begin{array}{l}\text { Soldier in Reserve Forces deployed to } \\
\text { Solomon Islands 2008/09. No longer in } \\
\text { Reserve Forces }\end{array}$ & $\begin{array}{l}\text { October } 5 \text { 2012, University of } \\
\text { Otago Library, Dunedin }\end{array}$ \\
\hline Henry & $\begin{array}{l}\text { Soldier in Reserve Forces deployed to } \\
\text { Solomon Islands 2007/08. Still a } \\
\text { member of Reserve Forces }\end{array}$ & $\begin{array}{l}\text { October } 4 \text { 2012, } \text { workplace } \\
\text { library, Christchurch }\end{array}$ \\
\hline Andrew & Ex-minister, businessman, Malaitan & $\begin{array}{l}06 \text { June 2012, workplace office, } \\
\text { Honiara }\end{array}$ \\
\hline Ronnie & $\begin{array}{l}\text { Security guard, kidnapped during the } \\
\text { tensions, Guale }\end{array}$ & $\begin{array}{l}07 \text { June 2012, } \\
\text { Casino hotel, Honiara }\end{array}$ \\
\hline Billy & Government bureaucrat, Guale & $\begin{array}{l}13 \text { June 2012, workplace, } \\
\text { Honiara }\end{array}$ \\
\hline $\begin{array}{l}\text { Mary } \\
\text { Rich }\end{array}$ & $\begin{array}{l}\text { Married villagers where New Zealand } \\
\text { Army camped after } 2006 \text { Chinatown } \\
\text { riots, Guale and Malaitan respectively }\end{array}$ & 15 June 2012 , West of Honiara \\
\hline $\begin{array}{l}\text { Rachel and } \\
\text { James }\end{array}$ & $\begin{array}{l}\text { Friends living in Henderson near the } \\
\text { military base GBR, Guale }\end{array}$ & $\begin{array}{l}19 \text { June 2012, in the market, } \\
\text { Honiara }\end{array}$ \\
\hline
\end{tabular}

\section{How Information Was Analysed}

Dunn notes, "Researchers analyse interview data to seek meaning from the data" (Dunn, 2010, p. 125). In order to find this meaning, I used latent content analysis to search interview transcripts for main themes under headings based on context, practices, attitudes and experiences (Dunn, 2010; Waitt, 2010). Keeping in mind that

\footnotetext{
${ }^{12} \mathrm{~A}$ discussion on limitations and the areas of further research that these limitations highlight can be found in Chapter Eight: Conclusions.

${ }^{13}$ Guale is the name given to people ethnically from Guadalcanal
} 
this was an iterative process, some initial codes fell by the wayside while others were developed further. Nvivo software was used to aid this process.

The themes present in participants' narratives identified during the coding process were further analysed using discourse analysis. Discourse analysis is a well-established approach for feminist academics attempting to make sense of the gender structures that are present in the surrounding world. This is because studying masculinities and femininities pose particular methodological challenges. They are not visible in 'reality' but are expressed through every-day embodied practices which can be difficult to measure (Bevan, 2011; Sasson-Levy, 2002). Exploring gender with regard to the military is interesting as there are particular silences around men and gender. Men are constructed as the norm, where they are 'soldiers' that women, as 'female soldiers', are measured against. As a result of these silences, how certain forms of masculine behaviour continue to dominate are left unexamined, and the plurality of men's gendered performance is not made visible (Bevan, 2011; Sasson-Levy, 2002).

Post-structural discourse analysis is useful for investigating the gendered identities represented in interviews because of its close attention to the gendered meanings attached to soldiers' language (Duncanson, 2009). Discourse analysis as a methodology is deeply interested in language, recognising that language is socially and politically constructed, generating meaning through constructions of problems and subjectivities simultaneously (Hansen, 2007, p. 63). As soldiers create their identities by carrying out certain practices, how they understand these practices can be explored by paying close attention to the structures of meaning present in their language. Similarly, local people understand soldiers' identities through observations of their performances, thus discourse analysis can be used to investigate the particular ways that they discursively understand soldiers' behaviour in their reflections.

Furthermore, feminist Lene Hansen's theory of "linking and differentiation" offers possibilities for identifying the gendered language present in soldiers' reflections. In this theory, terms such as 'male' are linked to a collection of qualities. For example, 'men' can be connected to qualities such as strong, rational and active. This understanding of 'men' is juxtaposed against the oppositional term 'women', which is 
linked to the similarly juxtapositioned qualities - weak, irrational and passive. Within this dichotomy the privileged term is commonly associated more broadly with masculinity, whereas femininity becomes devalued as the 'Other'(Bevan, 2011; Hansen, 2007).

Because masculinities are fluid, practices associated with masculinity and femininity change. When practices are repeatedly linked to qualities that have traditionally been attached to masculinity then these practices become masculinised. As gender is a relational concept this process has subsequent implications for practices considered feminine. For example, the importance of building cross-cultural relations in peacekeeping may not be considered to be masculine on its own, but if it is linked to qualities that have traditionally been associated with masculinity in positive ways, such as ensuring security and effectiveness, then cross-cultural relationship building becomes identified as masculine when it may have been considered feminine previously (and thus devalued). (Bevan, 2011; Duncanson, 2009)

By analysing the soldiers' and local Solomon Islanders' reflections and stories regarding the RAMSI mission with the aforementioned feminist discourse analysis, I have been able to ascertain some of the different ways that masculinities are understood and articulated in relation to intersecting attributes of identity. Without investigating the differences in understanding, it is not possible to identify the impact that gender has on peacekeeping performances in the Solomon Islands.

\section{Negotiating Self-Other Relations and other Ethical Considerations}

Conducting individual research, especially in unfamiliar environments can be challenging. One can be faced with fear, anxiety, self-doubt and uncertainty (Leslie \& Storey, 2003). Because every researcher carries with them a diversity of experience that differentiates them from all other individuals, their challenges will be unique. Complex and uneven power relationships will affect the ways that the participants and interviewer interact, and the kinds of information that is generated (Dunn, 2010). At different times during the research process, the researcher will experience a sense of power differently. As a result, when considering the kinds of issues encountered, "the values of researchers can never be eradicated from their work and no amount of 
methodological technique or declarations of bias can strip them of their theoretical presuppositions" (Higate \& Cameron, 2006, p. 220). In this next section I will reflect on the ways that my identity intersected with some of the issues I faced.

\section{Thinking About Myself}

Like the feminist geographer Gillian Rose, the idea of writing my positionality into my research practice seemed difficult, perplexing and full of wrong turns (Rose, 1997). The challenge in pinpointing the 'right' kind of information to be considered in order to research ethically was fraught with uncertainty. What parts of myself should I make visible to my participants and others who read this thesis? Would being a woman be important to the men I was going to talk to? Would it be important for women? It seemed to me that declaring 'who I was' would resonate with Sparke's argument that in doing so "seems only to provide a mantra of relief from the more detailed and difficult task - the perverse task...of examining the complex contradictions constituting one's positionality" (Sparke, 1996, p. 213) and might tempt me to declare who I 'was' and then fail to practice reflexivity throughout my research. As my thesis progressed and I 'entered the field' my attention was increasingly drawn to acknowledging my gendered experience of the research process. Likely a result of my ongoing interest in gendered experience, my mindfulness of this is an important aspect of the way I interpreted my engagement with my research environment.

Higate and Cameron (2006) highlight the challenges of collecting data in a highly masculinized institution such as the military and the different ways the gender of interviewers is impacted by this. My application to conduct research with the New Zealand Army was never granted and when this became apparent to me I was plagued with the idea that my application had failed to be taken seriously because I was an inexperienced unaffiliated, young female researcher. Higate (2006) discovered that in interviewing senior military personnel, his status and gender played an important role in the way he and his participants interacted, as did being an 'insider' to the military organisation. Much feminist and post-colonial (Gilbert, 1994; Kobayashi, 1994; Mattingly \& Falconer-Al-Hindi, 1995) research sees researchers as 'holding' power in relation to their participants. However, while individual soldiers within the organisation informally expressed interest in participating, ultimately I was not given 
access to interview soldiers - nor have I ever discovered why, indicating that the researcher does not necessary always hold the power.

Kezar notes that most critical feminist literature on research focuses on "empowering disenfranchised individuals or groups" by critically examining their circumstances. Slote Morris notes that the difficulties associated with interviewing 'elites' ${ }^{14}$ often means the majority of researchers choose to interview those considered less powerful in relation to the interviewer. This is despite the fact that in many cases it is only through engaging with those considered to 'hold the power' that one can "challenge power structures that limit their humanity" (Kezar, 2003, p. 395).

The failure to gain permission to interview Regular Force soldiers in the New Zealand Army and the subsequent time I spent on arranging alternative interviews demonstrates the realities of attempting to interview people with significant officially employed 'gatekeepers'. I believe that as Kezar argues, interviewing 'elites', presents an opportunity to engage with those in positions of power and attempt to understand how dominant narratives of power are maintained. Only through engaging with the military is it possible to understand how particular discourses of masculinity retain their hegemonic position and are made visible while alternative masculinities and femininities are not. However, while I failed to gain access to Regular Force soldiers, I have found that regardless of Kezar's argument, my close attention to the individual narratives of two Reserve Force soldiers presented a unique opportunity to explore they ways that individuals experience and navigate discourses of masculinity that are considered dominant, with close attention to the contradictions of gender that are present (and normal) in their discussions.

Ultimately it was my friendship with someone who happened to be a Reserve Force soldier that allowed me to sidestep the difficulties faced in being granted permission to conduct interviews through the New Zealand Army. However in doing so, new

\footnotetext{
14 Elite interviewing is defined by Morris (2009) as "those with close proximity to power' or with particular expertise. 'Elite interviewing is characterized by a situation in which the balance is in favour of the respondent' ((Burnham, Gilland, Grant, \& Layton-Henry, 2004, p. 205), and this can lead to additional challenges in gaining access and the respondents' tendency to seek to control the agenda (Morris, 2009).
} 
ethical considerations arose. Drawing on friendship networks in order to get interviews presents its own ethical dilemmas. There were potential risks to our friendship posed by the way that I choose to interpret their perceptions in this thesis, which I attempted to navigate based on my own sense of ethical codes. That the participants were Reserve Force soldiers (thus the Army was not their primary employer) and one was no longer employed by the Army, was helpful with regards to their willingness to allow me to interview them, as I felt that their positions allowed more freedom for them to discuss the Army critically. However, I recognise it is possible that they withheld sensitive information. Finally, it is easy to be less aware of gendered experiences in familiar environments, thus I would like to note here that it cannot be forgotten that in many countries the position of women would mean even soldiers considered friends may find it inappropriate for a women to be asking questions about being a soldier - especially with the Combat Exclusion policy for women in many militaries around the world. Thus I consider myself incredibly fortunate to have interviewed even these two soldiers.

When it came to my experiences in the Solomon Islands, my gender became more obviously at the forefront of how and why I interpreted and acted in particular ways. The sense of alienation that resulted from being in an unfamiliar environment is considered normal for researchers (Leslie \& Storey, 2003) but I was not prepared for the impact this would have on my ability to confidently search for participants. I experienced constant attention from men which I understood as gendered. Sometimes it was curious, sometimes playful but also often it left me feeling threatened and uneasy. In this following research journal entry the conflicting feeling this raised in me are apparent:

The boys here yell out to me heaps, or whisper in my ear if I walk past - or some of the other Kiwi girls - their crotch gets grabbed or they get kissed. At the soccer game last week they were yelling out to me "salty fish, salty fish!" which means "slut, slut!" Most of the time it's okay, they just say "good morning," or "hey sista." I hate the feeling that it gives me - that I have to walk around, not smiling, not making too much eye contact, wearing ridiculous amount of clothes. I went out the other day with a dress that went past the knee but the shoulders were less covered - and I ended up going and changing because I was getting hassled so much. Also, I don't know what the right cultural response would be. Like I asked Lisa and she said that she used to get 
upset, but now she yells back "whatever boy - there's my uncle over there - you should be careful what you say!" I asked the Kiwi girls about it and they were all blasé about it - not even like "you just get used to it," more like maybe threatened by me even talking about it? They made me feel lame - like I was weak or something.

The sense of unease that these experiences gave me contributed to my discomfort in travelling anywhere outside of Honiara. Additional to the expense and travel difficulties, I chose not to travel to the Weathercoast to seek participants as a result. Similarly, I was less willing to engage with strangers that I encountered on a day-to-day basis, meaning I potentially missed out on some valuable interview opportunities. Some academics have noted the emotional work involved in research (eg. Punch 2012; Davidson, Bondi, and Smith 2005; Evans 2012), however discussing the gendered and sexualised experiences of fieldwork and the impact that this has on collecting data is not common (Diprose, Thomas, \& Rushton, forthcoming). However, as my experiences highlight, this is problematic for preparing for fieldwork and taking into account the difficulties the researcher will potentially face.

On further reflection because of these kinds of experiences I came to understand the practice of reflexivity involves highlighting the significance of the power dynamics and emotions between the researcher and their environment within the context of research (Higate \& Cameron, 2006). Much post-structural feminist literature argues that (Gilbert, 1994; Kobayashi, 1994) academic women are in a position of privilege. Academic women have access to education, decide what questions to ask, direct the flow of conversation and have the final power of interpretation when presenting their research (Rose, 1997). Yet, as my above experiences demonstrate, power is not fixed with academic women alone. While I have the ultimate power to return home and can choose what information I include in this thesis, my success 'in the field' depended on being impervious to attention based on my gender.

My understanding of acting ethically is not only about complying with the "strict codes of institutional paperwork" (Sultana, 2007, p. 376) it is also tied up with intuitively interpreting contextual specificities. In the proceeding situations, where I had little time to think through the many implications of my actions, it was necessary to rely on 
my own ethical codes and my sense of what was most respectful in that situation. At times I experienced situations where my power as the researcher was apparent. For example, on one occasion the feminist voice in me yelled concern when I sat uncomfortably amongst a group of market sellers while one man with obvious status seemingly ordered women to come and talk to me. But I also experienced the opposite at times. The power of local participants to say no was often apparent to me, and exercised many times. Because I am not a Solomon Islander, my lack of Pijin and my inability to understand cultural subtleties at times meant that I had difficulty understanding situations. On many occasions I was perplexed about why people did not get back to me about possible interview contacts. In two interviews as the interviewee expressed impatience with the length of the interview, I chose not to seek further elaboration on explanations I was unclear about.

Ultimately, the numerous open, friendly and helpful people that I encountered both in New Zealand and in the Solomon Islands overshadowed the difficulties that I faced and empowered me to generate valuable research data. This is the salient point to take away from the proceeding discussion of difficulties- that while a discussion of these difficulties is important to explore to understand the boundaries this places on my research conclusions, this thesis is also a testament to the numerous small kindnesses of others who contributed to overcoming these difficulties.

\section{Other Ethical Considerations}

Engaging with human subjects in the research process is difficult and carries many ethical considerations that need to be worked through. In the past, research has been undertaken with little ethical consideration or questioning of the implications research may have for the participants. Both Victoria University of Wellington and the Solomon Islands Government have processes in place to ensure that researchers engaging in primary research gain ethics approval.

Students engaging in primary research with human participants must comply with a Victoria University of Wellington code of ethics. This requires students to provide to participants an Information Sheet and a Consent form prior to being interviewed (see Appendix 2a, 2b, 2d and 2e). These forms explained who I was, what I was researching 
and what I was intending to do with the information that they provided. They also stated that participants could withdraw any of the information they provided up until the November $1^{\text {st }} 2012$ with no consequences. I also explained verbally to each participant the content of the forms and that in signing the form, participants were acknowledging that they had understood the information I had provided and were willing to take part. I explained that their names would remain confidential and that I would use a pseudonym to refer to them throughout my thesis and any subsequent publications. Several of the participants expressed that they had no problem with their real name being used, but to maintain consistency I have seen it expedient to uses pseudonyms for all the participants.

The Solomon Islands Government requires all researchers engaging in fieldwork in the Solomon Islands to attain a research visa. The cost of the visa was \$240 (Solomon Island Dollars). The research permit was gained with significant difficulty that I did not foresee. A substantial amount of my time in the first two weeks in the Solomon Islands was spent following up my research permit application and acquiring additional letters to support my application. With the aid of several people both in New Zealand and the Solomon Islands I was able to acquire a research visa retrospective to my time in the field. Several people gave me advice to not wait for the application to be approved before starting my interviews due to my limited timeframe. This was sound advice due to the fact that my application was not granted till well after my return to New Zealand (see Appendix Three). While I was uneasy with the ethical dilemma this presented, I trusted that individuals who agreed to be interviewed were able to display their own agency to say no to being interviewed if they felt it would impact them negatively.

Though I discuss the 'ticked boxes' (Hopkins 2007) towards the end of this chapter I regard this information as no less important than any of the proceeding information. Indeed once the interview was over, participants were left with only their memories, and the information and consent forms I gave to them. 


\section{Conclusion}

In this chapter I have discussed the decisions that I made in order to plan, carry out my research and interpret my data. I have further discussed some of the ethical dilemmas that I faced and attempted to describe and share some of my situated understandings of the knowledge that I used to work through these issues. In doing so I acknowledge that my understandings are limited and representation of my only ever partial interpretations of events. In the next chapter I will detail some of the contextual information that this thesis is placed in. 


\section{Chapter Four: RAMSI - A Pacific Solution}

\section{Introduction}

In this chapter I will outline some wider contextual information that frames the research settings I chose for this research. As this thesis uses the contribution of the New Zealand Army to the Solomon Islands in the RAMSI mission as a case study, I carried out the research in two locations - one was geographic - the Solomon Islands, the other situated in the shared experience of belonging to the New Zealand Army as a Reserve Force soldier ${ }^{15}$. These two locations have disparate histories, politics and geography, but they have been brought together by the RAMSI mission. In this chapter I will give some historical and cultural background of the New Zealand Army. Secondly, I will discuss the conflict in the Solomon Islands that led to the RAMSI mission. Finally, I will outline RAMSI.

\section{The New Zealand Army}

The NZDF is considered "three forces in one". They are made up of the New Zealand Army, the Royal New Zealand Air Force and the Royal New Zealand Navy. Despite being part of larger organisation, each service has a different history and culture. For example, the New Zealand Army is the land based arm of the New Zealand Defence Forces and they state:

The unique culture of the New Zealand Army has been shaped and defined by a range of complementary influences. These include the martial traditions of the British soldier and the Maori warrior; our history, heritage and experience of war; and the characteristics of wider New Zealand society (NZ Army, 2012a).

The Defence Act 1990 gives the NZDF the legal basis for their activities. These activities include; "defending New Zealand and any area which New Zealand is responsible for defending; protecting the interests of New Zealand anywhere in the world; contributing forces under security treaties and other collective arrangements; contributing forces to the United Nations (UN); or in association with other

\footnotetext{
${ }^{15}$ The Territorial Forces were renamed the 'Army Reserves' in 2010. They are still commonly referred to as the Territorials.
} 
organisations or states in accordance with the UN Charter; assisting civil powers during emergencies in New Zealand or elsewhere" and "providing any public service" (Rolfe, 2012a). The NZDF has been involved in UN peacekeeping continuously since the 1950s including contributions to Pakistan, Somalia, Bougainville, Cambodia and Iraq (Capie, 2012). While New Zealand's peacekeeping has most often occurred under the governance of the UN, several missions have occurred under regional organisations such as with the RAMSI mission. Since the Vietnam War the NZDF's focus has been primarily been on peacekeeping. The Army has noted that the administering of relief aid and participation in peacekeeping-focussed missions has been important for creating high levels of trust and a positive image of the Army within the New Zealand public (Martin, 2011).

The gender and ethnic composition of each of the three services, and the Reserve Forces, are also different, based on their different histories and cultures. As of May 2012 the Regular Force sections of the Army was 86.8 per cent male; 48.6 per cent of personnel identified as 'European', 22 per cent 'Maori', 21 per cent 'Other', 4.4 per cent 'Pacific Peoples', 1 per cent 'Asian' and three per cent n/a. The Reserve Forces were recorded as of a very similar composition to the wider army (Rolfe, 2012b), thus because of the lack of data available to me on the demographics of the forces deployed throughout RAMSI, I presume that a similar percentage of women and those who identify as other than European were deployed throughout the RAMSI mission in the Reserve Forces.

While there is limited information available to the public on the gender policy of the NZDF, the overarching strategy towards valuing gender within the forces is outlined in the 2007 Progress on the Integration of Uniformed Women in the Armed Services (Soagia-Pritchard, 2007). The report highlights the increasing demands for deployments in different cultural, social and regional settings, thus the NZDF aims "to optimise the performance through strengthening of the NZDF's inclusive culture, recognising that this strength is partly derived from the differences that each individual brings" (2007, p. 6). The report indicates that for the Defence Forces, 'gender' is understood as a synonym for 'women'(Carver, 1996). For example, the report outlines "how gender integration has met women's needs" by outlining a 
Pregnancy Management Policy and a Flexible Working Arrangement Policy and a Child Care Policy (2007, p. 4). I was unable to access any information about the gender training in the New Zealand Army preparing soldiers for deployment.

The Reserve Forces are the part-time component of the New Zealand Army. The New Zealand Army states "The Army Reserve is made up of every-day New Zealanders who do their normal job in the community then conduct military training in their spare time. Living, working and training in their local community the Army Reserve is the public face of New Zealand's Army." Reserve Force soldiers are considered to have the best of both the civilian and military worlds as personnel are able to maintain a civilian life, yet utilise their civilian skills for the benefit of the forces. Reserve Force soldiers are organised into six regionally based regiments and are trained in basic soldier skills, which include first aid, weapons handling, fitness and field craft (NZ Army, 2012b).

In 2006, the New Zealand Army announced that the RAMSI deployment would consist mainly of Reserve Force soldiers to the Solomon Islands (Riley, 2006). As Major General Lou Gardiner said at the time "This kind of deployment is ideal for the Territorial Force to take a major role in. The mission in the Solomon Islands requires strong infantry skills and an ability to get on well with the local people. Territorial Force soldiers have the best of both worlds, robust infantry training and good everyday people skills from their civilian lives" (Riley, 2006).

\section{'The Tensions'16}

While 'ethnic tensions' are commonly cited as the cause of the recent conflict in the Solomon Islands, they are arguably only one of a combination of factors. Teaiwa (2005, p. 271) notes with regards to the Pacific region:

\footnotetext{
${ }^{16}$ While I want to introduce some historical grounding for this thesis regarding 'the tensions' I would like to recognise that while I believe it is beneficial to give some context in order to situate this thesis in a particular time and place, I also believe "Simplistic assumptions made about any one country's pathological trajectory or genealogy adds little to in-depth understanding of the complex nature of conflict." (Higate \& Henry, 2009) Thus I pay respect to the multiple personal stories and experiences of 'the Tensions' and recognise my own inability to fully 'explain' how or why they occurred, nor foresee the long-term effects they will have.
} 
Ethnic diversity alone does not cause bloodshed or bitterness. Every major conflict in the last 30 years has had at its heart inequitable access to resources. The resulting competition for limited resources has often been converted into antagonism played out along the latent social fracture lines etched by ethnic, class, gender and religious identities.

Since independence from British colonial rule in 1978, increasing numbers of Malaitans migrated to the island of Guadalcanal to take advantage of economic development in and around Honiara. Differences in matrilineal and patrilineal inheritance traditions mean that inter-marriage between Guale and Malaitans led to disruptions of traditional land inheritance on Guadalcanal. Further exacerbating factors such as government corruption, poor governance, competition for government resources and low levels of Solomon Island nationalism, created simmering tension. This is thought to have been intensified by the relatively young population, $42 \%$ being under the age of 14 and 55\% aged between 14 and 64 years. This was coupled with high unemployment, which resulted in a large proportion of under-employed urban disaffected 'youth' who exploited customary compensation practices for cash "backed by menace" (Fraenkel, 2004, p. 11). Additionally, also considered as a causal factor is the flow of arms, fighters and expertise from the recently ended Bougainville conflict after 1998 (Henderson \& Watson, 2005, p. 402).

In 1998 the Guale militant group Isatabu Freedom Movement (IFM) was formed (the group later splintered and the Guadalcanal Liberation Front (GLF) was formed) and it began to threaten Malaitans who had settled on the Guadalcanal Plains and around Honiara (Matthew Allen, 2007). The formation of the Malaitan Eagle Force (MEF) in 1999 is considered a response to the increasing insecurity this caused. The ineffectiveness of the police forces in maintaining law and order is also considered to have led to the formation of the militia groups. The militias consisted of men, though Greener et al. has made reference to anecdotal evidence suggesting "that there has been complicit and active involvement by women in promoting or supporting conflict in Solomon Islands" (Greener et al., 2011). ${ }^{17}$ In June 2000 the MEF broke into the national armoury and forced the resignation of Prime Minister Bartholomew Ulufa'alu (Henderson \& Watson, 2005).

\footnotetext{
${ }^{17}$ The wife of the notorious MEF leader Jimmy 'Rasta' Lusibaea being one women who faced charges of murder (Amnesty International, 2004).
} 


\section{RAMSI operation 'Helpim Fren' ${ }^{18}$}

Several efforts to resolve the conflict were made both internally and externally with the help of non-Solomon Islanders. This included the 1999 Honiara Peace Accord, the Panatina Agreement and later the Townsville Peace Agreement in 2000. Charlesworth (2008) notes that the role women have traditionally undertaken as peace brokers in the Solomon Islands resulted in the formation of groups such as Women for Peace to try and bring together warring parties. Some women conveyed an increased sense of individual and collective empowerment as a result of their roles as peacemakers during the conflict. By 2003 failed attempts at a resolution to the conflict prompted then Prime Minister Allan Kemakeza to request outside intervention in April 2003. As Greener notes, "the ability of the state to maintain order had withered to such a degree that outside help was viewed by many to be the only effective way left to restore law and order" (Greener, 2005, p. 215). Unlike in 2000 when a similar request had been made by Prime Minister Ulufa'alu, the 9/11 attacks and the recent 2002 Bali bombings had led to a shift in Australian and New Zealand thinking about regional conflicts. The security environment in the Solomon Islands came to be considered a region issue, with regional consequences (Henderson \& Watson, 2005). Therefore, the involvement of New Zealand and Australia was seen as necessary to ensure regional security. Sanctioned by the Pacific Islands Forum, the Australian led RAMSI mission was seen as a "Pacific solution to a Pacific problem" (Clark, 2003).

In July 2003, 2225 police and defence force personnel were deployed to the Solomon Islands (Capie, 2012; Henderson \& Watson, 2005). New Zealand and Australia were the main contributors, with significant contributions also coming from a total of fifteen Pacific Island nations (RAMSI, 2012a). The mission did not seek the sanction of the UN but was welcomed by the President of the UN Security Council, and commended by then UN Secretary-General Kofi Annan (DFAT, 2012). RAMSI was multilateral in approach, aiming to "restore civil order in Honiara and throughout the country - by

strengthening the rule of law, stabilise government finances, promote longer-term economic recovery...[and to] rebuild the machinery of government" (Wilson, 2009).

\footnotetext{
${ }^{18}$ The Pijin name given to the operation.
} 
The initial phase of the assistance mission aimed to create a 'security pause' in the spiral of criminality, corruption and violence (Greener-Barcham, 2007). The surrender of weapons and public disposal occurred quickly and was largely viewed as success. Harold Keke, a militant leader with a reputation for "ruthless and erratic behaviour', was convinced to surrender, and arrests of other militants occurred, including the leader of the opposing militia, Jimmy 'Rasta' Lusibaea (Henderson \& Watson, 2005).

Initially the military component of RAMSI was to wind down sometime in 2006, but the outbreak of rioting after the April 2006 parliamentary election of Snyder Rini, which resulted in the burning of China town and injury to several RAMSI police officers, triggered broader deliberations of the RAMSI mission and its success (M. G. Morgan \& McLeod, 2006). This resulted in an extended timeline for the presence of the military. Since 2006 the military component of the RAMSI mission has experienced a gradual wind-down of their duties that will see their withdrawal in the second-half of 2013 (Island Business, 2012). The final of the New Zealand deployments withdrew in November 2012 with over 1500 Defence Force personnel having served (RAMSI, 2012b).

When considering New Zealand's involvement, the Deputy Police Commissioner Steve Long advocated for the inclusion of a "coercive force" to back-up the police in order to be effective and not too high risk for the RSIP (Greener-Barcham, 2007). Thus the NZDF were seen as an appropriate inclusion into the assistance mission. From 20032012 Regular Force members of NZDF contributed an infantry platoon to RAMSI, which is the main combat unit in the New Zealand Army (Greener, 2005). This was at times supplemented with members from Reserve Force battalions from around New Zealand. At its peak NZDF had contributed 200 individuals. This was scaled back to approximately 33-55 personnel on two three-month rotations per year (GreenerBarcham, 2007). The platoons were initially given the task to:

[P]rovide protection for the Participating Police Force and other parts of the Mission, necessary due to the serious law and order situation and the large number of illegally-held weapons present in the Solomon Islands community at the time" (RAMSI, 2012b). 
Since the initial deployment their presence has been understood to be as a deterrent to any further conflict. In providing this sense of 'security' soldiers have in engaged in a variety of tasks with this aim in mind, while attempting to maintain a clear distinction from policing duties. These include security patrols and presence at observation posts, providing security for Rove prison, accompanying the Participating Police Forces (PPF) in their work, intelligence gathering, transportation and logistical support for the overall RAMSI mission and a 'response and reserve' capacity (Greener-Barcham, 2007). In effect this means the majority of soldiers' work has focused on travelling in vehicles and on foot and includes a reasonable amount of talking to local Solomon Islanders. The skills necessary to accomplish these tasks include the ability to be friendly, chat informally taking into account cross-cultural differences and communication skills such as relationship building and negotiation.

While the New Zealand Aid programme funds part of the RAMSI mission through the deployment of police, to the Honiara city council and the Ministry of Finance and Treasury (New Zealand Aid, 2012) funding for the New Zealand Army's presence comes through funding from the government for defence ${ }^{19}$.

\section{Violence During the Conflict}

Women and men experienced the conflict differently, however during the Tensions, both men and women were victims and perpetrators of violence. The conflict centred around Honiara, in the island of Malaita and on the remote Weathercoast region of Guadalcanal (see Appendix One: Map of Solomon Islands, and Appendix Two: Map of Guadalcanal). A report by Amnesty International (2004) gives some indication of the form of insecurity Solomon Islanders endured:

In January, civilian leaders from the Weathercoast of Guadalcanal, the main island, publicly reported incidents of torture, rape, forced displacement and the burning of up to 175 village homes by both supporters and opponents of a police operation against rebel leader Harold Keke. The Solomon Star newspaper stopped reporting on the issue after delegates who had been quoted in the paper were threatened and ill-treated. Harold Keke's Guadalcanal Liberation Front (GLF), which together with other rebel groups had initiated civil conflict in 1998, was well-known for terrorizing settlers and villagers on Guadalcanal.

\footnotetext{
${ }^{19}$ I would like to note that I faced difficulties in gaining exact numbers and statistics on the New Zealand Army's contribution to RAMSI.
} 
It has been noted that sexual violence against women and girls during the conflict was an entrenched feature with a variety of people responsible, including police, members of the militia or private individuals (Amnesty International, 2004; Leslie \& Boso, 2003). For example, a health study conducted during the conflict in 2002 interviewed 300 men and women Solomon Islanders and found that the majority knew someone who had been raped, and almost half had witnessed gang rape. More than half, including women, said they "had participated in long line rape [gang rape]". Additionally, studies have found that as violence tends to increase during conflict (Meintjes, Pillay, \& Turshen, 2001), domestic violence against women also increases, which appears to have been the case in the Solomon Islands (Amnesty International, 2004).

Academics such as Carpenter and Sjoberg have argued for the need to pay attention to the male victims of conflict both civilian and those who take up arms (Carpenter, 2001; Sjoberg, 2006). Solomon Island men and boys also experienced violence during the conflict. The customary practice of reparations meant the responsibility for correcting the harm done against families lay with men. The rape of a relative on Guadalcanal by GLF or IFM groups in 1999 was a common motivation to join the MEF. On the Weathercoast, GLF militants under the command of Harold Keke used punishment, including torture and execution of men in order to terrorize and control the communities supposed to be under his rule. Furthermore, the coercive nature of the militants meant that young boys who were "under threat to prove allegiance to the militia" were pressured to commit violence against their own families (Amnesty International, 2004).

\section{RAMSI and Gender}

The end of war often sees the beginning of an increase in gender-based violence ${ }^{20}$ (Meintjes et al., 2001). ${ }^{21}$ Thus RAMSI's gender policies are important to pay attention to, as well as how much attention was given to specific gender issues by RAMSI in the

${ }^{20}$ Gender-based violence (GBV) is defined as "violence that is directed against a person on the basis of gender. Gender-based violence reflects and reinforces inequalities between men and women" (European Institute for Gender Equality, 2006).

${ }^{21}$ For example, "It is alleged that sexual exploitation of young girls actually increased after the Peace Agreement because some ex-militants received large compensation payments, and/or wages if they were recruited to the police force, and so had the means to utilise sex workers" (UNIFEM Pacific SubRegional Office, 2010). 
post-conflict period. As Greener et al. (2011, p. 18) notes "this notion that peacebuilding is to promote a 'just society' takes us beyond the mere cessation of public violence between armed militants to that of a deeper form of peace within society".

Perhaps an indication of the importance given to gender issues post-conflict, a RAMSI appointed gender advisor, who was charged with "work[ing] across police and civilian capacity building programmes" in order to "improve the way it builds, monitors and reports gender within its development programmes," was not appointed until March 2009, six years after the mission had begun (Greener et al., 2011, p. 21). More broadly, the RAMSI focus on disarmament, demobilisation and rehabilitation of men as perpetrators of violence has failed both to recognise men as potential victims, or the role that women may have played in perpetrating the violence.

On the RAMSI website, 'gender issues' are understood to be about women, reflecting a wider blurring of 'women' issues and gender issues in post-conflict Solomon Islands. For example their website states:

Although there are few women in decision-making positions in the public service and law and justice institutions, women's capacity for leadership is strong. By supporting women's leadership potential and removing barriers to accessing justice via legislative reform, RAMSI is helping the Solomon Island's Government to change this situation (RAMSI, 2012c).

Similarly, research into gender issues in post-conflict Solomon Islands reflects this bias towards researching 'women' when considering issues of gender in the Solomon Islands. Greener et al. (2011) and Charlesworth (2008) both acknowledge their own lack of attention to men and masculinities in their research and emphasis the need for more research into this area. Despite their focus on women, they provide useful insights into gendered considerations when evaluating RAMSI and the peace process. Greener et al. (2011) argue that while RAMSI should be commended for attempting to put gender considerations into practice, they could be doing better. For example, they point out on the positive side that because the mandate of RAMSI was multilateral in approach, from the beginning the lack of women in government institutions and as 
politicians was a concern. As a result, while efforts to increase the participation of women have yielded few results, there have been increasing numbers of women recruited to the RSIPF, and the Solomon Island government, amongst other positive measures, has ratified the United Nations Convention on the Elimination of All Forms of Discrimination Against Women (CEDAW) in 2002.

Charlesworth (2008) has been critical of the failure of RAMSI to ensure that women partake in the peace process at the cessation of the conflict, pointing out that many women who had been involved in peace processes during the conflict were marginalised post-conflict because of RAMSI's culturally inaccurate assumptions about the role of women in the Solomon Island being confined to the 'domestic sphere'. The failure to recognise their customary roles in peace processes because of generalised ideas about their traditional roles in Solomon Islands served to diminish their status (Greener et al., 2011; Higgins, 2008). Greener notes that in addition to side-lining women in the peace processes, RAMSI have done little to reduce violence in the everyday lives of women, ${ }^{22}$ pointing to a survey done in 2008 where 31 per cent of female respondents felt their community was safe and peaceful. Only slightly more, 40 per cent, of men respondents responded that they felt their community was safe and peaceful.

\section{Conclusion}

This chapter has shown that histories and cultures of the NZDF and the Solomon Islands is hugely different, yet the RAMSI mission brought these two spaces together in new and challenging ways. I have highlighted that during the conflict and the subsequent RAMSI mission men and women's experiences were different but both were victims and perpetrators. Therefore, considering gender as a central concern of the conflict in the Solomon Island and the RAMSI mission is vitally important to understanding the implications of soldiers in the post-conflict development space further, both for soldiers and local prospects for peace that is reflective of gender and racial equality. With this in mind, in the next chapter, using a gendered analysis, I will

\footnotetext{
${ }^{22}$ Approximately 64 per cent of women and girls report having experienced physical or sexual violence in the home. No statistics of the violence experienced by boys and men are available (Greener, Fish, \& Tekulu, 2011).
} 
begin to discuss some of the ways that two soldiers, Steve and Henry, reflected on, and understood their experiences in the Solomon Islands. 


\section{Chapter Five: "Hard-out War-y" Types and "Living and Breathing" the 'Hearts and Minds' Approach}

\section{Introduction}

In the previous chapter, I outlined the research process and its challenges. I now shift my focus to exploring the narratives of Henry and Steve who were deployed to the Solomon Islands for three month rotations in $2006 / 7$ and $2007 / 8$ respectively.

This chapter is divided into three parts. The first section discusses the features of masculinity commonly associated with hegemonic forms of militarized masculinity, and closely examines Henry and Steve's interviews for perceptions that aligned with these militarized forms of masculinity. I suggest that there is some continued valuing of more hegemonic forms of military masculinity evident in their interviews. However, as explored in the second section of this chapter, I also suggest that Steve and Henry challenge and rework these forms of masculinity by valuing skills that have typically been associated with femininity and alternative forms of masculinity. In the final section, I discuss the aspects of their reflections which are neither militarized nor fit with non-hegemonic masculinities that challenge or offer alternatives to militarized masculinities, but can be understood as 'task-orientated masculinities'.

Definitions of masculinities that emerge within collective practices reside as much within organizational patterns and practices, as within individual personalities (Barrett, 2001, 78). While there has been increasing examination of the discourses of masculinity evident in various militaries around the world, there has been no attention given to New Zealand peacekeepers. New Zealand soldiers are considered particularly good at winning 'hearts and minds' because of their ability to "soak up the culture and integrate with the people" (Army News, 2007) - both skills that challenge and rework the privileging of expressions of hegemonic militarized masculinities. This makes investigating New Zealand soldiers a valuable contribution when seeking to further understand how different masculinities impact local communities.

Overall, in this chapter I suggest that while soldiers continue to value aspects of the military that are more aligned with hegemonic forms of militarized masculinities, they 
also challenge and rework these forms of masculinity. Non-violent conflict resolution practices that are understood as most effective for bringing about peace in the Solomon Island context are also valued. By exploring narratives evident in Steve and Henry's interviews, that can be aligned with 'task-orientated' masculinities, I will also note that the transitional nature of these masculinities demonstrates the importance of paying attention to how masculinities operate in New Zealand peacekeeping missions. If we do not highlight and place value on alternative non-violent practices of masculinity, ways to resolve conflict that do not utilise violence risk being used to give hegemonic masculinities a softer edge that does not ultimately challenge the power and respect that hegemonic masculinities hold.

\section{Militarized Masculinities: The "hard-out war-y" types}

According to feminist literature, the forms of masculinity traditionally valued in the military are problematic for effective peacekeeping (Cockburn \& Zarkov, 2002; Enloe, 1993; Higate, 2004; Rehn \& Johnson Sirleaf, 2002; Whitworth, 2004a, 2004b). This is because in the past, the image of the warrior soldier has been the "epitome of masculinity in many societies" (Enloe, 1983; Wicks, 1996, p. 29) and the predominant role of soldiers has lain in their capacity to inflict violence. In order to justify violence and convince male soldiers to engage in combat, the association of the capacity for violence with manliness has been necessary (Goldstein, 2003b). The hegemonic expressions of masculinities which soldiers are expected to aspire are most commonly described as 'militarized masculinities'. Attributes generally linked to militarized masculinities include a belief in one's own rationality, toughness, bravery, the need to control, and the valorisation of the 'traditional warrior'(Duncanson, 2009; Higate, 2003). For example, Woodward describes militarized masculinity in the following excerpt:

There exists an array of gendered cultural attributes informing the practice of military life, identifiable as features of masculine military identity. The attributes include pride in physical prowess, particularly the ability to withstand physical hardships; aggressive heterosexuality and homophobia, combined with a celebration of homosociability with the team; the ability to deploy controlled physical aggression; and a commitment to the completion of assigned tasks with minimal complaint (Woodward, 2003, p. 44). 
Militarized masculinities can be described as hegemonic because of their coercive nature (R. W. Connell, 2001). As discussed in chapter three, the concept of hegemonic masculinity refers to a particular socially endorsed "idealized image of masculinity in relation to which femininity and other masculinities are marginalized and subordinated" (Barrett, 2001, p. 79; R. W. Connell, 1995). This does not mean that other forms of demonstrating or experiencing masculinity do not exist. On the contrary, masculinities are diverse and are constantly in a process of change. However, as Duncanson (2007, p. 193) argues "it means that this model commands power and respect and is recognizable as an ideal", despite the fact that most men will not likely fit the description. In pursuing hegemonic masculinities, men are more typically able to guarantee respect and authority over others who espouse inferior forms of masculinity (Carrigan et al., 1985). While within the military a multitude of masculinities can exist based on a number of factors, including job specification (Barrett, 2001), some are privileged over others, making some ways of being a man, and being a soldier, hegemonic.

Traditional militarized masculinities can also be defined as hypermasculine. This is most often displayed through the use of violence, and/or the threat of violence, to maintain control and solve problems (M. Bevan, 2011, p. 61). In many cultures, guns are associated with masculinity and the use and display of weapons are important in displaying one's masculine power, as are demonstrations and celebrations of physicality (Farr, Myrttinen, \& Schnabel, 2009). Myrttinen argues that conflict situations tend to reinforce constricted definitions of masculinity, stating:

Men are often expected by tradition or by other societal pressures, from both other men and women, to be either warriors and/or protectors. Failure to live up to these expectations may lead to frustration and violence against those perceived to be in an even weaker position, e.g. in the domestic environment (Myrttinen, 2004, p. 32).

For example, in western peacekeeping interventions public displays of high-powered, high-tech weapons are meant to be understood both "as symbols and tools of western technological and military superiority, visible warnings to all would-be rogue challengers while also sending a reassuring message of a benevolent protective force to the civilian population" (Myrttinen, 2004, p. 32). 
Training for combat situations remains a key site for the production of militarized masculinities (Hearn, 2012). With a soldier's superior physical abilities and training in the use of arms, soldiers are equipped with the skills to inflict violence in order to gain or maintain narrowly defined versions of "security". John Hockey (2003) notes that basic training is a rite de passage where recruits earn the right to be a soldier through a series of tests. He states that for the mostly young men (16 to 24 ) going through this training, it can be interpreted as a transition from being a 'boy' to being a 'man'. Hockey argues that emphasis is placed on meeting the physical demands necessary to being an effective infantry soldier. The ability to cope with these demands is then a prime indicator of an individual's masculinity.

Valorisation of toughness and physical strength is a key aspect of hypermasculinity associated with hegemonic militarized masculinity. Close examination of Steve and Henry's language indicates the continued valorisation of attributes associated with hegemonic military masculinity. For example, when asked what the most difficult aspect of the pre-deployment training was, both associated difficulty with the physical aspects of training. Henry commented that in his training, the heat on the tarmac when they were training was difficult. Steve commented:

...the hardest part for most of them [the soldiers] probably would've been the riot training scenario where... the training cell... got the biggest, baddest, blackest motherfuckers from the battalion to come and kick the shit out of us and like it was a bloodbath (laughs), it was horrible. [Be]cause... they took our batons off us as well and basically gave us wee lengths of pipe so we had no defence. We were in full gear and these boys had been there and done it before and gave us a kicking, like literally people came out of it - suspected broken arms, fractures, covered in bruises.

In Steve's quote it appears that there is also a sense of pride in the toughness and ability to 'take a kicking'. These feelings are important as they imply a valorisation of attributes aligned with militarized masculinities. It appears therefore, that for Steve, this training exercise is both a physical test and a rite of passage. This is further evidenced when he describes his inability to help his fellow soldiers because of an injury he had received prior to the pre-deployment training, which meant that he was not able to take part in the training activity and had to observe from the back: 
...yeah that, I mean it was horrible for me I didn't like that [sitting] down the back watching the boys get a kicking but I had people keeping a close eye on me down the back to make sure I didn't do myself any further damage so...

In this comment Steve expressed his frustration at his inability to take part in the riot exercise with his platoon. Desiring to be 'one of the boys' and part of the team, he was disappointed to not be taking part in this 'rite of passage' where he too could secure his masculinity by demonstrating toughness and willingness to protect his mates.

Further, Steve and Henry used language that is associated with hypermasculine practices when it came to describing soldiers that they considered to be role models. For example, while recognising that these kinds of skills could not be optimised in the Solomon Islands context, Henry demonstrated admiration for war-fighting when he stated:

[A] another guy I worked with in the field of intelligence - he was senior $\mathrm{NCO}^{23}$. He was just hard out war-y, like he'd been to Afghanistan and seconded to the marines to train American marines in Afghanistan. He'd been a sniper, a recon' soldier, and an intelligence operator and was just, he just had, he oozed that military confidence. But that would be more beneficial in a conventional warfare environment - but that confidence oozed out of him, but on peacekeeping he could really get on the front foot and get shit done.

As previously noted, hegemonic models of masculinity are those which command power and respect, and are recognised as an ideal (R. W. Connell, 2001; Duncanson, 2009). In this quote, Henry demonstrated that he admired and respected another soldier for practices associated with violent militarized masculinities, indicating a continued valuing of traits associated with hegemonic militarized masculinities. This quote is also interesting as his language demonstrates the tension he feels between what he admired about this soldier and what he considered useful for the peacekeeping role in the Solomon Islands. This highlights the contradictions that soldiers must navigate between what is required for a peacekeeping role and militarized understandings of masculinity. This quote perhaps demonstrates that ideas

\footnotetext{
${ }^{23}$ Non-commissioned officers are the primary and most visible leaders in the armed forces. The advice and guidance of non-commissioned officers is considered particularly important for junior officers.
} 
about what is considered the 'ideal' are being called into question by those occupying a peacekeeping role.

Steve gave several different examples of soldiers he considered role models through their physical war-fighting masculinities. For example, "my section commander and 2IC were great they'd both been to Timor and that was back on the bats, back when they were jungle fighting so they had brilliant experience through that, [that] they were passing on to us". These examples were in contrast to the reasons that Steve gave for why he did not consider some members of his platoon good leaders. He states the reason for this: "just...things like one of them had really bad fitness and that kind of thing as the soldier you do judge each other on. That and he was also sleeping with one of his soldiers which is never ideal". This quote is interesting to note as Steve demonstrates he does not respect this particular soldier because he is sleeping with another female member of the platoon. On one hand, this aligns with aspects of militarized masculinity which valorise the team bonds between fellow soldiers, yet at the same time, Steve demonstrates a rejection of the aspect of militarized masculinities which have been described as 'aggressive heterosexuality' (Woodward, 2003) as he does not admire his fellow soldier for engaging in a sexual relationship with a woman.

Being considered 'more of a soldier' was linked to situations where the soldier's body was placed in higher risk situations - indicating that soldiering involving war-fighting abilities continues to be admired and valued by both Steve and Henry. For example they both expressed the desire to be deployed to Afghanistan:

Kiri: What, what's attractive about Afghanistan? If, you know, the ideal situation [arose] and you were able to go?

Steve: It's more like proper soldiering - there is that higher risk. Like I am a bit of an adrenaline junkie but I mean it's another thing it's like a new experience... Going to Afghanistan you know [would be] something completely new, whole new circumstances and you know and it's got a bit more prestige as well within the Army, like Sollies is bottom of the barrel then it's Timor... and then there's... Afghanistan out there at the top.

Steve's comment that a deployment to Afghanistan holds more prestige indicates that across the wider army, there is a continued valuing of practices associated with 
militarized masculinities. Henry also reflects this continued valuing of militarized masculinity, highlighting that Afghanistan is more sought after as a deployment because of the element of risk involved:

Henry: Afghanistan would be a more sought after deployment absolutely, yeah, yeah absolutely yeah, it would be a higher bar I would imagine.

Kiri: What do you think, why do you think that is?

Henry: Cause there's bullets flying both ways (laughs) there's conventional warfare aspects to it... and probably it's probably a harder deployment cause there's less in common between us and the Afghanis.

Interestingly, in his final comment, Henry states that Afghanistan is also harder because there are less cultural similarities with Afghanis, reflecting the belief that Afghanistan is a tougher deployment. In doing so he is associating peacekeeping skills with the need to be a tougher man and thus positioning peacekeeping as masculine. This suggests that masculinities associated with successful non-violent peacekeeping are also becoming valuable to soldiers' practice (Duncanson, 2009).

Another important way that militarized masculinity is maintained is by inhibiting women from taking part in practices more associated with militarized masculinity (M. Bevan, 2011). This is because the participation of women in traditionally masculine practices is seen as threatening to the order that constructs this as a space where only men can succeed. Their exclusion can be enforced through legal means of preventing participation, such as the combat exclusion policy still present in many militaries. Alternatively women's exclusion can be enforced through social disciplining such as believing women are not suitable or equipped for military life. Women have the most difficulty attaining the respect and power that results from enacting hegemonic models of masculinity: no matter how strong they are, or how well they fit in with the boys' behaviour, their "physical embodiments prevent them from fully enacting the model" (Duncanson, 2009, p. 193). For example, as Barrett (2001) noted in his research into U.S soldiers' language, associating women and weakness was reproduced through references to women's inability to endure the hardships and stresses of military life. 
Examples of this are evident in Henry's interview. For example, he stated that one woman "got sent home cause she went a bit crazy - or was always a little bit crazy (laughs)". Steve initially acknowledged that having women in the platoon could be useful, but with further questioning, Steve described women in his platoon in ways that would suggest he is sceptical of the value of their presence in the military. For example he described their inability to withstand the hardships of deployment, which resulted in overly emotional behaviour. This is highlighted when Steve was asked about gender awareness training:

Steve: We didn't receive any really thorough gender awareness but I think having females in all the sections and in our support you know probably helped us as well. So you if, if there was a woman quite often we send the female to do the questioning - just more...more approachable, more friendly is the theory.

Kiri: Mm-huh, okay, yeah... like you'd send women to speak to [local] women... or women to speak to everyone?

Steve: Yeah, usually the women that was, I mean it was our plan at the start. It turned out our females weren't all that great unfortunately (laughs) which I mean... I don't mean to sound sexist but they really sucked (laughs).

Kiri: In what way did they suck?

Steve: In all sorts of ways. Like for starters they weren't particularly good soldiers I mean, when you're in the army that's kind of...

Kiri: In what sense do you mean... not very good soldiers?

Steve: Not particularly good with weapons' systems, carrying packs, getting by without any sleep, one of them was much better than the other one but she sort of withdrew into herself and stopped interacting with the section and that kind played with the dynamics. Yeah and the other one got really homesick and stopped eating and things - it was quite worrying.

This is similar to what Kimmel (2001, p. 96) has argued. He believes that through socialisation boys learn that being a man means not being a woman. Barrett (2001) elaborates on this belief in his study of hegemonic masculinities in the U.S navy. He found success for men was associated with not quitting in the face of hardships. This notion was constructed in comparison to the performances of women in the forces who were described as 'giving in' 'folding' or 'getting off easy.' Ultimately, this is problematic as the patterns of practice allow men's dominance over women to continue (R. W. Connell \& Messerschmidt, 2005). 
These notions also align with what Hockey has noted in the process of becoming a soldier, "a certain kind of stoicism is engendered through an acceptance of particular kinds of suffering caused by physical exertion, lack of sleep, and exposure to climatic variation" (Hockey, 2003, pp. 16-17). In this quote, even the woman who Steve considered was better at being a "good soldier" let her emotions get to her and she withdrew from the team, demonstrating she was unable to cope with the hardships of military life. Steve associates being a 'good soldier' with military masculinities such as strength, endurance and technical skills and in doing so fails to challenge the hegemony of militarized masculinity. This is despite the fact that physical strength and toughness may be of limited value in a 'low-security threat environment' such as the Solomon Islands.

As mentioned earlier, another aspect of militarized masculinity evident in Steve's narratives is the importance of the team bond. Homosocial relationships between men have been a key element of gendered military identities (Woodward, 2003). The New Zealand Reserve Force is 16.1 per cent female (Regular Force is 16.2), thus male soldiers, while likely mixing with women, do so in very small numbers and at times, not at all. While soldiers are measured on their individual traits of endurance, aggression, stoicism, at the same time the success of an operation is contingent on the close support and collaboration of fellow soldiers. Away from family, friends and partners for extended periods of time, loyalty to, and comradeship with one's 'mates' is a crucial aspect of militarized masculinities, even at the expense of one's own safety. Male 'mateship' can also be understood as a "celebration and affirmation of masculinity" (James, 1994). While teamwork and cooperation is important for operational success, Hockey has argued that on another level is there is an underpinning message that "real men support their mates in all situations"[emphasis added](Hockey, 2003, p. 19). The sexual abstinence required of soldiers on deployment also contributes to construction of the idea that the team is 'in this together'. In the interview, Steve mentioned the relationship occurring between a female platoon member and the section commander. Steve believed having relationships within the platoon is "very much frowned upon" and is not good for the team, he explained why: 
It happened, it actually started happening quite a bit and it creates all sort weird love triangles and tensions and favouritism and especially within chain of command I mean that's just ridiculous you can't, the rest of the section can't, even if they are being treated fairly aren't going to feel that way. So it it's not really fair on anyone and I mean it was quite, it's not particularly pleasant going four months without...you get by (laughs).

While Steve commented during the interview that engaging in relationships with police members of the NZPPF is less of a 'taboo', where a blind eye was turned if you could get away with it, with regards to a relationship occurring within his own platoon, Steve's attitude reflects the belief that the commanding officer and the soldier he was having a relationship that 'gave in' to sexual desire, unlike the rest of the platoon who were able to "get by". In doing so, they demonstrated an inability to endure the hardships of a soldier's life that includes sexual abstinence on deployment. Ultimately, they are considered to have threatened the team bond by failing to put the team before themselves, thus compromising the success of the mission.

Another way that soldiers demonstrated a continued valuing of militarized forms of masculinities was evident in their opinions about being armed with weapons. Weapons are central to a hyper-masculine gendered identity that legitimises the threat of violence to coerce and deter others. That soldiers are trained to employ violence in a controlled and disciplined manner is a key way that soldiers are differentiated from other combatants. Weapons are an integral part of this identity performance, adding depth and credibility that soldiers will use force if they deem it necessary (Higate \& Henry, 2009). Soldiers carrying weapons in a peacekeeping space overtly shows that despite all other proclamations of 'winning hearts and minds' conflict resolution is about the use of controlled violence to create peace. The following quote is illustrative of this situation. The quote demonstrates the importance of training for a soldier's sense of security. I had just asked if Henry ever felt unsafe or threatened on patrols:

No... I mean, if you weren't armed, or if there wasn't ten of you, you might but, the discrepancy, the gap between what the locals are capable of and what an armed and trained infantry section can do is massive (laughs). There's just, you wouldn't...yeah [trails off]. Plus [the] army gives you an extreme amount of physical confidence, like you go beyond, outside the realm of what an actual 
threat is presented to you. You feel bulletproof and at night you are because you're wearing a Kevlar body armour so nah not really no. Even someone could be horribly drunk and aggressive and you wouldn't feel at all threatened.

The importance of carrying a weapon is elaborated further in the following quote which demonstrates the threat of violence and use of weapons as key to a soldier's performance of masculine identity. Henry states:

People say... when I say I went to the Solomon Islands with the army, "So you were walking around with the gun?" and I'm like "yeah because there's nothing more useless than a soldier without a gun." I mean... a soldier without a gun is nothing, you might as well just have policemen or security guards so yeah if you want the Army there, that's up for debate sure, but if the army is there, they should be armed.

Reflecting on the issue of carrying weapons in the Solomon Islands security context asks us to examine whether it was necessary in this context. In the following quote, I posed this question to Henry. He discusses the importance of the gun to a soldier's sense of security and identity:

You could tone that down to everyone carrying pistols but pistols are just sort of inaccurate and sort of dangerous really. But yeah I think I would have felt vulnerable, you feel a lot more vulnerable if you don't have a weapon, but that's to do with your training as a soldier really, you just feel very naked without it. If you don't have a weapon and something did go wrong, and I acknowledge the probability of something going wrong was extremely low, but if something did go wrong then you're on pretty much an equal footing with the locals and that's 50/50. Like I was deployed with guys who are $19-20$ years old, small guys and in a street fight with locals who've been in a fight before then that's...50/50 at best. I mean... I've never been in a fight (laughs) I wouldn't know what to do! Yeah, yeah I think they're essential...I think they were essential at the time, maybe not anymore.

In this quote, Henry's comment that he would feel naked without a weapon indicates that carrying it is an important part of being a 'soldier'. Carrying a weapon appears to be premised on the need to be prepared 'just in case' - that despite all intelligence, soldiers need to deploy violence to protect themselves if necessary. The belief that weapons are required regardless of the acknowledgement that Solomon Islands was a low security threat, indicates a continued belief in the use of violence as a last resort. While this does not fit the image of a 'trigger happy' 'macho' soldier, the continued 
linking of a soldier's sense of identity with weapons and the capacity for violence, evidenced in the previous quotes, suggests that ideas about how to resolve conflict still rely on militarized masculinities as a last resort.

In this section, I have examined some of the ways that Steve and Henry demonstrated a continued valorisation of practices and perspectives that align with hegemonic forms of militarized masculinities. The adoption of hegemonic militarized forms of masculinity rests on the subordination of alternative masculinities and femininities. This is problematic as the continued valuing of attributes associated with hegemonic military masculinities continues to undermine the value and legitimacy of alternative non-violent practices that are more useful for creating long-term peace for local people. In doing so, soldiers may reinforce local gender inequalities by failing to engage with women in ways that recognises their agency, and with local men as nonrational perpetrators of violence. However, as I discuss in the next section, there are possibilities offered by individual soldiers' negotiations of identity that sees them embody their masculinities in ways that create "relations of democracy, mutual respect and equality" (Duncanson, 2007, p. 24) with local people, and that challenge or offer alternatives to militarized masculinities.

\section{Being "totally sold on hearts and minds": Alternatives to Militarized Masculinity}

The goal of this next section is to explore some of the ways that Steve and Henry described their roles as peacekeepers that resist or offered alternatives to militarized masculinity. I will discuss the ways that non-militarized masculinities were seen as beneficial for peacekeeping. I suggest in this section that the masculinities attached to soldiering are in the process of changing in the New Zealand Army as a result of the new skills required in peacekeeping.

Masculinities are fluid and relational constructions, defined in binary opposition to femininity, with connections to dichotomies whereby the first 'masculine' term in each pair is generally valued above the second 'feminine' term, such as active/passive, competitive/cooperative, rationality/emotion. Because communicating and building relationships of trust and respect takes time, the everyday practices of peacekeeping 
such as building friendships, negotiating, drinking coffee and chatting can be framed as ineffective and lacking action. If, however these practices are linked to bravery and effective soldiering, hegemonic forms of militarized masculinities are disrupted (Duncanson, 2009), as this thesis argues occurs in the Solomon Islands.

Similarly, the literature on peace-building is clear about the importance of engaging local communities in the process (Vuga 2010; Haddad 2010; Tomforde 2010; Harland). The ability of peacekeepers to build relationships that are respectful, and that demonstrate an awareness of local culture, is believed to be imperative to successful peacekeeping. Prioritising learning local culture and language demonstrates a sensitivity to local practices that relies on qualities in soldiers such as compassion and communication (Duncanson, 2009). Thus, I propose that the valuing of these skills can be understood as an important way that Steve and Henry demonstrated a respect for alternative non-violent masculinities.

Both Steve and Henry clearly believed that learning the local Pijin was a priority for soldiers deployed to the Solomon Islanders. In the following quote for example, when asked what they covered during training Steve stated although it was not a large part of their pre-deployment training, language training was seen as the most valuable skill to take on deployment:

We also did language training, like officially within the whole contingent we didn't do all that much but my section commander was, that was right up his alley learning how to speak it. He had deployed to East Timor twice previously and [also] some of my 2IC's [had as well] so they knew the language was... the most valuable skill we were going to take over there.

Similarly, Henry described the advice he gave to another soldier departing for a subsequent rotation:

When our replacements came in I recognised the guy that I'd done my basic training with and I said "there's two thing you should really concentrate on, get as fit as you possibly can and learn the language." Two things would be my advice to anyone going there, just learn language as best you can, and more and more.

In another example, when asked about the what became the most useful skill in the Solomon Islands, Steve demonstrated learning Pijin language skills was useful enough to engage in learning it when 'off-duty': "Probably, from the official pre-deployment 
training it was probably the language, but in saying that... most of the language training we did was after hours and unofficial". Steve further recognised the importance of cultural training by noting that what the training they did do was not enough. Steve believed the cultural training was "just rubbish" and "did need to be improved": "We had some sort of cultural training which was ridiculous, like it was no use to anyone, the woman taking it had no idea what was happening, she had just been given a slide show and told to go down [to the South Island]".

More broadly, building relationships with local people by communicating with them in culturally specific ways was another important and valued aspect of training that challenged militarized masculinities. Henry described this:

One part of it was that intelligence chatting, low level intelligence gathering, you know, asking open ended questions, not generating the conclusions out of the question... things like that. With regard to language training just you know "hey how are you?" "Where are you from?" They're notorious storytellers so if you want to get information out of them about what happened during the troubles for... you wouldn't say: "what happened here, who are the bad guys?" You would say: "tell me a story about, can you tell me a story about that time and they'll tell you a story. Yeah... just being friendly and smiling, glasses off and waving.

This quote highlights the importance of the training that prepared Steve and Henry with the ability to engage with Solomon Islanders in a respectful way. The value of this training is demonstrated in the following quote where Steve described a way that he saw New Zealand soldiers acting differently from Australian soldiers:

I mean it even comes down to the little things like...we had locals doing our washing they'd come into camp every day, and you know we'd go drop off our bags in the morning and you come back two hours later and all the Kiwi washing would be done and the Aussies' wouldn't cause (laughs) the ladies can tell the difference in our uniforms and because we stop off and have a chat. And you know we found them quite useful when we'd go and try and practice our Pijin and at the same time they'd be trying to practice their English. So you're having these conversations and neither of you are speaking your own language and no one quite knows what's going on (laughs). Yeah we'd give them wee bribes and treats and stuff and you know. Things like that [are] just the sign that somehow we must be favoured. And I don't believe it's entirely to do with the bribes, I think it's more to do with you know just being friendly. The Aussies complained about it to no end - like they had their commander 
trying to figure out why their washing wasn't getting done first and stuff (laughs).

In this quote we can see that Steve also clearly enjoyed stopping and having a chat to the women doing the soldiers' washing. It appears that the women also appreciated this. In doing so, taking what may seem like small actions, these men actually challenge and rework the idea of what is appropriate behaviour for a soldier. Furthermore, hegemonic forms of masculinity that have typically rested on the subordination of the 'Other' in the military are undermined (Duncanson, 2007). Seeing the value in building friendships with the women who washed their clothes challenges the hierarchy of gendered and racial inequalities that echoes more colonial relationships between white, western 'experts' and local women who are relating to westerners by doing menial tasks for them. The challenges this makes to militarized forms of masculinity are important to note and will be discussed further in the next chapter.

With many ex-militants in the Solomon Islands still not held accountable to official kastom justice systems, an important way that soldiers are were able to demonstrate their ability to provide security, was through communicating that they were paying attention to beneficial outcomes for local people. The proceeding quotes demonstrate that Steve and Henry both placed value on engaging with Solomon Islanders in ways that were friendly and recognised local residents as equals. This point is important to note, as face to face communication is the primary means through which soldiers' intentions are able to be interpreted and assessed by local people. This detail is especially important in a Pacific Island county where meeting face-to-face is culturally appropriate (Vaioleti, 2006). When soldiers fail to engage in culturally sensitive ways, it is clearly noted by local people (local residents' perspectives will be discussed further in Chapter Seven). As a result, continued failure to interact leads to deep criticisms of peace processes. Indeed, Allen (2006) argues the 2006 Chinatown riots were a result of police and military failure in connecting and integrating with the local community. As Allen argues, that police personnel present at the riots were unable to speak Pijin was a significant disadvantage as not only were they were unable to negotiate with the crowds, they also did not understanding the implications of the crowd saying the 
Pijin word for Chinese, 'waku'. This resulted in the failure to diffuse the tension, which led to the burning of Chinatown district in Honiara (Allen, 2006).

Another way that soldiers are able to demonstrate commitment to peacekeeping skills and challenge what is considered masculine soldiering, is by criticising aspects of traditional soldiering which are not seen as effective. Appearing strong and acting aggressive is an important aspect of being a soldier which has traditionally been seen as a vital demonstration of masculinity in the military. When describing the training for the 'hearts and minds 'approach, Henry challenges this, stating their intention was not to appear aggressive:

Reinforcing the fact that we were there, we're not there with an aggressive posture, there is no enemy as such, as a normal soldier would be trained, yeah, you were there to engage and impress and...interact with the population in a very friendly way.

For Henry, those who were not committed to the peacekeeping approach were considered unprofessional or did not comprehend the value of this approach:

I mean you just, the group I went with just totally totally [emphasis] sold on hearts and minds, just lived and breathed it the whole time and anyone who showed a hint of being contrary to that was regarded as just an idiot or unprofessional or just doesn't get it, like doesn't understand it.

Steve similarly challenged militarized masculinities by criticising the 'typical' army leadership approach, stating:

...the platoon commander as well was... a good influence for me on leadership and [I] took a lot of my... my style of leadership [from him]. Once I got promoted [it] was very much based on his. Because I mean you could just see how effective it was from the bottom and it wasn't... the typical army shouty angry, it was more concentrated on getting things down, being positive and having a laugh when appropriate.

Henry also challenged the unemotional militarized soldier by discussing the aspects of training which placed value showing empathy for Solomon Islanders by not eating in front of people who may have little food:

The training was be polite, be friendly, be open, be engaging, don't be aggressive, don't eat in front of them because I mean they don't have food, they like, they're hungry some of the time so chowing down on army food is 
pretty rough because they don't have that much food... Yeah - just generally the hearts and minds.

Similarly, Henry demonstrated kindness when they shared food with a family who lived behind one of their observation posts by Rove prison:

At Rove... our accommodation area which was just a shed... divided by a pretty big fence with a house... And we'd eat our food - and you'd get a T.V tray basically, like a little tin foil box and that would be your meal. And if there were ever food left over you'd just hand it through to that family, they'd eat, but that was pretty informal...

The soldiers' behaviour aligns with Newsome's (2007) argument that empathy is an essential part of being a soldier. This is also recognised by Weiss who states that, "If deployed military members lack the ability to empathise and lack stress tolerance, they may violate human rights and the rule of law and thereby jeopardise...the NZDF's mission" (Weiss, 2012, p. 9). Empathy is therefore important not only in preventing human rights abuse of local populations, but as something that wins "hearts and minds".

Carreiras (2010) emphasises that images of masculine heroism attached to soldiering are not static and have shifted throughout history. Rather "Particular meanings and cultural conceptions associated with masculinity and femininity have undergone significant historical shifts inside the military, as they have in the host societies (Carreiras, 2010, p. 474). Thus, if gender identities are dynamic and changing then it holds that traditional militarized masculinities can become less valued and alternative ways to be a 'good soldier' can emerge (Duncanson, 2009). For example, as we have seen in this section, an important way that soldiers demonstrate masculinities that are not the hegemonic norm is by placing value on communicating successfully with local people and being culturally sensitive. This process of change can offer opportunities for reconsidering the way that soldiers engage in peacekeeping. In order for hegemonic forms of masculinity to lose their salience, other masculine ways of acting must be brought to the fore and positioned as valuable, including linking femininities to masculinity in ways that men perceive as valuable. 


\section{Task-Orientated Peacekeepers?}

A final aspect of the soldier's expression and valuing of masculinities that I consider in this chapter is 'task-orientated masculinities'. In referring to 'task-orientated masculinities' I am referring to those forms of subjectivity considered most useful in getting the job done in a particular place that may or may not contravene the usual way of doing things or standard procedures. I suggest that the spaces created by Steve and Henry's challenges or reworking of more militarized forms of masculinity, offer potential to delink masculinities from the necessity of using violence to achieve peace. However, these gaps are also in danger of being subsumed into hegemonic forms of peacekeeping masculinity that continue to position men in positions of privilege. While I question whether peacekeeping is engendering new forms of hegemonic masculinities in the armed forces, it must be noted that my conclusions are limited by the number of soldiers I interviewed.

If we understand masculinities as changing, this also means that aspects of masculinity that are positioned as the most desirable for men to aspire to also change. In paying attention to the new ways that peacekeeping engenders masculinities in soldiers we must also question whether this shifting sense of what is valued to be a good soldier is also creating a new hegemonic masculinity. In both Steve and Henry's language, there was the presence of mixed and sometimes contradictory valuing of masculinities associated with militarized masculinities and those associated with peacekeeping. This conflict centred on what is considered most useful for achieving the goals of the peacekeeping mission against what has traditionally been valued in the military. This conflict is interesting to note as the predominance of evaluating peacekeeping missions in ways that are linked to 'action' indicates a valuing of 'task-orientated' masculinities (Bevan and Mackenzie, 2011).

Valuing action is linked to masculinities as it is on one side of the active/passive gender dichotomy discussed in the previous section. Bevan and MacKenzie (2011) have noted that task-orientated masculinities have the potential to be negative. They argue that the development of 'task-orientated' ${ }^{24}$ masculinities in the New Zealand Police

\footnotetext{
${ }^{24}$ 'Task-orientated' masculinities can also be referred to as 'action-orientated' masculinities.
} 
Officers working in Timor "can act as a barrier to the prioritisation of qualities needed to build collaborative relationships with local police officers". Similarly, if taskorientated practices are promoted in ways that are more closely tied to traditional masculine ideas about the military then this can be problematic for peacekeeping that is gender sensitive and respectful of local conflict resolution practices. For example, placing value on maximising effectiveness means soldiers can fail to see the value of considering gender at the cessation of violence. This failure can mean not seeing the importance of engaging with local women as important stakeholders in building peace. Henry reflected this idea of local women:

The women are pretty reticent but, yeah, just when the rubber hits the road yeah you deal less with women cause they are less forthcoming. But no we weren't aware of any cultural considerations around gender.

This belief is problematic as Charlesworth (2008) notes, while many women welcomed RAMSI because of the immediate effects it had on reducing violence, many felt sidelined in the peace-building process. Indeed as Greener et al. suggests, the assumption by RAMSI that women are confined to the domestic sphere meant there was simultaneously a failure to engage women in peace-building process and a reinforcing of the idea that a woman's place was in the domestic sphere. Something as simple as failing to engage with local women indicates that gender considerations were not reflected on as important to achieving the mission goals and highlights the importance of gender specific training that examines these issues.

Similarly, side-lining women in the process did little to "yield a great deal of peace at the domestic level" indicative in the continued high levels of gender-based violence in the home (Greener et al., 2011, p. 20). When Steve was there in $2007 / 8$, four years after the RAMSI intervention, he still reflected this view that gender issues were not considered important for the creating of a kind of 'peace' that includes peace for women in the home: 
At the time... domestic violence wasn't a priority within securing the Solomon Islands. So I mean we were there before the gender advisor came and started sorting out those sorts of issues so...yeah. ${ }^{25}$

As Meintjes points out, it is no small matter that the cessation of armed conflict often sees an increasing incidence of gender-based violence against women (Meintjes et al., 2001). Indeed, as Greener et al. (2011, p. 18) argues:

If a gender perspective is to be integrated into peace operations rather than merely tagged on the end of those operations as a nod to political correctness, peace ought therefore be viewed more broadly as a state of being wherein 'society is demilitarised and war economies are converted . . . [and] demilitarisation is ensured at all levels, including the household' (AusAID, 2006: 9).

This has also meant searching for those who committed violence against women during the conflict may have not been a high priority. This is reflected in the mostly absent mentions of rape from any charges laid against former police officers and militants, despite the high incidence of rape during the conflict (Amnesty International, 2004b; Greener et al., 2011).

Steve and Henry described the tasks they engaged in as useful in the context of the mission, possibly indicating that a form of 'task-orientated' masculinities is being produced as part of an evolving form of hegemonic masculinities. If we understand hegemonic masculinities as fluid and changing in order to retain power and respect ( $R$. W. Connell, 2001), soldiers adopting practices more traditionally associated with femininity is potentially problematic if they are packaged with other hypermasculine or militarized forms of masculinity. If practices more traditionally associated with femininity are adopted in order to retain power and respect alongside militarized masculinities, it may result in the continuing exclusion of alternative masculinities more conducive to the creation of peace through non-violent means. Hooper (2001), Demetriou (2001) and Niva (1998) have explored the ways that hegemonic masculinities shift in order to retain power. They point out that a change in ideas

\footnotetext{
${ }^{25}$ Though Henry also stated, if they had seen a domestic violent incident "we would've stopped it, probably stopped it harder and faster. Yeah. Yeah.... if I saw a domestic violence incident [I would be] perfectly confident of stopping it with extreme prejudice."
} 
about masculinities is not necessarily progressive for ideas about women and femininity, nor alternative subordinate forms of masculinities. For example, Niva points out that involvement in the First Gulf War saw a shift in hegemonic masculinity where an "openly articulated sense of manly vulnerability and human compassion" replaced "bravado or stern invincibility" engendering a new 'tough but tender' hegemonic masculinity. This construction, Niva argues, is based on race as well as gender and positioned U.S soldiers as liberal and compassionate in contrast to the positioning of Arab men monolithically as "backward in their macho and hypermasculine ways" (Duncanson, 2007, p. 197). In combining toughness and aggressiveness with sensitivity, the position of these elite men become even harder to challenge. Thus demonstrating that hegemonic masculinities can evolve in such ways that the distribution of respect and power is unchallenged (Duncanson, 2007).

When we consider this idea of evolving hegemonic masculinity in the context of peacekeeping, the question arises: while the practices and traits of the ideal model of masculinity in peacekeeping may change in relation to the tasks required of peacekeeping, will there always be a hegemonic model available only to elite groups of men (or women who are adopt hegemonic masculinities)? Soldiers linking the value of building relationships with local people and demonstrating empathy to achieving the mission can be understood as a mechanism that allows soldiers to justify their presence in the Solomon Islands. Furthermore, while soldiers are engaging with local people with a sense of equality and respect, they are still holding the power very literally by holding weapons and by having the ultimate decision how to use that power. Thus, skills that have developed as a result of the requirements of peacekeeping become part of a shifting identity of hegemonic masculinities.

Yet, I also believe that Steve and Henry's emphasis on achieving tasks offers potential spaces for masculinities to be rewritten in the military. In the Solomon Islands, both Steve and Henry saw building relationships with Solomon Islanders as hard work and an important part of "getting things done". Duncanson has suggested that when masculinities associated with peacekeeping are "constructed through relations of empathy and mutual respect, we get a democratisation of gender relations rather than new hierarchies being created" (2007, p. 211). Furthermore, as Bevan and Mackenzie 
also note, task-orientated masculinities may have some benefits - such as focus on hard work and taking initiative. With this in mind I suggest similarly, that if masculinities that promote non-violent conflict resolution practices are delinked from militarized masculinities that rely on the capacity for violence, and instead framed as valuable and desirable, then these masculinities may have positive benefits for achieving peace in post-conflict spaces.

In the following quote, for example, Henry describes how it was harder work for Australians to get down from their trucks so they did not engage with local people as much as a result. In doing so he links successful peacekeeping with actively making the effort to get down of their vehicles:

Like [it was] a big effort and sometimes they just wouldn't bother cause you know you could be stopping every 200 metres just to stop, whatever and immediately we would just step off and you would go to them like an informal all round defence so you have a sort of circle facing outwards and but yeah, just immediately talking to people, your weapons slung on the back and you'd just sort of hands... open neutral posture with your sunglasses up and yeah they didn't do that.

Similarly, in describing why Henry admired his section commander he links qualities associated with being task-orientated with successful peacekeeping:

My section commander was disciplined and focused soldier so and he, you know was, he adopted you know, was a firm follower of the peacekeeping role. But even, sort of I admired him outside of the peacekeeping role around barracks and throughout the whole deployment his shit was tight, like he was always organised, professional, disciplined, focussed, work[ed] hard...

In the previous section we saw how Henry and Steve clearly placed value on behaviour such as stopping and interacting with local residents. Crucially these were seen as effective for achieving the mission. For example, when Steve is explaining why he thinks Australians are less willing to engage in these peacekeeping tasks he focuses on the importance of goals that hold true to peacekeepers:

Henry: [the Australians had] probably most crucially a lack of training... because some of our guys could have been equally as bad but we.... just got exposed to the training and why you were receiving this training and... what 
the goal is and then once you adopted that there's a goal then everyone's going hard out towards it [emphasis added].

Militaries can be understood as "a very rational, goal-orientation organization based on maximising effectiveness....with very well-defined roles and missions" (Michael \& Ben-Ari, 2010, p. 668). The presence of discourses such as: "[he] work[ed] hard" (Henry), "try and get things done" (Steve) and stating "on peacekeeping he could really get on the front foot and get shit done" (Henry), suggests that an important way soldiers understand their role as peacekeepers is through evaluating the mission based on achieving goals. Indeed for Steve, the New Zealand Army's reputation lay with this ability, stating: "over the years we've built our reputation as people who you can talk to and who are willing to help and who listen and try and get things done". As discussed in the first part of this section - the focus on 'action' can be problematic if it leads to evolving hegemonic masculinities that do not challenge distributions of respect and power, however, this is not so in Steve's statements.

When qualities that have traditionally been positioned as feminine are described as a form of action and linked to masculinities in a way that delink masculinity from violence, then great potential is created toward valuing non-violent conflict resolution practices in the military. To conclude this section, the following quote from Henry demonstrates the very real possibility of integrating gender considerations as a goal of peacekeeping, if framed in a way that is appropriate for soldiers understanding of their practices:

Henry: I think people would be surprised about how intelligent and how liberal and progressive the military is...I really would I think people have a distorted view of it. Officers go to university, just like everyone else and... they are very good at recording what's happened and learning. And they're very very motivated people so they want to learn they want to learn from experiences, they want information and they want to achieve their mission, if the mission is peacekeeping they'll pursue it hard using the best doctrine available.

\section{Conclusion}

The central aim of this thesis is to question whether a shift to peacekeeping roles engenders new identity experiences for soldiers. To do this, in this chapter I have examined the comments made by Steve and Henry about their experiences in the 
Solomon Islands and analysed their reflections about their mission. I have suggested that analysis of the two interviews indicates that Steve and Henry often challenged or acted in ways that offer alternatives to militarized masculinities by demonstrating a commitment to practices focussed on building positive relationships with Solomon Islanders. However, at the same time they both still valued more masculine aspects of the military that are linked with militarized masculinities. These findings are similar to the conclusions of Duncanson $(2007 ; 2009)$ who noted there is significant tension within British soldiers' discourses between the skills that are seen as useful to achieving peacekeeping aims, and violence-orientated masculinities traditionally valourised in the military. A soldier's expertise rests in his or her ability to inflict violence (Haaland, 2012, p. 64). In no other profession is the sanctioned capacity to kill and maim the core function that differentiates one from others. However, while "the core task of the NZDF is to conduct military operations" (NZDF, 2010)" and it relies on soldiers' ability to use their superior strength in arms, organisation and numbers, the success and enjoyment New Zealand soldiers get out of interacting with local residents tells a different story about what individuals value as part of their role as soldiers, and indicates some challenges and resistances to militarized masculinity. It also indicates the importance of valuing alternatives to militarized masculinity within the military itself. If those involved in peace-building do not challenge the dominance of the ideal, they are 'complicit', reaping the rewards of the "patriarchal dividend" (Carrigan et al. 1985: 594).

Finally, I have suggested that the value placed with the need for skills that are most effective for bringing about peace in the Solomon Island can be linked to 'taskorientated' masculinities. I note that this could demonstrate the way that hegemonic forms of masculinity shift and evolve to retain power, or alternatively, I have argued that these forms of masculinity hold potential for 'regendering' the military (Hooper, 2001). In the next chapter, I will further explore Steve and Henry's understandings of peacekeeping by analysing other intersecting aspects of identity that were important to the way they framed peacekeeping. 


\section{Chapter Six: Framing Peacekeeping - Intersections of Identity}

\section{Introduction}

As noted in the previous chapter, gender identities are fluid and multiple. Other intersecting notions of identity are also important to the construction of masculinity. In this chapter I will argue that when considering the performance of masculinity by soldiers, we must also consider the ways that ideas or narratives about identity, such as nationality or the 'culture' of the army, intersect with the gendered understandings of New Zealand soldiers. It is important to do so because considering intersecting attributes of social identity, like nationality, is an essential part of understanding how power is attached to masculinity in different ways in different social contexts. Peacekeeping offers a unique opportunity to explore the intersecting identity, as layers of performance and identity become particularly strong where "differential international and inter-communal placements of race, ethnicity and nation come into play" (Kirby \& Henry, 2012).

I begin this chapter by demonstrating that a desire to help is an important way these New Zealand soldiers understand their role as peacekeepers. This is somewhat reliant on a discourse of 'Othering' through imagining the Solomon Islands as somewhere in need of help. However, in the second section of this chapter I will argue that this discourse is complicated by New Zealand soldiers' perceptions that their presence in the Solomon Islands is more legitimate and effective because of their ability to be more in touch with local practices, in comparison to the perceived cultural insensitivity of Australian soldiers. Furthermore, I will argue that praise of other participating forces from Pacific Island countries indicates newer understandings of what behaviour is valuable in a peacekeeper. Thus soldiers are not only challenging hegemonic militarized conceptions of masculinity, they are also challenging the construction of 'white western' soldiers as most effective in bringing about peace and 'development'. Finally, I will discuss some aspects of their identity understandings that do not fit with the previous discussions. This will highlight that complexity and contradictions are similarly part of the fluid identity experiences of soldiers. 


\section{Willingness to Help Others}

In each cultural context there is a range of available models of masculinities, but not all these ways of being a man are valued (Cornwall, 1997). Ideas about what constitutes the 'ideal' masculinity for men to aspire to change through time. Additionally, they are mediated by historical-cultural narratives. Woodward (2003), in examining the gendered identities of British soldiers, argues that gender identities in the military are "constituted and expressed not only socially but also spatially" (2003, p. 44). By this she means that masculinities and femininities in the military are made and given expression with reference to the specific locations and contexts in which they are constructed - paying particular attention to the formation of masculinities that are historically and culturally contingent. As Carriers points out:

The way that gender impacts on peacekeeping missions is affected by the existing domestic and cultures of contributing countries' military forces. Variables such as the level of gender integration of the forces, the specific value patterns on gender relations they bring into national peacekeeping, and the soldiers' ability to cope with cultural diversity (within the military and towards local contexts) are essential in determining what happens in the field of gender (Carreiras, 2010, p. 471).

One particular narrative that is drawn on by the NZDF is the perception that New Zealanders hold a genuine desire to help others. As Weiss found, a common response to her questions relating to the reason the NZDF respects human rights and the rule of law in international defence deployments was "that is just how New Zealanders are" (Weiss, 2012, p. 16). This has resulting effects on how personnel perceive their interactions with local people. For example in the following quote a senior NZDF staff member ties NZDF's desire to act for the greater good to relating to local people on an equal basis:

We come along to often dangerous places without a hidden agenda. New Zealand has always deployed its forces for the greater good, to do the right thing, not for self- interest at the expense of those people we are helping. By our actions and by our ability to relate one on one with those people, we very quickly gain the trust of local people and can deal very well with social differences, ethnic differences, without any kind of inference of treating them as second-class citizens. I think we can look at someone who is poor or uneducated and not treat them like they are lesser citizens than us. I think that is a gift we have. We're not there to push our values but we live our values (Weiss, 2012, p. 19). 
This construction is important for justifying their peacekeeping presence more broadly, and for individual soldiers, any concerns over their inexperience working in an unfamiliar overseas environment is potentially allayed by the belief that they are genuinely there to help. Within this narrative soldiers not only become responsible for ensuring the safety of local people in the more traditional military sense, but their understanding of their presence begins to shift to a differing perception of the very nature of soldiering. This desire to help blurs more traditional understandings of who can be an agent of development. This may be particularly evident in an environment such as the Solomon Islands, where security threats were considerably lower than a deployment like Afghanistan and thus enabling greater participation in local culture.

Both Steve and Henry reflected the belief that their presence to 'help' in the Solomon Islands was a valuable contribution. For example, in the following quote Steve describes, as the highlight of his trip, the repairing of a health clinic by soldiers. In explaining why it was so rewarding, he constructs local residents as grateful and in need of help:

It was like the highlight of my trip at the end...cause the locals had all been helping us all week, we were having to turn people away because we just didn't have room to fit everyone in. Like we were doing almost nothing ourselves, we were like fighting locals for the jobs cause (laughs) you know they were so keen to... We'd brought the materials and they just, they didn't want us to do any work cause they were so grateful for that and we wanted it to be our sort of gift to them with the work complete so, you know at the end of that they put us up for a big dinner and we contributed to it as well. They said they were going to cook and it was sort of like a pot-luck so we just had all our rat-packs (laughs) horrible army food, like chucked them all in one big pot, we ate all their food and they ate all ours, so everyone was happy. So I mean that was the highlight of my trip and the only time we really did aid work which is a real bugger because that was so much more rewarding than sitting around and so much more beneficial as well.

Moreover, in the following quote we can see how development work has begun to be seen as something soldiers should be engaged in on peacekeeping missions, highlighting this increasingly blurry understanding of a soldier's role:

Kiri: Do you think the army should do more of that kind of work? Cause they don't do a lot over there... 
Steve: No they don't, I don't know why not. There should be more collaboration with NZAID and they should be utilising the soldiers to go and do all these things cause even when I was there...it was an extreme[ly] low-threat environment - we didn't have like anything that was really going to cause any trouble, like it was, I don't even think there were any decent bills going through parliament, no elections, not even any big football games, so I mean we should have been out doing it - I would have much preferred to. I find it a bit of failing of the mission but in saying that I mean there are costs and the job we are there to do as some superiors like to keep telling us (laughs).... left and it really sunk in like when I was leaving, I was like: "this place for the last four months has [become] safe[er] and I'm leaving it in a better state than when I came here," so then like it sunk in then. You know like with the likes of the med clinic it was really nice doing it and you know we felt it was so appreciated by the locals you know that felt great. But it didn't really sink in until I was leaving which was a couple of months later and then you're just like you we should have done so much more, could of done so much more. So I mean I did feel quite under-utilised but on the whole it was a positive experience.

Soldiers' discourses about the local environment and people as 'in need' are important for maintaining the idea that their presence is necessary. This quote also demonstrates that for Steve, helping local residents served to not only legitimise his presence, it also made him feel good. Heron (2007) has noted that the construction of 'the Third World' or 'developing' countries is commonly presented in such a way that it is understood as a place of "suffering, starvation and bloodshed". In this way development becomes not just about helping others, but also about making 'us' feel good in giving. This discourse normalises the soldiers' centering of themselves in relation to other people's needs as the bringers of knowledge, values, and ways of doing things that are the 'right way', that are based on liberal values and capitalist expansion. This can erase the agency of local peoples and local notions of what development should 'look like' in relation to the local context (Heron, 2007). For example in the following quote it appears that according to Henry, the Solomon Islands was much in need of help, and his understanding of what constitutes development is framed in terms of capitalist investment both externally and internally to the Solomon Islands:

[I was]a little bit surprised about how developed some parts of it were but then surprised how undeveloped it was sort of like you know, the highways, some of the highways were pretty good and it was like that's indicative of pretty lot of effort you know, of a functional government, that's indicative you know when they build a road and it has curbs that's, like there's been a functioning government there at some point and they got stuff done. And just because I'm an economist by academic location, it's surprising how it had been invested in, 
even in quite mundane stuff - people had built buildings, property developers had built buildings on the hope they'd get rent enough to pay it off and that's a big risk. So I was like quite surprised by how big the pool of global and local capital must be get stuff done like that, there must be an entrepreneur with enough money, a lot of money, enough money that they don't have to work to say "I want to make a bit more by building a house or building a building" in the middle of fuckin' nowhere. You know the last place on earth that you'd ever think, to have a crack at making a little bit more money, so I was yeah I was sorta surprised by the economics of it...yeah.

This construction of the Solomon Islands as 'developing' and 'in need of help' from New Zealand and other western countries could be understood as relying on the construction of the Solomon Islands as more chaotic and in need of increased liberal 'order'.

This construction of the Solomon Islands can also be tied to constructions of local combatants by soldiers. Duncanson (2009) found evidence that British soldiers link the practices of peacekeeping to rationality by constructing their masculinity in relation to the hypermasculinity of local fighting men. Perceiving local combatants as "excessively violent, aggressive, mad and irrational" serves to construct peacekeepers as "controlled, civilised, intelligent and rational" (Duncanson, 2007, p. 170). There was some evidence of the construction of local combatants in this way, in the soldiers' reflections. For example in the following quote from Henry:

There were nutters out there...we were just, this guy's sort of sent word and he wanted to meet me and another intelligence guy way out by Gold Ridge and he was just a nutter, he was like this...he adopted like Satanism as a thing but he wouldn't have known what Satanism, like they're just you know they just off the rocker you know, they like you know thinking that his penis had divine power and stuff but during the troubles he was a player like yeah...yeah.... Saw Jimmy Rasta ${ }^{26}$ once, met Jimmy Rasta...

Kiri: And what was your impression of him?

Henry: Oh, sort of coloured by, I knew what he had done, it's like "you prick." Yeah, yeah there's bad people out there. Definitely. And... we were doing overwatch onto the prison so you... knew who some of the key militants were, cause you carried, you had these cards, like a face-book but made out of laminated [materials] and you know you could, "oh yep that's that guy and this is what who he, what faction he was in and what sort of level he was at" and yeah...yeah fundamentally, I was pretty, pretty innocent probably going. But then you come across and you learn the history of what they did and it's

${ }^{26}$ Jimmy 'Rasta' Lusibaea was one of the leaders of the militant group the Malaitan Eagle Force. 
undeniable what they did, that's not propaganda or bullshit but fundamentally there some people out there that are, if there's no restraint around the society, if the society places no restraint on them, if there's not law to stop them... [then] they $\mathrm{d}[\mathrm{o}]$ some pretty horrible things.

This quote reflects an understanding of the local militants as "bad people" and "nutters", and the wider world as chaotic if order is not maintained, which shares similarities with Duncanson's findings ${ }^{27}$. However, a larger pool of interview participants would be needed to evaluate whether this is a part of a wider narrative of New Zealand soldiers across overseas deployments.

This individual narrative 'to help' is also part of a larger identity myth where peacekeeping interventions are framed as natural and benign. Portraying peacekeeping interventions in this way is problematic, because it fails to question the Western assumptions inherent in the justifications for intervention. Orford (1999) and Whitworth (2004a) have been highly critical of the emergence of masculinities associated with peacekeeping. They argue that discourses of peacekeeping reflect and reinforce colonial narratives that see peacekeepers as white, rational, developed, educated, civilised saviours, bringing democracy and human rights to the inherently violent, uncivilised, underdeveloped world (Orford 1999; Whitworth 2004). This desire to help others is believed by Razack to "serve the main purpose of nation-making and justification for maintaining a military, while at the same time framing the country in question as 'progressive' on the world stage" (Razack, 2004).

Considering the intervention justifiable based on notions of peacekeepers as advanced, democratic, and civilized only serves to leave the implications of Solomon Islands' colonial past unquestioned. It assumes more developed nations were not implicated in the root causes of the conflict and that a transition enabled by economic development will lead to a liberal peace. This narrative draws on gendered hierarchy where terms traditionally associated with masculinity are privileged over those associated with femininity. However, as the next section will discuss, these

\footnotetext{
${ }^{27}$ Some informal discussions with development workers in the Solomon Islands reflected this opinion that local militants were 'crazy' and irrational, one Army doctor described local people as 'primitive' and uncontrolled, cutting each other up with machetes. Local people also framed some militants as crazyHarold Keke for example, was widely considered to be not in his right mind.
} 
constructions of peacekeeping are complicated by New Zealand's understanding of itself as having positive bicultural relations. This narrative frames New Zealanders as particularly good at peacekeeping because they do not represent the 'normal' white western peacekeeper, calling into question monolithically negative representations of peacekeeping in the way that some feminist academics have raised (Orford, 1999; Razack, 2004; Whitworth, 2004a).

\section{The Pacific Way: Biculturalism/Multiculturalism}

There have been increasing calls for improved cultural sensitivity and cross-cultural relationship-building in the peace-building process. Some have argued liberal 'white' masculinity is constructed as the 'norm' that underpins peace-building (Higate \& Henry, 2009). This can have the effect of undermining or ignoring culturally appropriate peace processes. Greener et al., argue that "it is in part the overarching and generalising liberal agenda that informs post-conflict peace-building, which has presented some difficulties in addressing issues of gender and peace in the particular case of the Solomon Islands" (2011, p. 18).

However, the NZDF prides itself on its ethnic diversity: $17.5 \%$ of soldiers identify as Maori with infantry rising to about 45\% Maori (Weiss, 2012). Because of these numbers there is a belief in the NZDF that the high proportion of Maori in the forces, and the incorporation of aspects of Maori traditions, gives New Zealand soldiers a unique ability to engage with different cultures, particularly those in the Pacific. The confidence that New Zealanders make 'good' peacekeepers is partially reliant on the belief that New Zealand has a unique bicultural history, and the NZDF is particularly reflective of positive bicultural and multicultural relations. Drawing on this historicalcultural narrative was part of a broader narrative that was important for soldiers framing of their work in the Solomon Islands.

Higate and Henry (2010) similarly noted that perceived characteristics of nationality are constructed as an inherent element of UN peacekeeping by respondents involved in peacekeeping from across several peacekeeping missions, and "framing what peacekeepers 'were like'...as an explanation for how they approached their security work" (Higate \& Henry, 2009, p. 118). Nationality can be understood as the social 
constructions imagined and built by the people of a 'nation' encompassing the mental images people have of their common similarities and affinity with others in that nation. While national identity characteristics may be understood as inherent and 'natural', they are based on constructed ideas resulting from historical processes which foreground some narratives over others (Bell, 1996).

The wider perception that New Zealand's 'good race relations' with Maori and Pacific Islanders have resulted in a more equal and respectful New Zealand identity is evident, for example, in the following excerpt where a staff member comments that New Zealand's wider culture is responsible for soldiers' successful interactions with local peoples:

The NZDF is a cross section of society. It is the way that we are brought up. Yes, our multicultural society goes with us. I didn't realise how important this was until I was the PRT commander in Afghanistan. I had lots of soldiers, many under 20 years of age. I watched how we interacted with people in Bamiyan. There was none of this "we're better". Maori are brought up under hardship. There is an immediate affinity, a mutual respect (Weiss, 2012, p. 10).

This narrative has deep historical roots in New Zealand's military history. Jock Phillips has argued that, right from World War One the "achievements of Maori men... won the respect [of Pakeha] and were seen as providing a basis for harmony between the races" (Phillips, 1987, 286). Thus, "good race relations were founded upon a mutual admiration for the military achievements of the other race - so went the myth" (Phillips, 1987, 287). The Army reflects this history stating on their website that:

The unique culture of the New Zealand Army has been shaped and defined by a range of complementary influences. These include the martial traditions of the British soldier and the Maori warrior; our history, heritage and experience of war; and the characteristics of wider New Zealand society. Our culture helps develop and maintain espirit de corps, gives us a sense of our place as New Zealanders and (especially) New Zealand soldiers, and informs our doctrinal approach to operations (NZ Army, 2011).

Thus, this understanding of Army culture is articulated and given strength by narrative references to this historical-cultural identity (both within the Defence Forces and wider social context). New Zealand's own home-grown 'soldier hero' Willie Apiata, for example, embodies these cultural references while simultaneously strengthening this 
narrative by proving a hegemonic idea of masculinity for New Zealand, and particularly

Maori, men to aspire towards. Nicky Hager states:

Apiata was lauded as being brave, courageous and a hero, and, unusually for these overused words they appear to have been fully deserved. The story resonated in New Zealand because not only was he a hero, but he was a Kiwistyle hero: humble and decent, just looking after his mates, modest, tough, with a good sense of humour... Apiata, the son of a Pakeha mother and a Maori father, was also a positive symbol of New Zealand's evolving national identity and of its low level of racism (Hager, 2011, p. 216).

In speaking to Henry and Steve, they both stated they believed that there were good bicultural relations in the New Zealand Army. Henry explained:

The Army's a heavily Maori organisation so you're, you know, there's cultural differences there and there's a lot of respect for both cultures so people are pretty polite. The Army's way more liberal that most people think...it's more post-modern than people think.

He further explained this:

You don't get a lot of that [racism] in the New Zealand Army. You get a lot of like overt jokey racism. In fact they are like past racism... you can get away with racist jokes because it's like your race is meaningless in the same way, "you're fat" that's meaningless cause I don't really think [you're] fat, or you know you've got ginger hair or whatever. They're so far past, race is so acknowledged and integrated that they're past racist. You can actually, you can give someone shit about being a honky or Maori because no one cares, like it's just, they're past it.

At times Steve and Henry drew on these historical-cultural narratives when asked to explain the perceived success of the mission, especially in engaging with local people.

For example Steve comments on the culture of the New Zealand Army explaining:

Yeah I'd say... part of military culture is the language that each military uses and everyone's got different acronyms for different things and then you get the incorporation of te reo... You know it's just like... "kai time" and you say that to an Aussie and they're just like (confused look on face) (laughs) confused, [or] the old te wai wai express (laughs)... So there is a different culture and then like situations like the Solomon's peacekeeping you know it is maybe it just gives you a little bit more exposure to another [culture] and then you know from 
that it's easier... I think... the biculturalism or multiculturalism is quite deeply rooted in New Zealand society.

Henry also states that he believes the presence of Maori helped in engaging with local people:

I think New Zealanders in that environment benefit from having brown faces definitely. Even if only some of them are brown faces you know, definitely, [its] definitely helpful cause... there seems to be a little bit, they [Solomon Islanders] trust us a little bit more. Yeah I think it probably helps... Yeah I think there's cultural similarities, minor ones...

The Pacific identity of the wider mission and within the New Zealand Army was also important in the construction of New Zealand's perceived success for Steve. Steve less strongly drew on the presence of Maori in his narrative, possibly due to low numbers of Maori in his deployment. He attributed success in engaging with local people more to the presence of Pacific Islanders in his team. This is contrary to the findings of Higate and Henry, who noted that in Kosovo, peacekeepers from 'developing nations' were commonly constructed by soldiers from 'developed' 'white' countries in ways that reinforced negative racial stereotypes (Higate \& Henry, 2009). However, while UN peacekeeping missions are similarly made up of a wide variety of contributing countries, the legitimacy for the RAMSI mission is drawn foremost from the diverse experiences and cultures of the participating countries. The support of the Pacific Island Forum was sought before the mission began and the wider RAMSI mission framed was framed as regional response. Their website states that with people from "15 different countries, the RAMSI team is as diverse as the Pacific itself" (RAMSI, 2012a) indeed at the time of the initial deployment in 2003 Prime Minister Helen Clarke stated: "This is a Pacific solution to a Pacific problem. Thus it is important that our involvement is handled in a Pacific way" (Clark, 2003).

Soldiers from Pacific Island countries such as Tonga and Papua New Guinea can be considered 'less developed' in comparison to New Zealand, yet unlike in Higate and Henry's findings, they were not talked about negatively by Steve or Henry. Steve, for example, saw them as a real asset to the mission: 
I noticed that it was one of the guys the platoon was Tongan and he wasn't in my section but just pure out of his blackness, you know and he also spoke really good Pijin but he was he was really really approachable to the locals (pause). All the Maoris in our platoon... all the ones that I saw interacting, were all the really white ones. And I'm not sure if the locals so much differentiated, but I mean I noticed especially... when I was with the Tongans [on a search and rescue mission]... we'd go out and... they're almost locals when you see them interacting and you know and much better at it than we were...

He explains this further later in the interview:

The Kiwi-Tongan guy in our platoon he'd just stroll round, like really casually go up and just be able to start talking to almost anyone. And you know we just couldn't... quite bring ourselves to do that and I think you know because they felt more comfortable with him and you know he, the surroundings were so much less of a shock to him as well was probably quite a big thing. You know [he] could just go in [and] rock like that and you know just go round and be picking kids up and throwing them around and stuff (laughs) woo! And then like everyone's loving it and having a good time but it was like if I went and picked up somebody's kid and just threw it up in the air (laughs) people would be coming after me with machetes.

Similarly, when talking about the Tongan soldiers that were deployed at the same time as Steve, it is because they are Pacific Islanders he sees them as more effective at engaging with local Solomon Islands. In doing so, there is little assumption of white soldiers being superior in this regard:

And you see it when I was out with the Tongans as well - they do have that much better rapport. And yeah they can run round catching pigs and things... whereas if... the Kiwi soldiers went out and did it you know we might get in trouble or be told to pay compensation. The Tongans knew who to ask and what to ask yeah and how to actually catch pigs as well which makes a bit of a difference.

The New Zealand specific bicultural/multicultural version of 'white' masculinity that Steve and Henry spoke of can be understood in more positive light that that of Australian soldiers in the Solomon Islands. Constructions of Australians were an important part of Steve and Henry's understandings of their own peacekeeping behaviour. It appears that for New Zealand soldiers to say that they are better at race 
relations, they needed to compare themselves to Australians who were considered worse. Thus, for the two soldiers interviewed, the actions of Australian soldiers reinforced the perception that New Zealanders were better at interacting crossculturally. Both soldiers believe Australians acted in ways that were racist. For example Steve states:

I don't quite understand Aussies to be honest. I mean they're meant to be our closest neighbour and we...share all these cultural values but I don't believe it for a second (laughs)... Yeah, and I think...I don't know what it is whether it's theory a just the truth but pretty sure Australians are all just racist pieces of shit (laughs)... It's the Aussie that can't talk to the locals. They're terrible at it, it's hilarious. [It] cracks me up.

Henry similarly commented:

I think just the cultural, cultural factors, cultural similarities and yeah the Aussies really suffered from having very white guys who have never interacted with people of different cultures or have really negative interactions with, well just negative interactions. The Aussies were [pause] the average Aussie soldier can be pretty racist.

Steve described the following incident to give an example of Australian soldiers' racism:

One of the section commanders, Aussie section commander hit his soldier - I mean he was drunk - because he was Asian. Which is just like the craziest thing ever and you know excuses come flying around afterwards that... "Oh it was because he was getting cheeky or I thought he said something." Or something like that but the boys [in his section] were like nah he just hates him [his soldier] because he's Asian. Which is ridiculous I mean you can't get away with that sort of shit... well you can but shouldn't be able to. Outside of the camps... when you do see them they're less likely to interact like if you stop off and someone's got to nip into a shop, or you know you just stopping the wagon for a bit the kiwis would jump off and run round and say gidday, talk to the locals and the Aussie would of just sorta keep to themselves.

Henry also described the different way that New Zealand soldiers acted towards Solomon Islanders in contrast to the behaviour of Australian soldiers' behaviour:

Henry: they were really bad about taking their sunglasses off, they weren't trained to do that, if they were trained to do it then they didn't do it. One guy, yeah, one guy I saw who you know, did shake someone's hand but immediately used antiseptic gel (laughs) because you know, the rumour, the rumour is "oh Solomon Islanders they don't have toilet paper, so... what are they use for toilet 
paper? Their hand," which is probably bullshit right, but that's kind of...it's like yeah.

Kiri: So, he did it right in front of the person?

Henry: Yeah yeah yeah! Shocker ay!

The way that Steve and Henry used examples of Australian soldiers also demonstrates the ways that ways of acting as a good soldier are being delinked from masculinity by the valuing of ways of approaching peacekeeping that are non-hegemonic. In the following quote Steve explains why he considers Australians not good at peacekeeping tasks, and describes aspects of behaviour that are tied to militarized masculinities:

Kiri: What, what do you think makes them so bad, like what's an example of them....being bad at it..?

Steve: Just having no idea of language and just going up and just shouting at people and just getting frustrated, not being friendly, not having...not trying any small talk.

Steve believed that they were not empathic to local people and thus not as willing to engage:

Subtly I think they think... well it's not even that subtle, they just consider themselves to be quite superior to the Solomon Islanders... within our guys you know there's a wee bit of pity and you know just like "oh" specially like in the slums around Honiara like up Koa hill and that and you're like "oh, this is, I mean this would not be a nice way to live," but it's not..." nah shit we're better than you," it's ...empathic... Whereas the Aussies just would be like "ah this fucken disgusting let's get out of here," got no time for it, like they don't have that sort of empathy for the situation. Whereas yeah, we have a bit more... of that. And I think it probably comes [from] us having more... Pacific Islanders perhaps - being more integrated into the society.

Henry noted that while he believed Australians were sympathetic to local people they nonetheless did not see the value in learning Pijin:

I don't think they really learnt language, the Aussie didn't really learn language. Probably the Aussie soldier might have felt sorry for the local population maybe. But that would be about as far as it goes. They didn't really feel like they could interact with them as equals whereas we were definitely interacting with the population as equals.

For Henry, taking the time to learn Pijin demonstrated that they considered and interacted with local residents with a sense of equality that Australians failed to do. 
While a bicultural and multicultural culture in New Zealand and the New Zealand Army seems to have some impact on the ability of New Zealand soldiers to engage in peacekeeping tasks in ways that are perceived positively by local people (Solomon Islanders' perceptions are discussed in the next chapter), we must be careful not to assume that this guarantees soldiers acting in culturally appropriate ways. Yet in recognising the similarities in culture and differentiating themselves from other nationalities through the belief that New Zealanders are good at engaging and showing respect for other cultures, soldiers are not seeing themselves as monolithically 'white male heroes'. Recognising the importance of acting empathetically and with a sense of equality towards local people demonstrates that the 'Other' is not always "radically different and threatening Other" but rather, there are degrees of difference and "otherness" that are negotiated by soldiers (Duncanson, 2007, p. 184). This offers possibilities for acknowledging the everyday challenges soldiers make to hegemonic narratives of race and gender.

\section{Individuals' Negotiations of Identity}

Steve and Henry did not always subscribe to the narratives I have discussed to this point. At times they challenged these narratives. This highlights that complexity and contradictions are part of the fluid identity experiences of soldiers based on individual experience. For example, even though they argued at times that New Zealand soldiers were more culturally aware because of the presence of tikanga Maori in the Army, they also tempered this with discussion that attributed this to personal characteristics and situational factors. For example Steve stated:

In saying that, it'd depend on the person as well. I mean I was pretty good interacting with the locals.... I might be getting put on to a wrong track cause we only had one Maori girl in our section and she wasn't all that great with interacting with people on a whole... I guess some people have the gift of the gab and language helps as well. And also how willing the other person was how willing the local was to talk so I mean if they're not going to talk they're just going "me no save, me no save." And you're just like "shit" (laughs) and you know they'll just stonewall you and nothing's coming out and doesn't matter if you white brown yellow. I mean if they don't want to talk to a soldier then they're not going to talk to a soldier. 
While Steve drew on narratives of Maori presence in the Army as a reason for good community engagement, he also seemed somewhat sceptical of this at the same time, questioning whether the presence of Maori could be used as an explanation for their perceived good cultural awareness on missions at times. For example when discussing the mix of Maori and Pakeha traditions within the Army Steve commented:

Steve: Yeah I don't really identify particularly with it.

Kiri: Mmm... cause I know the ethos is kind of like the "best of both worlds."

Steve: I think that's the advertising campaign (laughs).

This may also be because Steve does not identify strongly with the Maori aspects of the Army. For example, Steve describes his confusion over the Maori induction into the Army pre-deployment:

When I was on my recruit training... I was just like "Oh my god what is going on, I have no idea what's happening." And you just sort of get filed in, sit down and they explain the Marae, cause we are the 'tribe of war' so we went all you know "we're a tribe woo!" ... But yeah I don't really identify particularly with it.

In the following quote he explains this further and this indicates the individuals' understandings of their identity are important to pay attention to:

Well I mean I didn't particularly have bicultural upbringing. Growing up in the whitest district in New Zealand, but since then I think like informally just through, cause there is quite a bit of culture brought into the Army.... And that was just sort of, it was quite tokenistic - like you go in, you have a hangi and don't understand things that are being told to you and then leave...It was a bit confusing.

Thus both Steve and Henry did not always buy into more dominant narratives about New Zealand soldiers. This is important to note as in exploring the intersecting narratives that allow hegemonic militarized masculinities to retain power, we must also pay attention to the ways individuals navigate these narratives. In doing so we recognise that individual's experiences of peacekeeping are not always unchallenged by their personal experiences. 


\section{Conclusion}

This chapter has considered aspects of identity other than gender that Steve and Henry drew on to frame their peacekeeping practices. By exploring these other aspects of identity I have demonstrated that New Zealand soldiers understand and conceptualise their role through a desire to help and an understanding of the Solomon Islands as somewhere in need of help, which relies somewhat on racial discourses. However, I have also suggested that ideas about nationality and cultural understanding are important for framing their presence as legitimate. New Zealand soldiers see their intervention in the Solomon Islands as more legitimate and effective because their ability to be more culturally sensitive. Further, in the context of wider feminist literature on peacekeeping (Orford, 1999; Razack, 2004; Whitworth, 2004a) their praise of other participating forces from Pacific Island countries and comparisons with the 'racist' behaviour of Australian soldiers indicates new understandings of what is valuable peacekeeping behaviour. I argue therefore that soldiers are not only challenging hegemonic militarized conceptions of masculinity as discussed in the previous chapter, they are also challenging the construction of 'white western' soldiers as most effective in bringing about peace and 'development' in the Solomon Islands. Considering these intersecting perceptions of identity raises the question: how did Solomon Islanders understand and frame participating forces? The next chapter will explore the reflections of local Solomon Island participants. 


\section{Chapter Seven: Solomon Island Peoples' Narratives about RAMSI soldiers}

The only way you can understand people is by coming interacting with people and watch them, how they move, how they live and they talk so you could easily understand them and then yeah you get to know them [Ronnie, 07 June 2012].

\section{Introduction}

In this chapter I explore the narratives of seven local Solomon Island participants about peacekeepers. This chapter is divided into two sections. As I discussed in Chapter Six, peacekeeping can be understood as politically contested in nature, drawing on notions of peacekeepers as white, rational and decisive - that reinforce particular gendered and racial stereotypes, and that work to justify interventions (Orford, 1999; Whitworth, 2004a). I highlight that while this understanding of peacekeeping can be used to understand the nature of peacekeeping interventions, this perception can also reinforce ideas about local people as passive victims of culturally intolerant, hypermasculine soldiers. In doing so, this discourse can draw attention away from investigating the way that local people actively engage with the political nature of peacekeeping missions.

In the first section I argue that broader socio-historical understandings of the countries involved in peacekeeping are important for shaping the way that Solomon Islanders understood the presence of soldiers. The second section focuses on some locals' perceptions of everyday interactions with soldiers. I argue that soldiers' practices that challenge militarized masculinities are often perceived positively by Solomon Islanders. Consistent with this perception, a failure to demonstrate non-violent masculine practices is interpreted negatively. It is important to note these perceptions because it demonstrates that while socio-historic narratives are important for framing local peoples' understandings of peacekeeping, local people are also more accepting of soldiers' presence if they place value on building relationships of trust with local residents. 
Finally, I explore some Solomon Islanders' reflections about the impact of having soldiers in the Solomon Islands. For some, the presence of armed soldiers was a welcome sense of security. However, for one participant in particular it raised questions about the appropriate way to solve conflict and about the kinds of 'security' soldiers can engender. With these differing perceptions in mind, I suggest that regardless of the ability of soldiers to engage with local residents in ways that build positive relationships of trust, the carrying of weapons, and the ability to use violence to solve conflict, has a negative impact on local masculinities and the creation of longterm peace.

\section{Historical Intersections: "It's historical”}

Critiques of peacekeeping have questioned the ways that interventions reinforce particular gendered and racialised hierarchies between local people and peacekeepers (Orford, 1999; Whitworth, 2004a). Thus, while peacekeeping interventions - such as RAMSI - tend to be framed as neutral enterprises, they are far from it (Higate \& Henry, 2009). Nor do local Solomon Islanders understand the presence of RAMSI as benign. The nationality of participating forces and the longer histories of interaction between the Solomon Islands and participating countries played a significant part in determining Solomon Islanders' perceptions of RAMSI soldiers. These perceptions questioned the racialised hierarchies that soldiers reinforced, showing particular dissatisfaction with the ways in which Australian soldiers reinforced these inequalities.

Ideas about nationality were similarly used to frame New Zealand soldiers in ways that challenged racial narratives present in peacekeeping operations. New Zealand soldiers were seen as friendlier, more compassionate, and more sensitive to local kastom and culture. For example, Andrew, a Malaitan businessman, drew on the wider historical relationships of friendship and 'inherent' cultural factors of particular nationalities to interpret the behaviour of soldiers:

New Zealanders, let me say this... Solomon Islands respect New Zealand and New Zealand people a great deal and they still do. And it's, it's a historical, what would you call it, it's a historical relationship, because New Zealand, especially the Anglican Church... they were, they're mission and their ministry in Melanesia, especially I'm speaking for Solomon Islands has been very very 
powerful. Most of the, of the pre and post-independence leaders like the Vesys [Devesis], the Keneloreas, the Leppings were all educated in New Zealand, including myself.

In this quote the longer history of interaction between New Zealand and the Solomon Islands is important for the way that Andrew interprets the presence of New Zealand peacekeepers. Andrew himself was educated in New Zealand and met and married a New Zealander. During my interactions while in the Solomon Islands, I found that almost every person I met had some New Zealand connection to share. Most often it was relatives that had been seasonal migrant workers in the fruit industry, or relatives who had been to school in New Zealand. However, I was also told about relationships between villages and New Zealanders going back to the presence of New Zealand soldiers in WW2, and even further back in history through the Anglican Church. Noting this longer history is important as outside of the actions of participating forces, wider narratives of positive relationships with New Zealand were significant to local residents. For example, Andrew thought the differences in the development of New Zealand and Australia as countries was a significant factor in the way soldiers approached their work:

And New Zealand people are different from Australians. You would know, you know the background to this whole thing, historically, it's you as an educated person understand it because New Zealand was colonised with the, with the understanding philosophy, mission to Christianise the Maoris, people like Samuel Marsden and others went there. Australia was colonised as a criminal outpost so that impact, that historical impact sticks to this very day and will last probably for a lifetime, for a long-time to come and while we are not psychologists... what happens in history... repeats itself. And also New Zealand is a small country, Australia is a continent and I think the peace, the Waitangi treaty and the peace that the English empire established with New Zealand set a pattern that would have image, a character to New Zealand forever. And so you don't have racial tension in New Zealand, there is hardly any pure Maori in New Zealand - I don't know if there are any pure Islanders in New Zealand (laughs). But of course Auckland is the biggest Polynesian city in the world, so that... has had a biological, cultural, social, political impact on... [the] character on New Zealand as a nation. So when New Zealanders come with this Army thing, Solomon Islanders can tell the difference between Australians, Fijians and New Zealanders. The other interesting thing is that New Zealanders whether you have a part-Maori soldiers or a Pakeha, full-blown Pakeha or partMaori, they all behave exactly the same. 
For Andrew, the history of race relations was an important factor when understanding the behaviour of participating forces. While Higate and Henry (2009) found that perceptions of peacekeepers relied on ideas about soldiers from 'white' countries as being better at peacekeeping, for Andrew at least, the perception of New Zealand having a better history of race relations, and the high proportion of Maori and Pacific Islanders in New Zealand society were seen as an asset. Andrew's opinion is similar to some of the articulations of Steve and Henry.

The importance of broader narratives about the participating forces' nationality was also demonstrated through perceptions of Australian forces. My own nationality as a New Zealander may have affected the way that Solomon Island participants' discussed New Zealand and Australian soldiers. Participants may not have felt comfortable criticising New Zealanders in the same way that Australians were. While, no doubt there is likely to be a multitude of positive historical connections with Australia too, Australians were commonly interpreted negatively by interview participants based on ideas about their national character. Andrew was particularly critical of the role of Australia in the RAMSI mission and further emphasised his belief that history is important to how soldiers acted. For Andrew, negative perceptions of Australians were based on widely intersecting factors. For example, he reflected the scepticism that many Solomon Islanders hold about Australia's attention to the Solomon Islands, believing that RAMSI is a form of Australian colonisation. RAMSI is Australia-led, Australia has the most directive role in RAMSI with other participating countries acting in a support role (Greener, 2005) and Australian personnel make up the highest proportion of RAMSI present in the Solomon Islands. As Allen notes, for the majority of the rurally based Solomon Islanders, RAMSI is primarily understood as a police and military operation and many of the 'heavy-handed' actions of RAMSI police officers and soldiers has resulted in resentment that they do not respect local kastom (M. Allen, 2006). This criticism is largely directed at Australian personnel who are seen as "arrogant and aloof" (M. Allen, 2006). In the following quote Andrew articulates this scepticism of Australia's presence, linking this to sensitivity to local culture and Australia's history of race relations: 
Australians conduct in RAMSI was purely on their strategy. They, they don't I don't think they have any in depth of understanding and appreciation for the culture of the people. And Solomon Islands is a little, it's a little multination... because all the different island groups have different cultures. Like you would understand it because you come from New Zealand, like... you are part-Tongan okay - their attitude and their customs is slightly different... Tonga is different again from [the] Cooks, Solomon Islands we have Melanesians, Polynesians and Micronesians... So then they started arresting people, you know, putting people in goal, in custody and... probably half of the people who were put in goal...were eventually released mostly, some of them, most of them just walked out free... not convicted. Some were convicted... for wrong reasons. It's basically... their practice with the aboriginal people in Australia... So without people realising it and appreciating it the New Zealanders and the Fijians uphold and understand and try to understand the Solomon Islands culture and [treat] people fairly. And so they would talk to people, they would not just walk in and arrest somebody, they would talk to local people and find out what information [there] is.

Andrew further linked this to Australia's treatment of Aboriginal Australians, demonstrating further the importance of historical narratives:

History speaks very badly of them. They murdered Aborigines just like kangaroos ... [they will] stand trial before Jesus Christ one day whether we like it or not, whether we believe it or not, whether we accept it or not.

Similarly, James, a Guale resident of Henderson in his early twenties, expressed the belief that Australians' national character was different and that they were more racist to Solomon Islanders:

And compared to the Australian people they might have some differences, so with some barriers to the people of SI... Maybe their character, how they approach, how they treat people or maybe because of the racism. We are blacks and [gestures they are] whites.

In explaining this further, James links understanding of soldiers to their nationality and cultural similarities. For example:

The Fijians and Papua New Guineans we are Melanesian people so they really part of the Solomon Island, but the Tongans and New Zealand they are same...only Australians different. We feel as if they are different, they are from the different world (laughs)

Kiri: Okay.

James: And even we feel as if they are boss, giants (laughs)

Kiri: Giants (laughs)!

James: And we feel like little kids and they is the giant (laughs). 
Andrew believed New Zealanders made better peacekeepers in the Solomon Islands because of perceived inherent traits as well as New Zealand's ability to understand the Pacific way of life:

I think it's an inherent attribute, I think Kiwis are a different group of people. They are mild, they are kind, and whenever they go, when they come to Fiji or go to Samoa or go to England... what you wear might affect you but inside of you have this cultural[ly] inherent attitude that you know, you respect the environment you live in. And New Zealand is in the Pacific and New Zealanders understand and appreciate the Pacific way of life and so it was very evident, it has been evident in RAMSI... [and] by the New Zealand personnel.

These discussions are highly ethicised, suggesting understanding of soldiers' behaviours are linked to deeper socio-historic ideas about New Zealanders', Australians' and other participating Pacific Islands' national characters. These sociohistoric ideas are important to explore as they demonstrate the importance of peacekeepers considering their complicity in wider historical-cultural narratives in the countries to which they are deployed. In doing so, individual soldiers are able to challenge practices that reinforce these broader understandings. The importance of paying attention to these broader narratives is highlighted by the failure of Australian soldiers to challenge the dominant historical-cultural narratives that Solomon Islands participants held. Perhaps if Australian soldiers paid more attention to these narratives individually they could challenge these narratives in their everyday practices.

It appears from investigating the reflections of Solomon Islanders about RAMSI peacekeepers, that for some participants local and global stereotypes were significantly drawn on as explanations of how peacekeepers approached their work (Higate \& Henry, 2009). Like Whitworth (2004a) and Orford (1999) suggest, this demonstrates that peacekeeping operations are not neutral enterprises and Solomon Islanders do not interpret them as such, indicating that the contested nature of peacekeeping interventions is an important way the behaviour of soldiers is evaluated (Higate \& Henry, 2009). However, local peoples' comparative references to unequal socio-historical race relations in Australia, with the perception that New Zealanders are less racist, complicates understandings of peacekeeping as wholly negative for local people. In the next section, I point out that unlike Whitworth and Orford's argument, the monolithic understanding of peacekeeping as a new form of colonialism 
is further complicated by paying attention to local peoples' perceptions of their everyday interactions with soldiers.

\section{Everyday Interactions: Sitting Together and "eating from the same plate"}

Higate (2007) and Duncanson (2007) believe that in order to explore criticisms of peacekeeping, it is essential to pay attention to the everyday experiences and realities of peacekeepers on the ground. They believe this can highlight the ways that soldiers demonstrate agency to create new identities that are more conducive to establishing respectful engagement with local communities and valuing non-violent conflict resolution practices. I argue that paying attention to local perspectives is also an important part of exploring this further. In exploring the everyday interactions of local residents with soldiers in this section, I suggest that for Solomon Island participants interviewed, soldiers' practices that challenge militarized expressions of masculinity are interpreted positively, and behaviours more linked to hegemonic forms of militarized masculinity are interpreted negatively.

An important aspect of building trustful relationships with local people is an emphasis on communication. This is especially apparent in the Solomon Islands. Allen notes "[i]n a Melanesian country such as Solomon Islands, successful communication depends on building relationships of trust. Ongoing interaction and exchange are the keys to developing such relationships, even if it is only friendly words that are being exchanged" (Allen, 2006, p. 197). Thus the engagement of soldiers with local people in their everyday activities was important for creating a sense of trust and equality. In the interviews conducted it was apparent that New Zealand soldiers were well regarded because of their willingness to interact with Solomon Islanders. For example, taking the time talk to people and answer their questions was perceived as something that was good for the community - as Billy, an older Guale government bureaucrat describes:

I remember one incident when I was in the village, that they came on a chopper and... the soldiers came with them [and with them] was a kiwi.... He was providing an escort for the leader [of] RAMSI.... When they were in the village while this man [the leader of RAMSI] was giving a talk, like he [the soldier] is engaging with the people in the village, talking and communicating, 
like discussing and things, yeah... it's very very approachable in a sense, yeah, people come up and ask him questions and things.

Ronnie, a Guale security guard, shared a similar view:

[Through] the whole civil unrest people really like the New Zealand army and police $^{28}$, they, what they find, they very friendly and kind people, sometimes you know, they don't discriminate anybody, sometimes people talk about the.... Australian Army, they say they no good, but for New Zealand they have no problem with our people, people really love the New Zealand Army, [and] the police... because how they treat the people... and how they interact with people and they were very kind to people and... they speak well to people, whenever they meet people they speak to them, even they invite people to come to the station sometime just to... come and just having conversation with them, they sometimes give things to people, food and water and other things, so people really like the New Zealand Army and the police yeah.

Ronnie similarly reinforced the value of communication skills by contrasting New Zealand soldiers' behaviour with the behaviour of Australian soldiers:

So at Banakira [Mbambanakira] whenever they send any police officer like in search of Banakira station, if they hear about New Zealand police there, people will come and ask for water even for other things, but when see Australian police or army went to the post then people don't like them, yeah, they say they don't know them, won't cooperate, they don't really like to interact with people, so they just stay in the station, don't go out and meet people yeah.

Andrew also talked about New Zealanders' willingness to engage with local residents.

He also attaches more masculinity to practices associated with peacekeeping such as engaging with local people in a relaxed manner:

Andrew: Sometimes it's good to demonstrate masculinity but sometimes it's not so necessary. I think when you are strong and when say when you are superior and you respect and you go down and uphold the weak park of society that has more impact, is more realistic and has a lasting... memory within a

\footnotetext{
${ }^{28}$ It is important to note here that military personnel's mandate in the RAMSI mission to support the PPF meant that soldiers and police were commonly seen in public together. There are significant differences in their uniforms and tasks and from my interactions with Honiara-based participants the difference between soldiers and PPF were understood. However in the following opinions and experiences discussing military personnel there are also some comments about police officers. As Bevan (M. Bevan, 2011) notes, police forces can similarly adopt hypermasculine militarized policing practices. The blurring between the two by local residents can be seen to indicate similarities in their behaviour, thus while this could be understood as a limitation of the data, I do not see this to be a significant problem for the purposes of this thesis.
} 
society. So in Solomon Islands for example if you are playing rugby and you show masculinity that's very very proper. Like McCaw or Carter you know are heroes okay. If you show a feminine or weakness and you're defeated people laugh at you. But if you're a military officer a lieutenant or a sergeant...you go in the village and you like (indicates be tough) you know, no. But when you go and say hello and you shake hands and they offer you something and you receive it, that has more respect...lasting respect. That's where there's a difference between Australia and New Zealand.

Kiri: Yeah okay. That's interesting.

Andrew: New Zealand officers would go in the village and they would do that. They would go out of their way you know, almost act unofficially, out of their code of conduct and profession and just talk to people and chat with them. Australians didn't do that. That's a huge difference.

Kiri: That's really interesting. So the Australians are coming in and they're like "ra ra ra", [like] they're men?

Andrew: Yeah, macho, you know macho.... It's not necessary. I mean for me if you show that it's just disgusting and I don't like it.

In this quote it appears that Australian soldiers are viewed negatively for putting on displays of masculine 'macho' power. New Zealand soldiers in contrast, challenged their own privileged position as peacekeepers by interacting with local people in ways that were outside their mandate in the Solomon Islands. While the unfavourable image many Solomon Islanders have of Australian soldiers was closely tied to a broader dislike of Australians in the Solomon Islands for both present and historical reasons (as discussed in the previous section), on an everyday level Andrew's comment demonstrates that overly masculine behaviour by Australian soldiers is considered disrespectful and not positive for the community in the long-term. The importance of not displaying power over local people is also highlighted in the following quote. Rachel, a Guale resident of Henderson in her early thirties, describes her engagement with Australian and New Zealand soldiers for whom the women were employed to do washing for (translated from Pijin). Her emphasis on how kind and calm New Zealand soldiers were makes one wonder what the behaviour of the Australian soldiers was like towards these women. Interestingly in Chapter Five (section two) Steve talked about this same interaction with the women who washed their clothes, to describe the importance of engaging with local people:

People from New Zealand are kind people, they are very kind. They are not like Australians, where two are three are good, but lots of them are very rough (it 
might have been very mean ${ }^{29}$ ). Even though we would lose their clothes they wouldn't become angry, they would just calmly look for the clothes. At that time there were a lot of soldiers so we used to mix their clothes up. Because all the soldiers have the same uniform so at that time when we lost their clothes they wouldn't become angry and they would just calmly look until they found them because all their clothes had their names on the side. So they would just take their clothes back and they wouldn't be angry, they are kind people. With food it was like that too. They eat anything, like Solomon Islanders. It was like they were just our friends as well, just ate anything.

This quote also emphasises that soldiers acted "like they were just our friends". Similar to this, James explained how New Zealanders' interactions demonstrated a sense of equality:

We don't have differences, we feels as - we the same people. They come from the same country, only maybe the culture and the language may be different but the behaviour and [we] notice their characters almost the same. Then they came in and eat with the black people, they sleep with the black people in the villages and so people don't have any differences, no fear whatsoever, they feel as if they are real brothers.

Allen (2006) notes that other Pacific Island soldiers participating in RAMSI were popular with local people based on their willingness to 'come down to the people' and it appears from my interviews there was a similar feeling towards New Zealand soldiers. In the above quotes we can see that taking the time to engage with Solomon Islanders in a respectful and friendly way is important as for James at least it demonstrates that they see local people as equals. In doing so, New Zealand soldiers were challenging the position of power that comes with being a peacekeeper and that is important for legitimising their entry into the Solomon Islands.

Equality and respect was also demonstrated further by the willingness of New Zealand soldiers to exchange and eat local foods. Allen (2006) noted in his research of Solomon Islanders' perceptions of the RAMSI mission that the broader PPF's (made up of mostly Australians) refusal to consume local foods played a negative role in building relationships of trust with local people. Haddad (2010) similarly noted that in Lebanon, French peacekeepers buying and eating local food is said to have been appreciated by Lebanese. While Henry discussed not eating in front of local people as important

\footnotetext{
${ }^{29}$ Translators comment in text.
} 
(discussed in Chapter Five, section two), Solomon Island participants saw soldiers consuming their local food and sharing their army food in return as positive and indicative of respect of customary ways of relating to others. Sharing food with guests is an important part of local custom that Ronnie talked about:

In our custom when we meet people the first time we usually kill pigs, yeah ... if you like come to my village, it's traditional welcoming people, visitors, friends. So that was happening, that what happen in the place. When we first went to Banakira [Mbambanakira] the New Zealand army have asked me to find pigs so I find, found three and they give me money to buy the pigs and they ask me to kill the pig and this when we first meet and interact. So that time we, we come together and eat and that is when ... our relationship begin, so we knew each other, yeah just build up a trust and the for the village. These people understand our custom, so you know when we kill the pig they don't ask us to, I mean, they didn't prepare the pigs and the food, they ask my people to prepare them for them and after everybody, we bring them to the camp and they ask me to call the people "come" and we sitting together and we share... So that is one way of respecting our custom.

Ronnie's comment about welcoming New Zealanders as guests raises a critical point. While local residents may see soldiers as guests in their country and community, soldiers may not always conceive of themselves in these terms. In this quote it appears that the New Zealand Army has recognised their position as guests and acted appropriately in accordance with Solomon Island custom. Ronnie describes this further when asked about the positive things the New Zealand Army may have done for the community:

Sometimes you know when they saw people walking around maybe very far, they would say "hey come here, friend here, come here, come have a drink," like water or perhaps something to eat like apple and other things yeah, just really army food, then they would ask out boys "can you go and get some coconut for us?" So our boys would find coconut for them. Even to dive in the river for fish.

In this quote New Zealand soldiers also demonstrate empathy for local residents by sharing food and water. Within New Zealand society empathy is commonly strongly linked to femininity and less privileged forms of masculine behaviour, and demonstrates to local residents that New Zealand soldiers possess a genuine desire to seek good outcomes for them. Similarly, in the following quote Ronnie describes how 
using the benefits of their military equipment, soldiers made everyday tasks for residents easier, demonstrating a desire to help people:

They have the big motorbike and when people like, they want to go round to the beach to catch ship or boat the army would take them down to the beach, even sometimes they carried goods from the ship, they drop off the goods like rice and flours. They would load their motorbike and carry them to their village. Very helpful yeah, whenever people need help they respond positively.

The perception of Solomon Islanders that New Zealand soldiers acted in culturally sensitive ways also linked to the presence of Maori soldiers and an understanding of the Pacific way of life. Unlike Australians, New Zealand soldiers were seen to not always act as the 'white, rational, developed, disciplined westerners' and thus Solomon Islanders felt more kinship with them. Steve and Henry articulated mixed affinity to the Maori aspects of the New Zealand Army; however Ronnie and Andrew both talked about this as an important aspect of why they saw the behaviour of New Zealand soldiers as better than that of Australian soldiers. The following quote shows that for Ronnie, the presence of Maori soldiers was positive:

Kiri: And how did you find that going back with the soldiers? You felt safe or were you still little worried about militants?

Ronnie: Ah, in fact when, ah get there, the army came and interact with us, and ah we really like the way meet people and how they interact with us, especially the Maoris (laughs) yeah they ask me to find some ah pigs

Kiri: Pigs? (Laughs)

Ronnie: And we bought about three pigs for them and then they ask me to kill the pigs and ask the women to cook them in our traditional cooking...

Kiri: Yeah in a Lotu...?

Ronnie: In a Motu...so relate well with them most times especially the time we go out to see our villages, for some they were quite few and many villages so one day the Army would accompany the group and go back to see their village and see how the, the ex-militants have ah, what they cause and what the damage, yeah so yeah everyday they are patrolling going out with the people to the villages and even to the gardens, people see the gardens at that time, most of the gardens were stolen by the militants, they used them up, so we have to go back and make new gardens, build new houses and yeah, it's really sad you know.

Andrew similarly tied this to a broader understanding of Maori culture and the Pacific way of life: 
Yeah... then the New Zealand Army personnel they would put on a haka, you know, or do something that's very very New Zealand cultural. Because New Zealand appreciate and they understand the Pacific way of life generally. Australia is a continent, the eastern side, the eastern side is aware of the Pacific; the western side is completely alien.... So those were things that were happening when RAMSI was here and this huge difference between New Zealanders and...that also applies not only to the military, but also to the police force. New Zealand police officers were completely different. They would go down the road, they would smile, they would say hello to people. The flaming Australians would not even say hello to a local... They just aloof, very aloof. And I think that situation if they don't understand it going to remain hindrance to Australians respect in the Pacific.

Billy also commented on this stating:

And I think ah, as I've said to you earlier, I mean with the exposure that the different culture, island cultures that you have in New Zealand, sort of prepares them for working here as well...and that's sort of an acceptance... you know, with the culture of the Solomon, the Solomon Island culture in general.

Another aspect of New Zealand soldiers' behaviour that is described positively is a willingness to act outside of rigid military structures. The disciplined approach of Australian soldiers was understood as not reflective of the 'Pacific way' by participants. Higate and Henry (2009) found that Irish soldiers who were perceived as more professional and focussed were more highly regarded in Liberia and it appears for Ronnie that this was true in the immediate period after the conflict. At the same time however New Zealand soldiers were also valued for their ability to act as more than just 'soldiers'. In the following quote Ronnie reflected on this, pointing out that sticking to the rules meant not mixing with local people. This was a serious impediment to engaging in behaviour that is beneficial for peacekeeping:

Ronnie: Oh yeah, the other thing that's in my observation is that I think the other Pacific Island[ers] we flexible yeah...

Kiri: Sorry?

Ronnie: They were flexible, you know - all of them have rules but they are flexible. They don't want to stick around the rules. Like the Australians they comply with the rules and they, they don't want to mix up with people; they always maintain their integrity yeah? So yeah... they're not like the New Zealand and the other Pacific Islanders...

For James, adhering to rules was interpreted as a lack of trust for Solomon Islanders, particularly with regard to consuming local foods. This reaffirms the point made earlier 
in this section - that consuming locally produced food is an important practice for peacekeepers:

They Australian people compared to New Zealand they restrict the soldiers to chew betel nut, even to eat local foods. Even the simple thing as a coconut juice...

Kiri: Yeah?! No?

James: ...they are not allowed, to drink coconut juice. The drink mineral water from Australia, not even brought mineral water from the Solomons... (laughs)...very strict.

Kiri: Wow, what are they scared of? They scared or...?

James: Poisonous or terrorism (laughs) ... But New Zealand people don't think there are terrorists in the Solomons, they feel as if Solomons' people are really peaceful country. Only... what made the tensions is the difference between these provinces Malaita and Guadalcanal. And then the Malaita people use the weapons, government weapons to scare Guadalcanal people.

While in acting 'disciplined' and 'professionally', Australians' behaviours adhere more closely to behaviours associated with militarized masculinity than peacekeeping skills. This demonstrates a failure to value building relationships as an important part of peacekeeping work. However New Zealand soldiers' willingness to not always act in a disciplined manner was not always perceived positively by local residents. The following quote highlights the gendered differences between local men and women's understandings of what kinds of undisciplined behaviours were considered acceptable:

Kiri: ...is there a time when maybe they did something that didn't make people so happy?

James: $\mathrm{mmm}$ as far as I can remember, I remember one guy from NZ he went down to the west of Honiara to a village called Kakabona.

Kiri: Okay, yeah.

James: And they used to take Marijuana (laughs).

Kiri: Okay, the soldiers?! Oh naughty.

James: (Laughs).

Kiri: And that made the locals not happy?

James: Yeah, the young people, these guys who used to smoke Marijuana with the soldiers, both of them happy. But the womens and others - no (laughs). Not really all of us are unhappy actually. They didn't do any wrong thing, only smoke marijuana ... (laughs).

Young men were seen as the most likely to fuel violence, thus soldiers placed importance on gaining their trust (Interview, October 05 Steve, 2012). The behaviour of the soldiers mentioned in James' reflection could be interpreted as attempting to 
gain trust of the young men by adopting local masculinities to 'be one of the boys'. Thus James, who was male and in his twenties, did not see this behaviour as problematic, however he also notes that this was not always perceived positively by "women and 'other' people". This highlights the ways that different expressions of masculinities can be interpreted by men and women, and perhaps across different age groups. Further research into the different ways that local Solomon Island women interpreted soldiers' behaviour could importantly explore the different understandings of different expressions of masculinity in more depth.

\section{"Bae tellim RAMSI come"}

Finally, it is important to pay attention to the perception of some residents that soldiers provided a welcome sense of security at the immediate cessation of the violence, while for others it challenged approaches to conflict resolution that were culturally appropriate in the Solomon Islands. In some of the following quotes we can see that soldiers having the capacity for violence was perceived as an important part of providing protection and creating a sense of security at the immediate cessation of the tensions. However, there is a contradiction in using armed soldiers to create peace in an environment where arms have most recently been used to terrorise civilians. Peacekeeping interventions raise many questions when considering whether their presence is appropriate. In this final section I will consider aspects of local residents' perspectives that discussed the positive and negative implications of having New Zealand, and other participating forces in the Solomon Islands.

In communities emerging from conflict the presence of armed soldiers can restore a sense of security in an often still volatile environment (Higate \& Henry, 2009). For local residents such as Ronnie and members of his village, returning home meant facing immediate dangers. Ronnie was from the Weathercoast region of the Solomon Islands and Ronnie's experience and that of his village were mediated by their violent experience of the conflict. The Weathercoast is the region that the 'notorious' Harold Keke camped out in the jungle. Ronnie explains:

I was living in Honiara until 2003 when RAMSI arrived... because the militants had raided our villages and burned down all our homes and our people escape to Honiara. So we were displaced for six-seven months. We were just living in 
Honiara until RAMSI came and they went to arrest the militants and then after seven months we were repatriated back to our homes. So that is when I first started to work with the RAMSI, especially the New Zealand Army when there were the first ones to [go] across to the Weathercoast. So they went over and they are the ones who look after us and everywhere we go they accompany us, went back to see our village and we go to build homes they accompany us and they're the ones who provide security and protection for our people. Yeah, there were about 1500 people displaced at the time - that were homeless and lost everything....And so that is what army doing during those days...so even when sometimes the ex-militant would appear in the garden and chase the women and children, we come and report that to the police and then straight away the army would respond and go out and search for them in the bush. The army is really having a hard time at that time you know, they really hard time, sacrifice them for our people, the sake of our people, women and children yeah. Sometimes they didn't even have rest, and all day going round with people and even sometimes spend night and day in the bush, try to catch those criminals yeah. So sometimes people really have sympathy with them.

In this quote, Ronnie describes the need for soldiers to protect them from militants in the initial period at the cessation of the tensions. Ronnie appears to also appreciate the way that soldiers pursued this security for his village at the expense of their own comfort, going out of their way to help the local residents. Because of the insecurity created by militants, for Ronnie, soldiers carrying weapons was an important part of giving them a sense of security so they could return home. Ronnie explains this further:

Kiri: How did you feel about them carrying guns?

Ronnie: The people... you know, they don't have problem cause you know we knew that the ex-militant have guns so when they saw the army have guns you know people really appreciate that's, that's what people needed protection yeah. So if the soldiers didn't have gun then it's easy for the militants to shoot our civilians yeah. So that's why everywhere we go the army was having meetings in the villages or communities, the army go with us and protect us. At the time the militants, most militants were still armed and they was just hiding around the bush so people fear that anytime the militants would kill them, us, so the presence of the army really gave confidence to the people and yeah, they feel secure...

Kiri: And so the militants they, when they saw the army came along, they come out and give up their guns or did the army have to go get them?

Ronnie: At the first place the army go out and they surrender the gun but still some of the rest hold onto the guns and not only guns, they armed with knives, the spears and other things yeah, so whenever they meet people, travel alone without the army they threaten them and you know, chase them, so at that time the people will come back to the station and the next day the army would go and search for them with the police and try to arrest them...yeah. 
Rich, a Malaitan living in a Village near Honiara, also expressed a similar sentiment to Ronnie, explaining that having soldiers patrol around their village made people feel safer:

Kiri: Did it make you feel safer for them to be here?

Rich: Yeah.

Kiri: How did they make you safer? Feel safer?

Rich: They stay and patrol around and people were frightened, the people don't want make fighting and so when the army come here from the village we feel safe.

Andrew similarly believed that a show of strength through arms was important for ending illegal activity. However, his comments are also important to note as they suggest that while he believed a show of arms may have been appropriate initially at the cessation of the tensions, the continued presence of weapons well past the initial end of violence became a sign of disrespect to local people. This indicates that if peacekeepers are going to be armed, once the immediate security threat has reduced it is important to quickly transition into peace resolution practices and reduce the obvious visible presence of weapons:

Kiri: How do you feel about the soldiers carrying their guns? Do you think [trails off]

Andrew: For the first part maybe for the first year it was necessary. It wasn't a threat, it was just a like show of a presence that somebody you know don't you know start you know threatening people; don't demand things because it's illegal. So initially it was necessary at the time. But when it dragged on you know for... the next ten years it was absolutely... not necessary. And even now if the people see... army truck driving down the road in Honiara with guns exposed you know it's, it's you know it's insulting.

Andrew: It you know, there's nobody [no local people] carrying guns, nobody shooting. And there was not one bullet fired the whole time they were here.

These quotes demonstrate that for some such as Ronnie and Rich, the soldiers carrying weapons and acting in ways that are more associated with militarized masculinity were positive because it made their village feel safer. Without soldiers' training that prepares them to spend nights not sleeping and pursuing armed militants, local residents such as Ronnie and Rich would not have felt secure enough to return home. Thus, while soldiers were valued by interview participants for their willingness to enact 
peacekeeping skills and demonstrate skills less associated with traditional military masculinities, at times, the sense of security only armed soldiers can provide in this situation was valued.

Higate and Henry (2009) describe the approach of Bangladeshi soldiers in Liberia, who acted with a particular 'humanitarian professionalism'. Interacting directly with local people by sharing food and facilities was intended to "break... down barriers between peacekeepers and people". Their behaviour was seen as receptive to the needs of local residents and "reassuring" (Higate \& Henry, 2009, p. 129). Yet in the Liberian context where the local population was significantly traumatised by the very violent conflict, peacekeepers that were 'tougher' and 'more military' were considered more beneficial by local people. Higate and Henry argue this demonstrates the different ways spaces of security can be produced by peacekeepers' actions. In the case of New Zealand soldiers, we can see that they appear to be producing different 'spaces of security' simultaneously. On one hand, they reassure local residents they are genuine by breaking down the barriers between themselves and local people, by engaging with local people in ways that are convey a sense of equality and respect. Simultaneously, soldiers, with the aid of weapons, benevolently reassure local residents that they can, and will, exert power by enacting more traditional military practices if necessary (Myrttinen, 2004).

Despite the belief held by Ronnie, Rich and Alex that soldiers produced a sense of security, I suggest that the use of weapons and the capacity for violence by peacekeepers can have potentially serious implications for the creating of long-term peace. When we think about armed peacekeepers' presence in the Solomon Islands context, there is a contradiction in peacekeeping using the threat of violence to create peace, and positioning them as somehow different to that of the militants - many of whom only picked up weapons after family members were harmed.

While I was in the Solomon Islands, a common reason that people gave to me to explain the cause of the tensions (both local people and foreigners) in addition to ethic tension, was the belief that the conflict resulted from the opportunism of bored, unemployed men and boys - the view that young men (raskals) had taken advantage 
of ethnic tensions to engage in violence and criminal behaviour. Because of this, the continued presence of groups of men and boys drinking the local brewed alcoholic spirit kwaso and chewing betel nut was a source of unease for some. Furthermore, when talking about ways to prevent further conflict, people noted that they hoped that the growing economy would help reduce these issues by increasing employment for men and boys. However, in these discussions, it seemed to me that there was less attention paid to examining the gendering of why young men had chosen join militias in the first place. I wondered whether this attention to reducing the conflict by economic means, was ignoring the challenges that liberal economic policies and more western cultural values were having on traditional ideas about masculinity.

Dolan (2002) has argued that in many societies men are caught between different forms of masculinity - unable to achieve either 'traditional' or 'modern' forms masculinities, resulting in a 'crisis of the gender $\operatorname{order}^{\prime}$ (Hovde Bye, 2005, p. 80). As a result Dolan suggests that in contexts where there are histories of violence and unstable socio-economic environments, violence may have become a means to achieve a sense of masculinity for some men in response to a perceived 'emasculation'. In the Solomon Islands the prevalence of weapons in the tensions, wielded by younger male militants, can be seen an expression of 'masculinity' and an exercise in power that aligns with aspects of hypermasculinity.

Hyper-masculine militarized masculinity has been described as a form of masculinity that equates manliness with sanctioned use of violence, aggression and force (Marianne Bevan \& MacKenzie, 2012). The use of weapons is an important part of this: "Weapons are used as status symbols but also as tools to achieve economic and social gains, wielding power over unarmed males and females" (Myrttinen, 2004, pp. 30-31). In highly militarized states, power and security is equated with the possession of weapons (Page, 2009). In many circumstances, the possession of guns by young men has meant they have been able to gain a higher degree of influence than what is the cultural norm, and above their community elders. In Sierra Leone, for example, this resulted in the overthrowing of the existing social order by seizing power through force (Page, 2009). With this in mind, the use of armed soldiers from Australia, New Zealand and other Pacific Islands to create peace, has important implications for local 
masculinities and ideas about appropriate ways to solve conflict that need to be examined.

For example, in the following quote Billy explains he felt the carrying of weapons meant local people came to see guns as a way to solve problems - reinforcing the reasons why people chose to arm themselves during the tensions:

Kiri: how did you feel about them carrying their guns around? Did you think it was...

Billy: Ahh, you know, just the sight of them, it is sort of intimidating...in a sense that like ah...l've expressed this several ways, several times...it's intimidating... and it also makes the traditional system sort ineffective.

Kiri: Right, yeah

Billy: In the sense that when... anything happening in the villages, "Oh, I know tellim RAMSI will come" "we will call RAMSI." So I mean everybody, whether it's Australia or New Zealand, it's RAMSI. Yeah...so "bae tellim RAMSI come." So I mean [they are] now talking about streamlining [an] exit strategy, so we come back to where we were. So if then like, for me one of the most important things is to empower... the traditional system in the villages and communities, yeah... Like it's just a mentality that people have, like when [someone] have a gun one have the power here, like you, you're the hero. Yeah so you have the power. So this guy, the chief and the elder in the village does not have the power. So to me I interpret that as an intimidation... Just the sight of it... you know when we had the ethnic tension, I'm a school teacher and you see the small children like that you are teaching in classroom some few years ago, [now] carrying guns. You know, it is, it makes you, you know stupid people like, you know, without any discipline... they can press the trigger anytime, I mean yeah, so... this kind of mentality lingers on, like you see people carrying gun and then when the soldiers come, the only difference is they have their uniform.

In this quote we can see that Billy questions the use of soldiers for resolving the conflict as it undermines culturally appropriate conflict resolution practices. For Billy, the use of guns by RAMSI soldiers, and the threat of violence implicit in this were no different from militants' behaviours - the only difference being that RAMSI soldiers were wearing a uniform. The use of weapons to create peace can be connected to hypermasculine practices and are problematic in post-conflict environments, where weapons have often been used by militants to challenge existing social structures; they can undermine culturally appropriate conflict resolution practices. This can have serious implications for lasting peace once peacekeeping forces have departed. With the departure of the military component of RAMSI from the Solomon Islands this year, 
considering these implications is particularly pertinent. The long-term impacts of this could be serious, because as Billy notes, when people have a problem they have come to rely on RAMSI to resolve these conflicts. This demonstrates that a failure to consider masculinities in peacekeeping means that examining the hypermasculinities that have often led to violence are not highlighted. Furthermore, non-violent masculinities that are important for the long-term promotion of peace continue to be ignored in post-conflict spaces.

\section{Conclusion}

In the previous chapter we saw the way that criticisms of peacekeepers as 'white male heroes' is complicated by soldiers' perception that New Zealanders are more culturally sensitive. In this chapter we can see how this criticism is also interrupted by some local residents' reflections on their interactions with soldiers. I have highlighted that Solomon Islanders are not passive subjects of a peacekeeping mission, and understand different countries' soldiers based on perceptions about broader historical-cultural understandings about different participating forces and their perceived cultural sensitivity. Furthermore, soldiers non-hegemonic behaviours that can be linked with femininity, and alternative masculine practices were most often commented on when discussion centred on New Zealand soldiers acting positively. These positive practices include valuing the need for cross-cultural relationship-building through communication skills, demonstrating empathy, respect for local cultural practices and a willingness to be flexible. Therefore, the everyday challenges soldiers make to militarized masculinities, by conducting themselves in ways that demonstrate respect, empathy and equality are important for mediating the perception that New Zealanders are not present to colonise the Solomon Islands. Yet I have argued that regardless of soldiers' ability to engage with local people in ways that build positive relationships that convey a sense of trust and equality, the carrying of weapons and the ability to use violence to solve conflict has a negative impact on local masculinities, and the creation of long-term peace. 


\section{Chapter Eight: Conclusion}

Generally, I hope that the Solomon Islands experience - if any such incident or uprising did ever come up again in the Pacific - I hope that Australia and New Zealand have learnt something in the Solomons - that they would do things probably, some things maybe different... I think for me it's very important, [it] doesn't matter what happens, you must always understand the background and the culture and the aspirations of the people you are dealing with. And I think that's where... RAMSI would be remembered a bit [with] mixed observation feelings in years to come in Solomon Islands. But for New Zealand, Solomon Islands people always respect New Zealand presence in Solomon Islands for a long time to come [Andrew, 06 June 2012].

\section{Introduction}

The complex practices of masculinities and identity are sometimes rendered invisible when considering gender in the post-conflict development space (Myrttinen, 2008). This is because most often questions of gender are seen as something that affects only women (Nduka-Agwu, 2009). My research has aimed to challenge this orientation by paying critical attention to an emerging area of research that recognises the importance of including men and masculinities in analyses of peacekeeping practices and post-conflict development.

The central aim of this thesis has been to question whether peacekeeping is engendering new identity experiences for New Zealand soldiers and what implications this process may have for conflict resolution and gender equality in post-conflict spaces - such as the Solomon Islands. To do this, I considered the understandings of peacekeeping that two soldiers deployed to the Solomon Islands as part of RAMSI shared. Secondly, I explored the perspectives of seven local Solomon Islanders who engaged with New Zealand soldiers deployed to the Solomon Islands.

In this final chapter, I review the three research questions I posed in the introduction of this thesis and what I found from exploring these questions. I discuss some of the theoretical and practical implications that have resulted from engaging in research into soldiers' gendered identities. Finally, I note some of the shortfalls of my study and conclude with some suggestions for potential future research. 
This thesis is situated across academic disciplines, but is anchored by a shared concern about critically engaging in development practices that are respectful and sensitive of racial and gendered inequalities present in the current discourses of development. While broader attention has been given to questioning the assumptions that underpin 'development' in post-development literature, (eg. Crush, 1995; Escobar, 1995; Ferguson, 1994; Rahnema \& Bawtree, 1997; Sachs, 1992) little attention has been given to the implications of soldiers' presence in the post-conflict development space by post-development academics. However, as the way that we think about development shifts and evolves, new actors in the development space must be considered. In doing so, the complexity of the development experience and the ways that development actors challenge and navigate discourses of development that reinforce inequalities of gender and race can be highlighted.

In conjunction with the little attention given to the implications of soldiers' presence in the post-conflict development space by post-development academics, feminist researchers have increasingly questioned the appropriateness of using soldiers to enforce peace in societies emerging from conflict. They argue that the kinds of violent militarized masculinities traditionally privileged in the military result in problematic expressions of masculinities that increase insecurity, gendered and racial inequalities between peacekeepers and local populations. However, if we understand masculinities as dynamic and changing, then by paying attention to the individual experiences of soldiers we can see that with the changing nature of what is expected of soldiers, alternative ways of behaving and everyday challenges to militarized practices of peacekeeping are increasingly made. This is important to research, as in order to engender non-violent practices of masculine identity that are more conducive to lasting conflict resolution practices, light must be shed on individual resistances to militarized masculinities.

\section{Summary of Analysis}

In Chapter Five I considered my first research questions: What forms of masculinity are evident from the understandings of two New Zealand soldiers and what forms of masculinity are valued in these narratives? In what ways do they challenge the hegemony of militarized masculinities? By analysing Steve and Henry's reflections 
about their mission to the Solomon Islands, I suggested that they valued and understood the need for non-violent conflict resolution and relationship-building skills that are most effective for bringing about peace in the Solomon Island context, but at the same time, they still valued aspects of the military that are linked to militarized masculinities and violence. I have argued that this is because a soldier's expertise continues to rest with his or her ability to inflict violence (Haaland, 2012, p. 64). However, at the same time, the enjoyment and success that these two individual soldiers derived from interacting with local Solomon Islanders conveyed a different story about what individual soldiers valued as part of their role. This behaviour shows that some soldiers offer challenges and resistances to militarized masculinity, which aligns with the findings of Duncanson $(2007 ;$ 2009). She noted there is significant tension within British soldiers' discourses about the skills that are seen as useful to achieving the aims of peacekeeping, but still valuing the violence-orientated masculinities traditionally valued in the military.

Finally, I outlined in this chapter that both Steve and Henry demonstrated that they valued practices of peacekeeping that align with 'task-orientated' masculinity (Bevan \& MacKenzie, 2012). In doing so, I argued that Steve and Henry's valuing of these masculinities potentially demonstrates the way that hegemonic masculinities can shift and evolve in such ways that the distribution of power and respect is unchallenged. However, I further argued that if 'task-orientated' masculinities are co-opted instead to promote the importance of gender and cultural sensitivity at the cessation of conflict, then those task-orientated masculinities can hold great potential for reworking and engendering non-violent masculinities in peacekeeping.

As well as highlighting the ways that Steve and Henry demonstrated practices of masculinity in their peacekeeping, I have explored other aspects of identity that Steve and Henry drew on to frame their peacekeeping practices. In Chapter Six I considered my second research question: In what ways do other intersections of identity frame peacekeeping in the soldiers' understandings? Through this question I have demonstrated that the way these two New Zealand soldiers understood and conceptualised their role as peacekeepers was framed by the Solomon Islands being somewhere in need of help. However, I also proposed that ideas about nationality and 
New Zealanders being 'good at' being culturally responsive are important for framing how soldiers understand their presence as peacekeepers. This is because they see New Zealand soldiers' intervention in the Solomon Islands as more legitimate and effective because of their ability to be more culturally sensitive. I have argued that this belief is based on perceived ideas about New Zealand's bicultural and multicultural history, and the presence of Maori in the Army. Moreover, comparisons with the 'racist' behaviour of Australian soldiers, and admiration for Pacific Island soldiers, indicate new understandings of what is valuable to peacekeeping behaviour. Thus their praise of other participating forces from Pacific Island countries not only resists militarized conceptions of masculinity, they also challenged the construction of 'white western' soldiers as most effective in bringing about peace and 'development' in the Solomon Islands.

In Chapter Seven I argued that in order to not construct Solomon Islanders as passive subjects of a peacekeeping mission, it is imperative to explore local residents' reflections about their interactions with soldiers. In this chapter I focussed on exploring my third research question: What understandings of peacekeepers are evident in Solomon Islanders' reflections on engagements with New Zealand soldiers during RAMSI? Thus in Chapter Seven I shifted my attention away from Steve and Henry, to exploring the data collected from interviewing seven Solomon Islanders. In doing so, I noted that Solomon Islanders' understanding of peacekeeping is interpreted through broader historical-cultural perceptions about different participating forces and their perceived cultural sensitivity. In conjunction with this, at the level of everyday interactions with soldiers, local residents evaluated their behaviour as positive based on practices that have traditionally been more associated with alternative masculine and feminine practices. These practices included valuing the need for cross-cultural relationship building through communication skills, demonstrating empathy, respect for local cultural practices and willingness to be flexible. Therefore, everyday challenges soldiers made to militarized masculinities in peacekeeping were important for underlining to local residents that New Zealanders were not present to colonise the Solomon Islands. However, on a final note, I argued that regardless of this ability of soldiers to engage with local people in ways that are positive for building everyday relationships of trust and equality, the carrying of 
weapons, and the ability to use violence to solve conflict that this implies, can have a negative impact on local masculinities, and the creation of long-term peace.

\section{Theoretical Implications}

While the NZDF withdrew from the Solomon Islands in November 2012, the conclusions I have drawn from my research have practical implications for current and future incidences of peacekeeping that the NZDF and the New Zealand Army decide to undertake if they are to increasingly enter the 'development' space.

This thesis has highlighted that when investigating the gendered experience of soldiers engaged in peacekeeping, we must be careful not to treat men's identities as static and unconnected to historical and cultural practices and understandings. While I have used a small sample of just two soldiers involved in peacekeeping, Steve and Henry's experiences and understandings of peacekeeping demonstrate that contrary to some feminist discourses on militarized masculinity, soldiers are not monolithically violenceorientated when conflict resolution is necessary.

Thus, in recognising masculinities as fluid patterns of ideologies and practices constructed though interactions (Barrett, 2001), I have demonstrated that soldiers' practices are in a process of change in response to the changing nature of soldiering. The need for soldiers to create security by engaging in practices that focus culturally appropriate and equal communication and relationship building is engendering new ideas about masculinity in the military.

Similarly, the value that local participants placed on soldiers' practices that challenged militarized masculinities, also demonstrates the importance of paying attention to fluid and relational constructions of masculinity. This is contrary to the majority of existing literature on militarized masculinities, which has argued that soldiers in the post-conflict development space are not conducive to increasing notions of security that include gender equality (Cockburn \& Zarkov, 2002; Enloe, 1983; Whitworth, 2004). 
Additionally, in considering aspects of soldiers' identity that intersect with masculinities, my research has demonstrated that in exploring peacekeeping practices, criticisms of peacekeeping that understand peacekeeping soldiers as inherently colonial in nature where 'white, western heroes attempt to save the third world' (Whitworth, 2004; Duncanson, 2007), are complicated by both soldiers and Solomon Islanders' understanding of the different participating forces in RAMSI. This argument has further demonstrated the importance of exploring the everyday experiences (Duncanson, 2007; Higate \& Henry, 2010) of soldiers and local people on the ground. Generalised narratives about peacekeeping fail to consider aspects of soldiers' practices that hold the potential to challenge the unequal relationships of development if brought to the fore.

Continued valourisation of military masculinity, and the negative way that local residents perceived these practices, indicates that when thinking about the implications for men and masculinity in the RAMSI mission more broadly, a failure of RAMSI to consider gender issues widely across the whole mission, right from the beginning of the intervention is problematic when it translated into the practices of soldiers on the ground. While gender considerations are emphasised in much of development practice, the lack of gender training for soldiers that reflects on the impact that their presence may have for gender is potentially damaging for valuing non-violent conflict resolutions in the post-conflict space. This lack of specific gender training is potentially even more precarious in an environment such as Afghanistan, where soldiers are unable to rely on similarities in Pacific cultures to understand the gendered implications of their practices.

Even in the Solomon Islands it is imperative to note this lack of gender specific training. While soldiers were trained in ways that highlighted the importance of being non-aggressive, empathetic and respectful of cultural differences when interacting with local people, this kind of training is still disconnected from discussions of gender. It is important to question this gap in training because, as Charlesworth (2008) has noted, the wider assumptions of RAMSI personnel about the 'traditional role' of women in the Solomon Islands as reticent, has meant women were excluded from peace processes. Thus, in the context of soldiers' everyday engagements with local 
people, a failure to talk to women, or approach them in a way that suggest they hold power, reinforces their exclusion from gaining respect and equality in post-conflict Solomon Islands.

On a final note, it is also imperative to highlight the underlying implications of using armed soldiers to create and enforce peace in societies recently emerging from conflict. Teaiwa argues that "as a culture of masculinity, militarism entails both a disciplining of bodies and a disciplining of social relations" (Enloe, 1990; Teaiwa, 2005b, p. 206). The process of militarization is the privileging of military solutions over all other avenues of action. Thus the presence of armed peacekeepers at the cessation of conflict reinforces and disciplines Solomon Islanders in such a way that conflict resolution practices that are non-violent (and most often associated with femininity) are ignored or not valued so highly.

Furthermore, as Myrttinen notes "given the delicate nature of peacekeeping operations... overt displays of militarized masculinity may end up backfiring, intimidating and alienating the local population" (Myrttinen, 2004, p. 32).Thus, regardless of soldiers' ability to engage with local residents in ways that build positive relationships of trust and demonstrate a sense of equality at an everyday level, in conflicts such as that in the Solomon Islands where the prevalence of weapons were important for determining who held power, the carrying of weapons by soldiers carries an underlying message about appropriate ways to solve conflict. Therefore, I would argue that while peacekeeping is engendering new, less violence-orientated masculinities within the military, the continued carrying of weapons by soldiers potentially impacted negatively on culturally appropriate conflict resolution practices in the Solomon Islands. As a result, ideas about appropriate ways to solve conflict are potentially militarized by the presence of weapons.

\section{Recommendations}

When thinking about the implications of this research for development and security practice some recommendations arise regarding the way that New Zealand Army personnel are trained and the values that underpin their approach to peacekeeping. 
Firstly, and most importantly the lack of gender training for deploying soldiers should be addressed ${ }^{30}$. Gender training that understands gender as not only relating to women, but to men and masculinities would be especially beneficial for New Zealand soldiers. This could focus on aspects of soldiers' practices that are positive for creating equality and respect, and pointing out why other practices are not. I have noted that if task-orientated masculinities are co-opted instead to consider the importance of gender and cultural sensitivity at the cessation of conflict, then task-orientated masculinities can hold great potential for engendering non-violent masculinities in peacekeeping. Perhaps if soldiers are aware of hegemonic forms of masculinity as not inherent, but rather a construct, then deciding to act differently is made more possible.

Additionally, while New Zealand soldiers should be complimented for demonstrating respect and conveying a sense of equality towards local people in the Solomon Islands context, it is important not to become complacent about cultural awareness because New Zealand soldiers understand themselves as 'good at it'. As comments from both Steve and Henry indicated, soldiers value training that prepares them for cultural aspects of their deployment. Continuing to value this aspect of the New Zealand Army should be frequently built on with training that adapts and changes. Equipping soldiers with not only the knowledge about the historical relationship between New Zealand and the host community, but also ways to engage with local residents in appropriate ways that adapt to changes in this relationship throughout a deployment should be continually emphasised in training.

\section{Limitations and New Areas of Research}

When making conclusions and exploring the implications of my research, it is important to acknowledge that there are several limitations placed on the conclusions I have found, and areas where future research would be beneficial.

The difficulties I faced in gaining permission to interview both Regular Force and Reserve Force soldiers through the NZDF was a significant limitation to the breadth of

\footnotetext{
${ }^{30}$ I recognise that my assumption that there is little to no gender training for soldiers deploying overseas is based only on the two interviews I conducted with Reserve Force soldiers deployed several years ago. My hope is that this has since been rectified and this recommendation is thus irrelevant.
} 
my results and conclusions. While my focus was on the everyday individual negotiations of identity by Steve and Henry, the understanding that masculinities in the military are fluid would be augmented with further interviews that included the diversity of differences in the forces, such as; rank, job specialisation, age group, gender, Reserve Force, Regular Force and ethnicity. For example, including the perceptions of both Maori and Pakeha soldiers would be valuable as it could highlight different understandings of peacekeeping in the context of this thesis discussion about New Zealand soldiers as 'more' culturally sensitive because of the presence of Maori in the Army. Moreover, as one Reserve Force participant stated, he believed the Reserves represent a less militarized force than the Regular Forces. This perception is interesting to note and I believe that further interviews exploring the differences between Reserve Forces and Regular Forces could highlight the fluidity of gender across the force.

Similarly, while I have attempted to draw attention to men and masculinities in this thesis, I recognise that gender subjectivities are experienced by women as well. Thus I recognise the small presence of local women's perceptions in this thesis, and none from soldiers who are women. Regarding women soldiers, it was never the aim of this thesis to explore their experiences of masculinities in peacekeeping. However, I do believe this is an important avenue of future research in order to understand how understandings and expressions of masculinities in the New Zealand Army affect the soldiering practices of women.

While in the Solomon Islands I sought interviews with both men and women about RAMSI soldiers, however luck and health conspired against me and interviews that I had planned with individual women fell through or I had to cancel due to illness. Further interviews with local women would enrich gendered and cultural understandings of peacekeepers explored in this thesis.

Finally, further research into local practices of masculinity in the Solomon Islands would provide a valuable perspective on local masculinities. I have noted that a failure to consider gender in a way that takes into account masculinities means soldiers may fail to consider the broader implications of their practices on how local men 
understand masculinities. Further research into local men and masculinities, and the way that soldiers' masculinities relate to this, would be valuable for challenging gendered practices that reinforce the valorisation of hypermasculinity in post-conflict communities. In doing this, it would be important to pay attention to the expressions of masculinity that challenge and resist hegemonic forms of masculinity, as this brings to the fore alternative masculinities and femininities that are more conducive to nonviolent conflict resolution.

\section{Final Thoughts}

The best way of expressing that solidarity with others in faraway places may not always be to use force in the faraway places they live in (Baker, 2012, p. 571).

A recent leaked report looking into the deaths of five New Zealanders in Afghanistan in 2012, written by a sergeant in the NZDF's military intelligence, highlighted "the aggressive stance of one senior officer with a tactical role, neglected relationshipbuilding skills with Afghan local people, which are always highly prized as a critical part of New Zealand's ability to maintain calm in Bamiyan" as he "want[ed] to turn Bamiyan into a more war-fighting role" (Fisher, 2013). This highlights that in some cases the valuing alternative approaches to conflict resolution practices for New Zealand soldiers, can literally mean the difference between life and death. Reflecting on the title of this research project, I have frequently thought about what engaging in the 'hearts and minds' approach means for peacekeeping, and post-conflict development more generally. To me, the idea of 'winning hearts and minds' that I encountered informally during my research (such as the New Zealand 'Army News') implies a commitment to engage with local people in ways that are non-violent and that do not rely on the valourisation of strength and force over others to achieve the goal of 'peace'. In order to do this, it is vital to pay attention to everyday and complex engagements between soldiers and local residents that challenge homogenous constructions of this relationship. Only in doing this can we highlight and value nonhegemonic practices of masculinity and femininities that are more conducive to the creation of lasting peace. 
As Connell (2000, pp. 29-30) notes:

Some of the qualities in "traditional" definitions of masculinity (eg. courage, steadfastness, ambition) are certainly needed in the cause of peace... The task is not to abolish gender but to reshape it; to disconnect (for instance) courage from violence, steadfastness from prejudice, ambition from exploitation.

My hope is that this thesis has challenged existing ideas about soldiers acting as peacekeepers in the post-conflict development space and demonstrated that by highlighting the fluidity of practices of gender, and other understandings of identity then conflict resolution practices may become "valourised by everyone, but not because of any linkage to masculinity" (Duncanson, 2007, p. 211). As a result, perhaps the dignity of individual men and women to be involved and understood as nonviolent in peace negotiations can be brought to the fore. 


\section{Bibliography}

Abrahamsen, R. (2004). A Breeding Ground for Terrorists? Africa and Britian's War on Terrorism. Review of African Political Economy, 31(102), 677-684.

Australian Civil Military Centre. (2012). Same Space - Different Mandates: A Civil Military Guide to Australian Stakeholders in International Disaster and Conflict Response (pp. 1-77). Australia.

Allen, M. (2006). Dissenting voices: local perspectives on the Regional Assistance Mission to Solomon Islands. Pacific Economic Bulletin, 21(2), 194-201.

Allen, Matthew. (2007). Greed and Grievance in the Conflict in Solomon Islands 19982003 (PhD dissertation). The Australian National University, Canberra.

Amnesty International. (2004a). Solomon Islands: Women Confronting Violence (No. 43/001/2004) (pp. 1-59). Amnesty International. Retrieved from http://www.amnesty.org/en/library/asset/ASA43/001/2004/en/f9274312d581-11dd-bb24-1fb85fe8fa05/asa430012004en.pdf

Amnesty International. (2004b). UNHCR | Refworld | Amnesty International Report 2004 - Solomon Islands. UNHCR. Retrieved November 4, 2012, from http://www.unhcr.org/refworld/publisher,AMNESTY,,SLB,40b5a20110,0.html

Arkin, W., \& Dobrovsky, L. (1990). Military Socialization and Masculinity. In Making War, Making Peace: The Social Foundations of Violent Conflict. Belmont, CA: Wadsworth Publishing Company.

Army News. (2007, March 13). 'Welcome Back Kiwis: Solomons Diary'. Army News. Wellington [N.Z.]. 
Aroussi, S. (2009). Women, Peace, and Security: Moving Beyond Feminist Pacifism. In Destablising gender in conflict, peacemaking and care. Presented at the PSA Annual Conference, University of Ulster.

Baker, C. (2012). Annica Kronsell. Gender, Sex, and the Postnational Defense: Militarism and Peacekeeping. International Feminist Journal of Politics, 14(4), 569-572. doi:10.1080/14616742.2012.726100

Barnes, K. (2006). Building an Inclusive Security Sector: How the EU can support gender-sensitive security sector reform in conflict affected contexts. Brussels: Initiative for Peace.

Barrett, F. J. (2001). The Organisational Construction of Hegemonic Masculinity: The Case of the US Navy. In The Masculinities Reader (pp. 78-99). Cambridge, UK; Malden, MA: Polity; Blackwell Publishers.

Beaudet, P., Haslam, P. A., \& Schafer, J. (2012). Introduction to international development: approaches, actors, and issues. Don Mills, Ont.: Oxford University Press.

Bell, C. (1996). Inventing New Zealand: everyday myths of Pakeha identity. Auckland: Penguin Books.

Bellamy, A. J. (2010). Understanding peacekeeping (2nd ed.). Cambridge, UK; Malden, MA: Polity.

Bevan, M. (2011). "The Hero Stuff"and the "Softer Side of Things": Exploring Masculinities in Gendered Police Reform in Timor-Leste. Victoria University of Wellington.

Bevan, Marianne, \& MacKenzie, M. (2012). Cowboy Policing: Observing Policing Masculinities in East Timor. International Feminist Journal of Politics, 14(4). 
Brockington, D., \& Sullivan, S. (2003). Qualitative Research. In Development Fieldwork: a Practical Guide (pp. 58-75). London; Thousand Oaks, California: SAGE.

Burnham, P., Gilland, W., Grant, W., \& Layton-Henry, Z. (2004). Research Methods in Politics. Basingstoke: Palgrave Macmillan.

Capie, D. (2012). New Zealand's Involvement in Peacekeeping. Te Ara/The Encyclopedia of New Zealand. Retrieved October 2, 2012, from http://www.teara.govt.nz/en/peacekeeping/1

Carpenter, C. (2001). Innocent Women and Children: Gender in Discourse of Justified Intervention. American Political Science Association.

Carpenter, C. (2002). Gender Theory in World Politics: Contributions of a Nonfeminist Standpoint? International Studies Review, 4(3), 153-165.

Carreiras, H. (2010). Gendered Culture in Peacekeeping Operations. International Peacekeeping, 17(4), 471-485.

Carrigan, T., Connell, R., \& Lee, J. (1985). Towards a New Sociology of Masculinity. Theory and Society, 5(14), 551-604.

Carver, T. (1996). Gender is Not a Synonym for Women. Boulder: L. Rienner.

Charlesworth, H. (2008). Are Women Peaceful? Reflections on the Role of Women in Peace-Building. Feminist Legal Studies, 16(3), 347-361.

Clark, H. (2003, July 24). Address at Ceremony to Farewell Solomon Islands Contingent. $\begin{array}{lll}\text { Wellington } & \text { [N.Z.]. } & \text { Retrieved }\end{array}$ http://www.beehive.govt.nz/speech/address-ceremony-farewell-solomonislands-contingent

Cockburn, C., \& Enloe, C. (2012). Militarism, Patriarchy and Peace Movements. International Feminist Journal of Politics, 14(4), 550-557. 
Cockburn, C., \& Zarkov, D. (2002). The postwar moment: militaries, masculinities and international peacekeeping, Bosnia and the Netherlands. London: Lawrence \& Wishart.

Connell, R. (1987). Gender and Power: Society, the Person, and Sexual Politics. Stanford, Calif: Stanford University Press.

Connell, R. (2002). Masculinities: the Reduction of Violence, and the Pursuit of Peace. In The Post War Moment: Militaries, Masculinities and International Peacekeeping. London: Lawrence \& Wishart.

Connell, R. W. (1995). Masculinities (1st ed.). Cambridge: Polity Press.

Connell, R. W. (2000). Arms and the man: using the new research on masculinity to understand violence and promote peace in the contemporary world. In Male Roles, Masculinities and Violence: a culture of peace perspective. Paris: UNESCO.

Connell, R. W. (2001). The Social Organization of Masculinity. In The Masculinities Reader (pp. 30-51). Cambridge: Polity; Blackwell Publishers.

Connell, R. W., \& Messerschmidt, J. (2005). Hegemonic Masculinity: Rethinking the Concept. Gender \& Society, 19(6), 829-859.

Cornwall, A. (1997). Men, masculinity and "gender in development." Gender \& Development, 5(2), 8-13.

Crush, J. S. (1995). Power of Development. London; New York: Routledge.

Davidson, J., Bondi, L., \& Smith, M. (Eds.). (2005). Emotional Geographies. Aldershot, England; Burlington, VT: Ashgate.

Demetriou, D. (2001). Connell's Concept of Hegemonic Masculinity: A Critique. Theory and Society, 30, 337-361. 
Denzin, N. K., \& Lincoln, Y. S. (2000). Handbook of Qualitative Research (2nd ed.). Thousand Oaks, Calif: Sage Publications.

Department of Foreign Affairs and Trade. (2012). Solomon Islands Country Brief. Australia. Retrieved November 5, 2012, from http://www.dfat.gov.au/geo/solomon_islands/solomon_islands_brief.html

Dinnen, S., \& Firth, S. (2008). Politics and state building in Solomon Islands. Canberra: ANU E Press; Asia Pacific Press.

Diprose, G., Thomas, A. C., \& Rushton, R. (2013). Desiring more: complicating understandings of sexuality in research processes. Area (Forthcoming).

Dolan, C. (2002). Collapsing Masculinities and Weak States - a Case Study of Northern Uganda. In Masculinities Matter! Men, Gender and Development (pp. 57-83). London: Zed Books.

Duffield, M. R. (2001). Global governance and the new wars: the merging of development and security. London and New York: Zed Books.

Dumont, J.-P. (1978). The Headman and I: Ambiguity and Ambivalence in the Fieldworking Experience. Austin: University of Texas Press.

Duncanson, Claire. (2007). Forces for Good? British Military Masculinities on Peace Support Operations. The University of Edinburgh, Edinburgh.

Duncanson, Claire. (2009). Forces for Good? Narratives of Military Masculinity in Peacekeeping Operations. International Feminist Journal of Politics, 11(1), 6380.

Dunn, K. (2010). Interviewing. In Qualitative Methods in Human Geography (3rd ed.). USA: Oxford University Press.

England, K. V. L. (1994). Getting Personal: Reflexivity, Positionality, and Feminist Research. The Professional Geographer, 46 (1), 80-89. 
Enloe, C. H. (1983). Does khaki become you?: the militarisation of women's lives. Boston, Mass.: South End Press.

Enloe, C. H. (1990). Bananas, beaches and bases: making feminist sense of international politics. Berkeley: University of California Press.

Enloe, C. H. (1993). The Morning After Sexual Politics at the end of the Cold War. Berkeley: University of California Press.

Escobar, A. (1995). Encountering development: the making and unmaking of the Third World. Princeton, N.J.: Princeton University Press.

Esteva, G. (1992). Development. In The Development Dictionary. London: Zed Books.

European Institute for Gender Equality. (2006). What is gender-based violence? European Union. Retrieved from http://eige.europa.eu/content/about-eige

Evans, M. (2010). Feeling Their Way: Four men talk about fatherhood in Valparaíso, Chile. Victoria University of Wellington, Wellington [N.Z.].

Evans, M. (2012). Feeling my way: emotions and empathy in geographic research with fathers in Valparaíso, Chile. Area, 44(4), 503-509.

Farr, V., Myrttinen, H., \& Schnabel, A. (Eds.). (2009). Sexed pistols: the gendered impacts of small arms and light weapons. Tokyo; New York: United Nations University Press.

Ferguson, J. (1994). The Anti-Politics Machine: "Development," Depoliticization, and Bureaucratic Power in Lesotho. Minneapolis: University of Minnesota Press.

Fisher, D. (2013, February 16). Training for Army Fighters Blasted. New Zealand Herald. $\begin{array}{lll}\text { New } & \text { Zealand. } & \text { Retrieved }\end{array}$ http://www.nzherald.co.nz/nz/news/article.cfm?c_id=1\&objectid=10865764

Fraenkel, J. (2004). The manipulation of custom: from uprising to intervention in the Solomon Islands. Wellington [N.Z.]: Victoria University Press. 
Gilbert, M. R. (1994). The Politics of Location: Doing Feminist Research at "Home". The Professional Geographer, 46(1), 90-96.

Goldstein, J. S. (2003). War and Gender: How Gender Shapes the War System and Vice Versa. Cambridge: Cambridge University Press.

Greener, B. (2005). RAMSI: The New Zealand Experience. In Securing a Peaceful Pacific. Christchurch, N.Z.: Canterbury University Press.

Greener, B., Fish, W., \& Tekulu, K. (2011). Peacebuilding, gender and policing in Solomon Islands. Asia Pacific Viewpoint, 52(1), 17-28.

Greener-Barcham, B. (2007). Crossing the Green or Blue Line? Exploring the MilitaryPolice Divide. Small Wars \& Insurgencies, 18(1), 90-112.

Haaland, T. L. (2012). Friendly War-Fighters and Invisible Women: Perceptions of Gender and Masculinities in the Norwegian Armed Forces on Missions Abroad. In Making gender, making war: violence, military and peacekeeping practices (pp. 63-75). New York, NY: Routledge.

Haddad, S. (2010). Teaching Diversity and Multicultural Competence to French Peacekeepers. International Peacekeeping, 17(4), 566-577.

Hager, N. (2011). Other people's wars: New Zealand in Afghanistan, Iraq and the war on terror. Nelson, N.Z.: Craig Potton Publishing.

Hameiri, S. (2011). Reality Check: The Critique of the Liberal Peace Meets the Politics of State-Building. In A Liberal Peace? The Problems and Practices of Peacebuilding (pp. 191-208). London; New York: Zed Books.

Hansen, L. (2007). Security as practice : discourse analysis and the Bosnian war. London [u.a.]: Routledge.

Hay, I. (2010). Qualitative research methods in human geography. Oxford; New York: Oxford University Press. 
Hearn, J. (2012). Men/Masculinities: War/Militarism - Searching (for) the Obvious Connections? In Making gender, making war: violence, military and peacekeeping practices. New York, NY: Routledge.

Henderson, J., \& Watson, G. (2005). Securing a peaceful Pacific. Christchurch, N.Z.: Canterbury University Press.

Hendricks, C., \& Hutton, L. (2008). Defence Reform and Gender. In Gender and Security Sector Reform Toolkit (pp. 1-22). Geneva: DCAF, OSCE/ODIHR, UN-INSTRAW.

Heron, B. (2007). Desire for development: whiteness, gender, and the helping imperative. Waterloo, Ont.: Wilfrid Laurier University Press.

Higate, P. (2004). Engendering (In)security in Peace Support Operations. Security Dialogue, 35(4), 481-498.

Higate, P. (2007). Peacekeepers, Masculinities, and Sexual Exploitation. Men and Masculinities, 10(1), 99-119.

Higate, P. R., \& Henry, M. (2009). Insecure spaces peacekeeping In Liberia, Kosovo and Haiti. London; New York: Zed Books.

Higate, Paul. (2003). Military masculinities: identity and the state. Westport, Conn.: Praeger.

Higate, Paul, \& Cameron, A. (2006). Reflexivity and Researching the Military. Armed Forces \& Society, 32(2), 219-233.

Higate, Paul, \& Henry, M. (2010). Space, Performance and Everyday Security in the Peacekeeping Context. International Peacekeeping, 17(1), 32-48.

Higgins, K. (2008). Outside in: A volunteer's reflections on a Solomon Islands Community Development Program (Vol. 3). Canberra, A.C.T: SSGM ANU.

Hoadley, S. (2005). Pacific Island Security Management By New Zealand \& Australia: Towards A New Paradigm (working paper). Centre for Strategic Studies: Victoria 
University of Wellington, 20(05). Retrieved from http://www.victoria.ac.nz/css/docs/working_papers/wp20.pdf

Hockey, J. (2003). No More Heroes: Masculinity in the Infantry. In Military Masculinities: Identity and the State (pp. 15-27). Westport, Conn.: Praeger.

Hooper, C. (2001). Manly states: masculinities, international relations, and gender politics. New York: Columbia University Press.

Hovde Bye, H. (2005). The Fight Against Domestic Violence In East Timor: Forgetting the Perpetrators (Master in Peace and Conflict Transformation). University of Tromso, Tromso.

Hudson, H. (2005). Peacekeeping Trends and Their Gender Implications. In Gender, Conflict and Peacekeeping. Lanham: Rowman \& Littlefield.

James, B. (1994). Gender, culture, and power: challenging New Zealand's gendered culture (Rev. ed.). Auckland; New York: Oxford University Press.

Kearns, R. A. (2010). Seeing With Clarity: Understanding Observational Research. In Qualitative Methods in Human Geography (pp. 241-258). Oxford: Oxford University Press.

Kezar, A. (2003). Transformational Elite Interviews: Principles and Problems. Qualitative Inquiry, 395-415.

Kirby, P., \& Henry, M. (2012). Rethinking Masculinity and Practices of Violence in Conflict Settings. International Feminist Journal of Politics, 14(4), 445-449.

Kobayashi, A. (1994). Coloring the Field: Gender, "Race," and the Politics of Fieldwork. The Professional Geographer, 46(1), 73-80.

Kronsell, A., \& Svedberg, E. (2012). Making gender, making war: violence, military and peacekeeping practices. New York, NY: Routledge. 
Office if the Special Advisor on Gender Issues and Advancement of Women. Landmark resolution on Women, Peace and Security (Security Council resolution 1325) (n.d.). Retrieved February 12, 2013, from http://www.un.org/womenwatch/osagi/wps/

Leslie, H., \& Boso, S. (2003). Gender-related violence in the Solomon Islands: The work of local women's organisations. Asia Pacific Viewpoint, 44(3), 325-333.

Leslie, H., \& Storey, D. (2003). Entering the Field. In Development Fieldwork: a practical guide. SAGE.

Letherby, G. (2003). Feminist Research in Theory and Practice. Buckingham; Philadelphia: Open University Press.

Lorentzen, L. A., \& Turpin, J. E. (Eds.). (1998). The Women and War Reader. New York: New York University Press.

Mansvelt, J., \& Berg, L. D. (2010). Writing Qualitative Geographies, Constructing Geographical Knowledges. In Qualitative Methods in Human Geography. Oxford: Oxford University Press.

Martin, J. (2011, February 15). Our Army - Trustworthy, Dedicated and Professional. NZ Army News, (417), 1-27.

Mattingly, D. J., \& Falconer-Al-Hindi, K. (1995). Should Women Count? A Context for the Debate. The Professional Geographer, 47(4), 427-435.

Mazurana, D. E., Raven-Roberts, A., \& Parpart, J. L. (Eds.). (2005). Gender, Conflict, and Peacekeeping. Lanham, MD: Rowman \& Littlefield.

McDowell, L. (1994a). Polyphony and Pedagogic Authority. Area, 26, 241-248.

McDowell, L. (1994b). Doing gender: feminism, feminists and research methods in human geography. Transactions of the Institute of British Geographers, 17(4), 339-146. 
Meintjes, S., Pillay, A., \& Turshen, M. (2001). The Aftermath: Women in Post-War Transformation. London; New York: Zed Books.

Michael, K., \& Ben-Ari, E. (2010). Contemporary Peace Support Operations: The Primacy of the Military and Internal Contradictions. Armed Forces \& Society, 37(4), 657-679.

Miller, L. L., \& Moskos, C. (1995). Humanitarians or Warriors?: Race, Gender, and Combat Status in Operation Restore Hope. Armed Forces \& Society, 21(4), 615637.

Mohanty, C. (1988). Under Western Eyes: Feminist Scholarship and Colonial Discourses, Autumn(30), 61-88.

Morgan, D. (2004). Theater of War: Combat, the Military and Masculinities. In Theorizing Masculinities. Virginia: Sage Publications.

Morgan, M. G., \& McLeod, A. (2006). Have we failed our neighbour? Australian Journal of International Affairs, 60(3), 412-428.

Moser, C. O. N. (1993). Gender planning and development: theory, practice, and training. London; New York: Routledge.

Myrttinen, H. (2004). "Pack Your Heat and Work the Streets"-Weapons and the Active Construction of Violent Masculinities. Women and Language, 27(2), 29-34.

Myrttinen, H. (2008). Violent Islands - Notes on Masculinities and Security Sector Reform Processes in Haiti, Solomon Islands and Timor Leste (pp. 76-90). Berlin: Free University Berlin.

Nanda, M. (2002). Do the Marginalized Valourize the Margins? Exploring the Dangers of Difference. In Feminist Post-Development Thought (pp. 1-357). New York: Zed Books. 
Navy Memories. (Nd.) Guadalcanal. Retrieved from

http://navy.memorieshop.com/Adair/Cruise-Book/Guadalcanal.html.

Nduka-Agwu, A. (2009). "Doing Gender" After the War: Dealing with Gender Mainstreaming and Sexual Exploitation and Abuse in UN Peace Support Operations in Liberia and Sierra Leone. Civil Wars, 11(2), 179-199.

New Zealand Aid Agency. (2012). Solomon Islands | New Zealand Aid Programme. New Zealand Ministry of Foreign Affairs and Trade. Retrieved November 6, 2012, from http://www.aid.govt.nz/where-we-work/pacific/solomon-islands

Newsome, B. (2007). Made, Not Born: Why Some Soldiers Are Better Than Others. Westport, Conn.: Praeger Security International.

Nielsen, J. . (Ed.). (1990). Feminist Research Methods: Exemplary Readings in the Social Sciences. Boulder, Colo.: Westview.

Niva, S. (1998). Tough and Tender: New World Order, Masculinity and the Gulf War. In The "Man Question" in International Relations. Boulder (Colo.): Westview.

The NGO-Military Contact Group. (n.d.). Sharing the Space: A Guide to Constructive Engagement with Non-Governmental Organisations and the Aid Community (pp. 1-12). United Kingdom.

New Zealand Army. (2011, February 14). NZ Army - Culture \& History. NZ Army, Ngati Tumatauenga. Retrieved February 11, 2013, from http://www.army.mil.nz/culture-and-history/

New Zealand Army. (2012a). NZ Army - Welcome. The New Zealand Army/Ngati Tumatauenga. Retrieved November 6, 2012, from http://www.army.mil.nz/

New Zealand Army. (2012b). Army Reserve (Territorial Force) | Defence Careers. Defence Careers. Retrieved November 6, 2012, from http://www.defencecareers.mil.nz/army/reserves 
New Zealand Defence Force. (2010). Defence White Paper 2010 (pp. 1-96). Wellington [N.Z.]: Ministry of Defence.

O’Reilly, M. (2012). Muscular Interventionism. International Feminist Journal of Politics, 14(4), 529-548.

Olsson, L., \& Tryggestad, T. L. (Eds.). (2001). Women and International Peacekeeping. London; Portland, OR: F. Cass.

Orford, A. (1999). Muscular Humanitarianism: Reading the Narratives of the New Interventionalism. European Journal of International Law, 10(4), 679-711.

Otto, D. (2006). A sign of "weakness"? Disrupting gender uncertainties in the implementation of Security Council Resolution 1325. Michigan Journal International Law, 13, 113-175.

Overton, J., \& Murray, W. E. (2003). Designing Development Research. In Development Fieldwork: a Practical Guide. London; Thousand Oaks, Calif: SAGE.

Page, E. (2009). Men, masculinity and guns: can we break the link? IANSA Womens Network. Retrieved February 13, 2013, from http://www.gapsuk.org/docs/iansa_wn_masculinities_paper.pdf

Paris, R. (2004). At war's end: building peace after civil conflict. Cambridge, U.K.; New York, NY: Cambridge University Press.

Parpart, J. (2002). Lessons from the field: Rethinking Empowerment, Gender, Development from a Post-(Post?) Development Perspective. In Feminist PostDevelopment Thought (pp. 41-56). New York, NY: Zed Books.

Pettman, J. (1996). Worlding Women : a Feminist International Politics. London; New York: Routledge.

Phillips, J. (1987). A man's country?: the image of the pakeha male, a history. Auckland: Penguin Books. 
Ponzio, R. (2005). The Solomon islands: the UN and intervention by coalitions of the willing. International Peacekeeping, 12(2), 173-188.

Pouligny, B. (2006). Peace Operations Seen From Below: UN missions and local people. Bloomfield, CT: Kumarian Press.

Pugh, M. C., Cooper, N., \& Turner, M. (2011). Whose Peace? Critical Perspectives on the Political Economy of Peacebuilding. Houndmills, Basingstoke; New York: Palgrave Macmillan.

Punch, S. (2012). Hidden Struggles of Fieldwork: Exploring the Role and Use of Field Diaries. Emotion, Space amd Society, 5, 86-93.

Rahnema, M., \& Bawtree, V. (1997). The Post-Development Reader. London; Atlantic Highlands, N.J.: Dhaka: Halifax, N.S. : Cape Town: Zed Books; University Press; Fernwood Pub. ; David Philip.

RAMSI. (2012a). RAMSI - What is RAMSI? Regional Assistence Mission to Solomon Islands. Retrieved November 5, 2012, from http://www.ramsi.org/about.html

RAMSI. (2012b). Final New Zealand Platoon Hands Over. Retrieved May 12, 2013, from http://www.ramsi.org/media/news/final-new-zealand-platoon-hands-overhtml

RAMSI. (2012c). RAMSI - Our work - Gender. Regional Assistence Mission to Solomon Islands. Retrieved November 6, 2012, from http://www.ramsi.org/ourwork/gender.html

Razack, S. (2004). Dark threats and white knights: the Somalia Affair, peacekeeping, and the new imperialism. Toronto; Buffalo: University of Toronto Press.

Rehn, E., \& Johnson Sirleaf, E. (2002). Women, War and Peace: The Independent Experts' Assessment on the Impact of Armed Conflict on Women and Women's Role in Peacebuilding. New York: UNIFEM. 
Rieff, D. (2003). A Bed for the Night: Humanitarianism in Crisis (1st Simon \& Schuster trade pbk. ed.). New York: Simon \& Schuster.

Riley, R. (2006, October 17). New Zealand: Territorial Force to Take on Solomons. U.S Fed News Service. Washington D.C.

Roberts, N. (2010). Spanning "Bleeding" Boundaries: Humanitarianism, NGOs, and the Civilian-Military Nexus in the Post-Cold War Era. Public Administration Review, $70(2), 212-221$.

Rolfe, J. (2012a, May). Governance of the New Zealand armed forces. Te Ara/The Encyclopedia of New Zealand. Retrieved November 6, 2012, from http://www.teara.govt.nz/en/armed-forces/3

Rolfe, J. (2012b, May). Defence Force personnel by gender and ethnicity, 2012. Te Ara/The Encyclopedia of New Zealand. Retrieved November 6, 2012, from http://www.teara.govt.nz/en/armed-forces/1/5

Rose, G. (1997). Situating knowledges: positionality, reflexivities and other tactics. Progress in Human Geography, 21(3), 305-320.

Sachs, W. (1992). The Development Dictionary: a guide to knowledge as power. London; Atlantic Highlands, N.J.: Zed Books.

Saikal, A. (1996). The UN and Afghanistan: A Case of Failed Peacemaking Intervention. International Peacekeeping, 3(1), 19-34.

Sasson-Levy, O. (2002). Constructing Identities at the Margins: Masculinities and Citizenship in the Israeli Army. The Sociological Quarterly, 43(3), 357-383.

Schnabel, A., \& Farr, V. (2012). Back to the Roots: Security Sector Reform and Development (pp. 3-359). Geneva Centre for the Democratic Control of Armed Forces (DCAF). 
Shannon, R. (2009). Playing With Principles in an Era of Securitized Aid: Negotiating Humanitarian Space in Post-9/11 Afghanistan. Progress in Development Studies, 9(1), 15-36.

Shepherd, L. J. (2008). Gender, Violence and Security: Discourse as Practice. London; New York: New York: Zed Books; Distributed exclusivelyin the USA by Palmgrave Macmillan.

Sjoberg, L. (2006). Gendered Realities of the Immunity Principle: Why Gender Analysis Needs Feminism. International Studies Quarterly, 50, 889-910.

Soagia-Pritchard, A. (2007). Progress on the Integration of Uniformed Women into the Armed Services 1998- Present. Wellington [N.Z.]: New Zealand Defence Forces.

Solomon Islands Map. (2007) Solomon Islands. Retrieved from http://www.turkeyvisit.com/solomon-islands-map.asp.

Solomons Mission Shifts Focus from Security to Aid. (2012, July 4). Islands Business.

Retrieved from http://www.islandsbusiness.com/news/index_dynamic/containerNameToRepl ace=MiddleMiddle/focusModuleID=130/focusContentID=29164/tableName=m ediaRelease/overideSkinName=newsArticle-full.tpl

Sparke, M. (1996). Displacing the Field in Fieldwork: masculinity, metaphor and space. In Bodyspace (pp. 212-233). London: Routledge.

Steans, J. (2006). Gender and International Relations: Issues, Debates and Future Directions. Cambridge: Polity.

Stiehm, J. (2000). Neither male nor female: neither victim nor exececutioner. In Male Roles, Masculinities and Violence: a culture of peace perspective (pp. 223-230). Paris: United Nations Educational, Scientific and Cultural Organisation. 
Sultana, F. (2007). Reflexivity, Positionality and Participatory Ethics: Negotiating Fieldwork Dilemmas in International Research. ACME, 6(3), 347-385.

Sylvester, C. (1994). Feminist Theory and International Relations in a Postmodern Era. Cambridge [England] ; New York: Cambridge University Press.

Teaiwa, T. (2005a). Ethinicity and Identity. In Securing a Peaceful Pacific. Christchurch, N.Z.: Canterbury University Press.

Teaiwa, T. (2005b). Articulated Cultures: Militarism and Masculinities in Fiji during the Mid 1990s. Fijian Studies, 3(2), 201-222.

The World Bank. (2011). World Development Report: Conflict, Security and Development. Washington D.C: The World Bank. Retrieved from http://siteresources.worldbank.org/INTWDRS/Resources/WDR2011_Chapter1. pdf

Thomas, C. (2001). Global governance, development and human security: exploring the links. Third World Quarterly, 22(2), 159-175.

Tomforde, M. (2010). How Much Culture is Needed? The Intercultural Dilemma of the Bundeswehr in ISAF. International Peacekeeping, 17(4), 526-538.

Tucker, V. (1999). The Myth of Development: A Critique of Eurocentric Discourse. In Critical Development Theory: contributions to a new paradigm (pp. 1-26). London: Zed Books.

UNIFEM Pacific Sub-Regional Office. (2010). Ending Violence Against Women and Girls (pp. 1-36). Suva: United Nations Development Fund for Women. Retrieved from http://www.undp.org.fj/pdf/unp/evaw.pdf

Vaioleti, T. M. (2006). Talanoa Research Methodology: A Developing Position on Pacific Research. Waikato Journal of Education, 12, 21-34. 
Vuga, J. (2010). Cultural Differences in Multinational Peace Operations: A Slovenian Perspective. International Peacekeeping, 17(4), 554-565.

Waitt, G. (2010). Doing Foucauldian Discourse Analysis: Revealing Social Identities. In Qualitative Methods in Human Geography (3rd ed.). USA: Oxford University Press.

Webb, C. (1993). Feminist Research: Definitions, Methodology, Methods and Evaluation. Journal of Advanced Nursing, 18(3), 416-423.

Weiss, C. (2012). Respecting Human Rights and the Rule of Law: The New Zealand Defence Force (pp. 1-37). Wellington [N.Z.]: Iam Axford Fellowship in Public Policy.

Whitehead, S., \& Barrett, F. J. (2001). Introduction: Part I, Defining and Locating Masculinity (pp. 27-29). In The Masculinities Reader. Cambridge, UK; Malden, MA: Polity; Blackwell Publishers.

Whitworth, S. (2004a). Men, militarism, and UN peacekeeping: a gendered analysis. Boulder (Colo.): Lynne Rienner.

Whitworth, S. (2004b). Militarized Masculinities and the Politics of Peacekeeping: The Canadian Case. In Critical Security Studies and World Politics. Boulder (Colo.): Lynne Rienner.

Wicks, S. (1996). Warriors and wildmen: men, masculinity, and gender. Westport, Conn: Bergin \& Garvey.

Willis, K. (2006). Interviewing. In Doing Development Research. London: Sage Publications.

Wilson, G. (2009). The Solomon Islands Government - RAMSI Partnership Framework: Towards a secure and sustainable Solomon Islands'. Presented at the State Society and Governance in Melanesia Program, Australia National University, 
Canberra,

Australia.

Retrieved

from

http://www.ramsi.org/Media/docs/091217-Special-Coordinator-Graeme-

Wilson---State-Society-and-Governance-in-Melanesia-presentation-Australian-

National-University-f84d1152-c8e0-4a15-99aa-22080038badf-0.pdf

Winchester, H., \& Rofe, M. (2010). Qualitative Research and its Place in Human Geography. In Qualitative Methods in Human Geography. Oxford: Oxford University Press.

Women's International League for Peace and Freedom. (n.d.). Security Council Resolution 1325 - General Women, Peace and Security. Retrieved October 25, 2012, from http://www.peacewomen.org/themes_theme.php?id=15\&subtheme=true

Woodward, R. (2003). Locating Military Masculinities: Space, Place, and the Formation of Gender Identity in the British Military. In Military Masculinities: Identity and the State. Westport, CT: Praeger Publishers. 


\section{List of Appendices}

Appendix One: Map of Solomon Islands

Appendix Two: Map of Guadalcanal

Appendix Three: Victoria University of Wellington Ethics Forms

Appendix 3a: Information Sheet for semi-structured interviews with Solomon Islanders

Appendix 3b: Consent form for semi-structured interviews with Solomon Islanders

Appendix 3c: Question guide for Solomon Islanders

Appendix 3d: Information Sheet for semi-structured interviews with New Zealand Army personnel

Appendix 3e: Consent form for semi-structured interviews with New Zealand Army personnel

Appendix 3f: Question guide for New Zealand Army personnel

Appendix Four: Approved research permit for the Solomon Islands 
Appendix One: Map of Solomon Islands (Source: Joint Geographical Support Faculty for the New Zealand Defence Force)

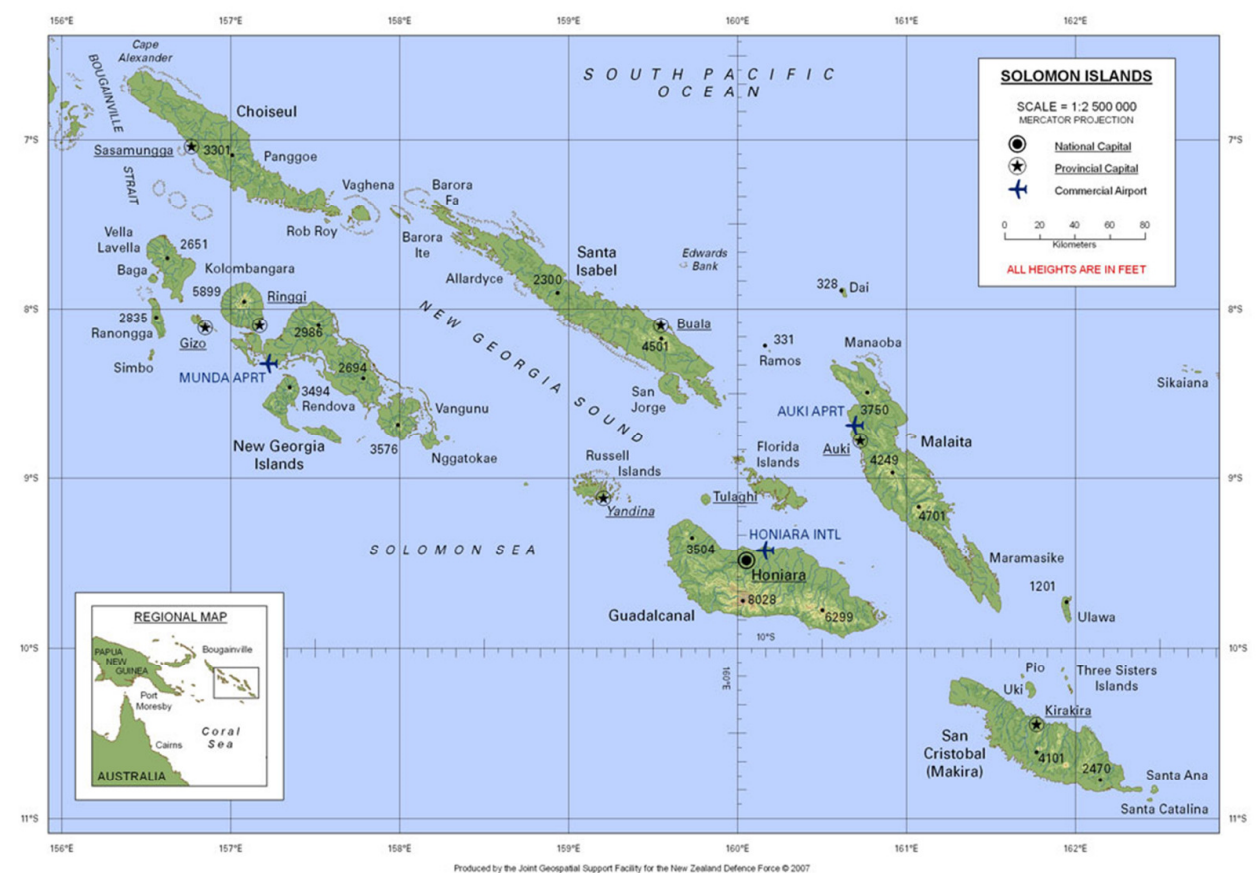


Appendix Two: Map of Guadalcanal (Source: Navy Memories)

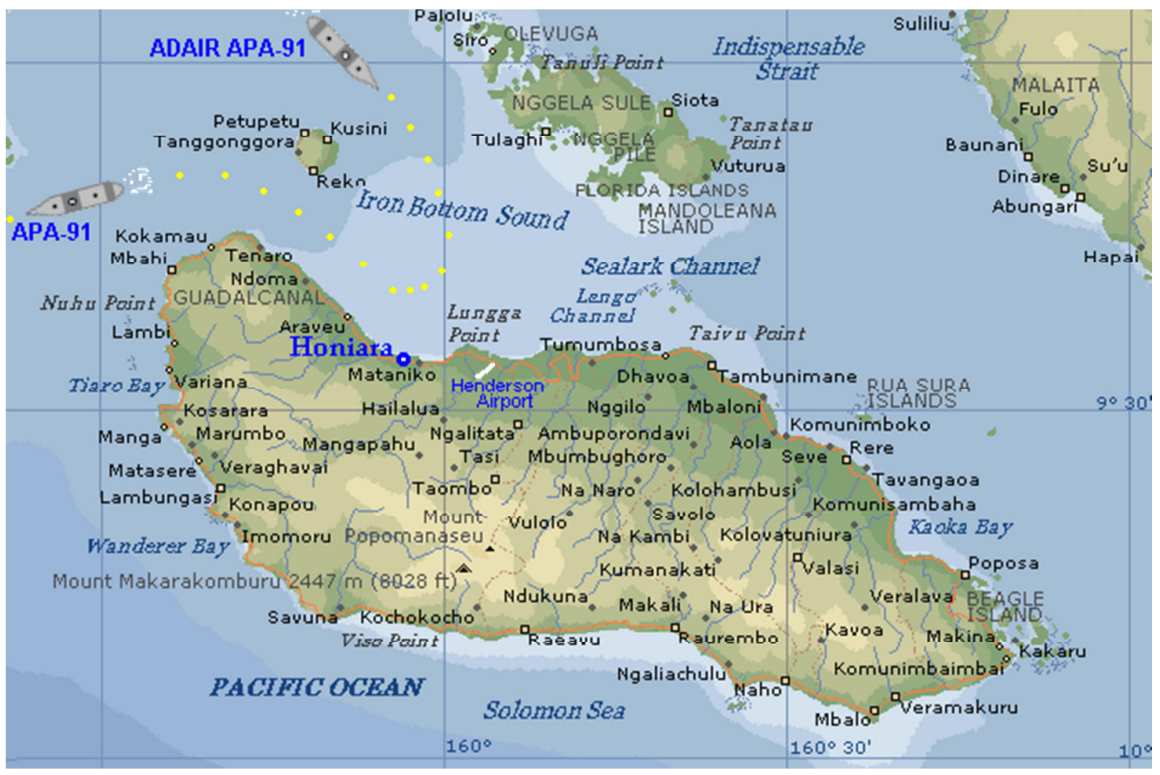




\section{Appendix Three: Victoria University of Wellington Ethics Forms}

Appendix 3a: Information Sheet for semi-structured interviews with Solomon Islanders

TE WHARE WĀNANGA O TE ŪPOKO O TE IKA A MĀUI

jô

N UNIVERSITY OF WELLINGTON

Title of project: Ngati Tumatauenga/The New Zealand Army: A force for good?

Researcher: Kiri Stevens: School of Geography, Environment and Earth Sciences, Victoria University of Wellington, New Zealand.

I am a Masters student in Development Studies at Victoria University of Wellington, New Zealand. As part of this degree I am undertaking a research project leading to a thesis. The project I am undertaking is a study of how New Zealand Army culture influences how soldiers interact with local populations. I am using the RAMSI mission as a case study.

I will explore what kinds of skills soldiers feel are important as part of their duties; if they think their cultural heritage affects why they entered the military; how this could affect how they engage with local people and conduct their operational duties.

In doing this study I would like to include the perspectives of local people in the Solomon Islands. I will explore what interactions local residents have had with the New Zealand Army, how successful they feel that the New Zealand Army has been in these interactions, whether they think the New Zealand Army demonstrated characteristics that were different from other participating countries defence forces; and whether they felt the New Zealand Army's commitment to biculturalism within the forces affected their interactions with the New Zealand Army.

With this study I will identify what the New Zealand Army are doing well in security assistance missions, and where policy can be developed that strengthens the development work that they undertake. This also contributes to understanding to how cultural diversity can be reinforced and valued in development work.

Responses collected will form the basis of my research project. All material collected will be kept confidential and no individual names will be attributed to specific opinions in the production of the research. Participants will be identified as being from civil society organisations that have worked with or alongside the New Zealand Army and acronyms such as LI1 (Local Informant 1) will be used when attributing specific opinions (unless interview participant indicates otherwise). Only my supervisor and I will listen to the tape recordings of the interviews. 
The thesis will be submitted for marking to the School of Geography, Environment and Earth Sciences and deposited in the University Library. It is intended that one or more articles will be submitted for publication in scholarly journals.

The University has granted me ethics approval to conduct this research.

\section{What is involved?}

- The interviews are designed to take 50-60 minutes and can take place at a mutually agreed time and place. You will be interviewed by Kiri Stevens. You will be required to sign the attached consent form prior to the interviews.

- Your participation is entirely voluntary. If you agree to take part in the interviews you are free to withdraw any information you have provided before data collection and analysis of the project is complete on 01/11/2012.

- You will be asked a list of interview questions regarding your perceptions of the New Zealand Army's behaviour and interactions with local communities on the RAMSI mission. You do not have to answer all questions.

- The interviews will be tape-recorded and transcribed. The recording will be used to complement the notes taken during the interview.

- All raw data collected during this interview will be accessed by the principal investigator and research supervisor only. These will be stored in a locked filing cabinet or as password protected electronic documents and destroyed after 5 years.

Please feel free to contact the researcher or research supervisor if you have any questions or would like to receive further information about this study

\section{Principal Investigator:}

Kiri Stevens

Masters of Development Studies student - Victoria University of Wellington

Kiri.Stevens@vuw.ac.nz

Ph: +64 210665280

\section{Research Supervisor:}

Dr Carol Harrington

School of Social and Cultural Studies- Victoria University of Wellington

Carol.Harrington@vuw.ac.nz

$\mathrm{Ph}:+6444637451$ 


\section{Appendix 3b: Consent form for semi-structured interviews with Solomon Islanders}

TE WHARE WĀNANGA O TE ŪPOKO O TE IKA A MĀUI

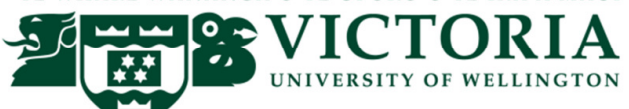

Title of project: Ngati Tumatauenga/New Zealand Army: A Force for Good?

- I have read and understood the attached 'Information sheet for interviews'. I have had an opportunity to ask any questions I may have about the study and about participating in the interview and have had them answered to my satisfaction.

- I agree to participate in these interviews and understand that I may withdraw myself (or any information I have provided) from this project by $01 / 11 / 2012$ without having to give reasons.

- I understand that the interviews will be tape recorded and transcribed, and that only the researcher will have access to this material. Any information I provide will be kept confidential to the researcher and her Supervisor.

- I understand that all written material and taped interviews will be stored in a locked filing cabinet or as password protected electronic documents and then destroyed after 5 years.

- I understand that the data I provide will only be used for the purposes of a thesis and any articles published from this thesis. No information will be released to others without my written consent.

I (full name) hereby consent to take part in

this study by being interviewed.

Signature:

Date:

Interview conducted by:

Signature:

Date:

$\square$ I would like to receive a summary of the research findings Yes / No (Please circle) 


\section{Appendix 3c: Question guide for Solomon Islanders}

Can you tell me about the ways that you have worked with or interacted with soldiers from the New Zealand Army?

Are there any New Zealand soldiers who you think could be considered role models for other officers in the RAMSI mission and what is it about them that make them role models?

Can you tell me about any instances where a NZ soldier/or soldiers acted in ways that you would describe as heroic?

Have you witnessed any NZ soldiers that do not share the same values or have similar characteristics to the majority of the force? If yes, how do you think that this has affected their ability to interact with other officers?

Can you tell me about any instances where NZ soldiers acted in ways that were positive experiences for local communities? What do you think made them good at this?

Can you tell me about any instances that the NZ Army soldiers were not so good at dealing with local communities and what do you think made them not so good at this?

When you think about the different countries defence forces involved in the RAMSI misson are there any countries you think were more sensitive to local custom/kastom? (how does nz compare?)

What do you understand the concept of cross-cultural relationship building to mean? What are cross-cultural issues?

What do you think are the main cross-cultural issues the NZ Army deals with in the community in the Solomon Islands?

Can you tell about an instance where you think the NZ Army dealt with cross-cultural issues better than other defence forces from another country?

Can you tell about an instance where you think the NZ Army dealt with cross-cultural issues worse than other defence forces from another country?

Can you tell me what you know about tikanga Maori/ Maori custom? Have you seen NZ soldiers demonstrate characteristics of tikanga Maori that are useful for understanding Solomon Island Kastom? 
Appendix 3d: Information Sheet for semi-structured interviews with New Zealand Army personnel

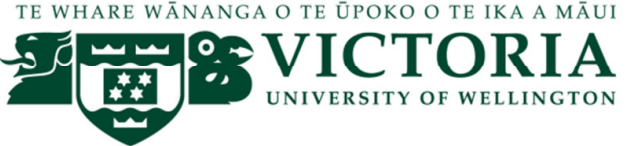

\section{INFORMATION SHEET FOR SEMI-STRUCTURED INTERVIEWS}

\section{Title of project: Ngati Tumatauenga/The New Zealand Army: A force for good?}

Researcher: Kiri Stevens: School of Geography, Environment and Earth Sciences, Victoria University of Wellington, New Zealand.

I am a Masters student in Development Studies at Victoria University of Wellington, New Zealand. As part of this degree I am undertaking a research project leading to a thesis. The project I am undertaking is a study of how New Zealand Army culture influences the ways that soldiers interact with local populations on deployment by using the RAMSI mission as a case study.

I will explore what kinds of skills soldiers feel are important as part of their duties; if they think their cultural heritage affects why they entered the military; how this could affect how they engage with local people and conduct their operational duties.

This project identifies what the New Zealand Army are doing well in security assistance missions, and where policy can be developed that strengthens the development work that they undertake. This also contributes to understanding to how cultural diversity can further reinforced and valued in the defence forces.

Responses collected will form the basis of my research project. All material collected will be kept confidential and no individual names will be attributed to specific opinions in the production of the research. Participants will be identified as being from the New Zealand Army and a pseudonym such as NZA1, will be used when attributing specific opinions. Only my supervisor and I will listen to the tape recordings of the interviews.

The thesis will be submitted for marking to the School of Geography, Environment and Earth Sciences and deposited in the University Library. It is intended that one or more articles will be submitted for publication in scholarly journals.

The University has granted me ethics approval to conduct this research.

What is involved? 
- The interviews are designed to take 50-60 minutes and can take place at a mutually agreed time and place. You will be interviewed by Kiri Stevens. You will be required to sign the attached consent form prior to the interviews.

- Your participation is entirely voluntary. If you agree to take part in the interviews you are free to withdraw any information you have provided before data collection and analysis of the project is complete on 01/11/2012.

- You will be asked a list of interview questions regarding your perceptions on NZDF roles and behaviour on the RAMSI mission. You do not have to answer all questions.

- The interviews will be tape-recorded and transcribed. The recording will be used to complement the notes taken during the interview.

- All raw data collected during this interview will be accessed by the principal investigator and research supervisor only. These will be stored in a locked filing cabinet or as password protected electronic documents and destroyed after 5 years

Please feel free to contact the researcher or research supervisor if you have any questions or would like to receive further information about this study

\section{Principal Investigator:}

Kiri Stevens

Masters of Development Studies student - Victoria University of Wellington

kiri.stevens@gmail.com

Ph: +64 210665280

\section{Research Supervisor:}

Dr Carol Harrington

School of Social and Cultural Studies- Victoria University of Wellington

Carol.Harrington@vuw.ac.nz

$\mathrm{Ph}:+6444637451$ 


\section{CONSENT FORM}

Title of project: Ngati Tumatauenga/New Zealand Army: Hearts and Minds?

- I have read and understood the attached 'Information sheet for interviews.' I have had an opportunity to ask any questions I may have about the study and about participating in the interview and have had them answered to my satisfaction.

- I agree to participate in these interviews and understand that I may withdraw myself (or any information I have provided) from this project by $01 / 12 / 2012$ without having to give reasons.

- I understand that the interviews will be tape recorded and transcribed, and that only the researcher will have access to this material. Any information I provide will be kept confidential to the researcher and her Supervisor.

- I understand that all written material and taped interviews will be stored in a locked filing cabinet or as password protected electronic documents and then destroyed after 5 years.

- I understand that the data I provide will only be used for the purposes of a thesis and any articles published from this thesis. No information will be released to others without my written consent.

I (full name) hereby consent to take part in this study by being interviewed.

Signature:

Date:

Interview conducted by:

Signature:

Date:

$\square$ I would like to receive a summary of the research findings Yes / No (Please circle) 


\section{Appendix 3f: Question guide for New Zealand Army personnel}

Are there any New Zealand soldiers who you think could be considered role models for other officers in the RAMSI mission and what is it about them that make them role models?

Can you tell me about any instances where a NZ soldier has acted in ways that you would describe as heroic?

Have you witnessed any NZ soldiers that do not share the same values or have similar characteristics to the majority of the force? If yes, how do you think that this has affected their ability to interact with other officers?

Are there any NZ soldiers that are particularly good at dealing with local communities and what do you think makes them good at this?

Are there any NZ soldiers that are particularly not so good at dealing with local communities and what do you think makes them not so good at this?

What do you understand the concept of cross-cultural relationship building to mean? What are cross-cultural issues?

What do you think are the main cross-cultural issues the NZ Army deals with in the community in the Solomon Islands?

Do you think that there are any internal cross-cultural issues within the NZ Army and can you tell me about these?

Can you tell me about any training you received to deal with cross-cultural issues while involved in the RAMSI mission? How did this help you to deal with cross-cultural issues in the RAMSI mission? 


\title{
Appendix Four: Approved research permit for the Solomon Islands
}

FORM - R.B

\author{
THE RESEARCH ACT 1982 \\ (No. 9 of 1982)
}

\section{RESEARCH PERMIT}

Permission is hereby given to:

1. Name: Kiri Stevens

2. Country: New Zealand

3. To undertake research in (subjects): How Cultural identity affects the way that New Zealand soldiers engage in development work overseas.

4. Ward(s): Honiara

5. Province(s):

6. Conditions:

a. To undertake research only in the subject areas specified in 3 above.

b. To undertake research only in the ward(s) and Province(s) specified in 4 and 5 above.

c. To observe with respect at all times local customs and the way of life of people in the area in which the research work is carried out.

d. You must not, at any time, take part in any political or missionary activities or local disputes.

e. You must leave 4 copies of your final research report in English with the Solomon Islands Government Ministry responsible for research at your own expense.

f. A research fee of $S B D 300.00$ and deposit sum of $S B D 200.00$ must be paid in full or the Research Permit will be cancelled. (See sec. 3 Subject. 7 of the Research Act).

g. This permit is valid until 31/8/12 provided all conditions are adhered to.

h. No live species of plants and animals may be taken out of the country without approval from relevant authorities.

i. A failure to observe the above conditions will result in automatic cancellation of this permit and the forfeit of your depesit.
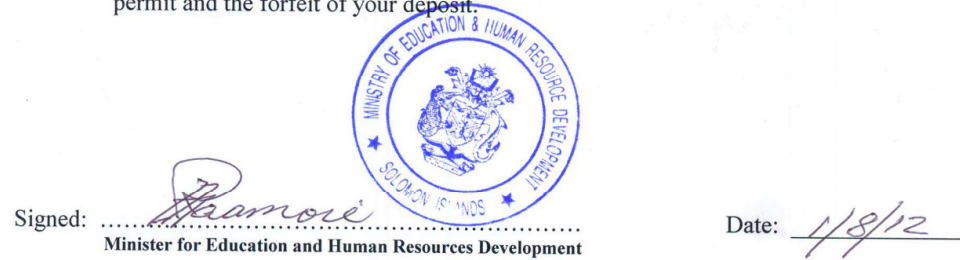